\title{
Using information on the broader economic impact of vaccines in evidence-informed decision making
}

Citation for published version (APA):

van der Putten, I. M. (2018). Using information on the broader economic impact of vaccines in evidenceinformed decision making: Connecting the dots. [Doctoral Thesis, Maastricht University]. Maastricht University. https://doi.org/10.26481/dis.20180702ip

Document status and date:

Published: 01/01/2018

DOI:

10.26481/dis.20180702ip

Document Version:

Publisher's PDF, also known as Version of record

\section{Please check the document version of this publication:}

- A submitted manuscript is the version of the article upon submission and before peer-review. There can be important differences between the submitted version and the official published version of record.

People interested in the research are advised to contact the author for the final version of the publication, or visit the DOI to the publisher's website.

- The final author version and the galley proof are versions of the publication after peer review.

- The final published version features the final layout of the paper including the volume, issue and page numbers.

Link to publication

\footnotetext{
General rights rights.

- You may freely distribute the URL identifying the publication in the public portal. please follow below link for the End User Agreement:

www.umlib.nl/taverne-license

Take down policy

If you believe that this document breaches copyright please contact us at:

repository@maastrichtuniversity.nl

providing details and we will investigate your claim.
}

Copyright and moral rights for the publications made accessible in the public portal are retained by the authors and/or other copyright owners and it is a condition of accessing publications that users recognise and abide by the legal requirements associated with these

- Users may download and print one copy of any publication from the public portal for the purpose of private study or research.

- You may not further distribute the material or use it for any profit-making activity or commercial gain

If the publication is distributed under the terms of Article $25 \mathrm{fa}$ of the Dutch Copyright Act, indicated by the "Taverne" license above, 


\title{
Using information on the broader economic impact of vaccines in evidence-informed decision making
}

\author{
Connecting the dots
}

I.M. van der Putten 


\section{Colofon}

The studies presented in this dissertation were conducted at the Care and Public Health Research Institute (CAPHRI), department of Health Services Research, Maastricht University. CAPHRI participates in the Netherlands School of Primary Care Research (CaRe), which has been acknowledged by the Royal Netherlands Academy of Science (KNAW)

This dissertation is made possible by funds from the Kootstra Talent Fellowship programme 2013, Care and Public Health Research Institute (CAPHRI) and the World Health Organization (WHO).

(C) I.M. van der Putten, Maastricht 2018

Cover: Evelien Jagtman (www.evelienjagtman.com)

Lay-out: Maartje van der Aa

Printing: Ridderprint BV (www.ridderprint.nl)

ISBN: 978-94-6299-988-6

All rights are reserved. No parts of this dissertation may be reproduced or transmitted, in any from or by any means, electronic or mechanical, including photocopying, recording or otherwise, without prior written permission of the holder of the copyrights. 


\title{
Using information on the broader economic impact of vaccines in evidence-informed decision making
}

\section{Connecting the dots}

\author{
Proefschrift
}

ter verkrijging van de graad van doctor aan de Universiteit Maastricht op gezag van de Rector Magnificus, Prof. dr. Rianne M. Letschert, volgens het besluit van het college van

Decanen, in het openbaar te verdedigen op maandag 2 juli 2018 om 14.00 uur

door

Ingeborg Maria van der Putten

Geboren op 31 mei 1989 te Den Dungen 
Promotor

Prof. dr. mr. S.M.A.A. Evers

\section{Copromotores}

Dr. M. Hiligsmann

Dr. R.C.W. Hutubessy (Wereldgezondheidsorganisatie)

Dr. A.T.G. Paulus

\section{Beoordelingscommissie}

Prof. dr. J.S.M. Krumeich (voorzitter)

Prof. dr. P. Beutels (Universiteit Antwerpen)

Prof. dr. C. J.P.A. Hoebe

Prof. dr. J.A.M. Maarse

Prof. dr. M.J. Postma (Rijksuniversiteit Groningen) 


\section{CONTENTS}

$\begin{array}{lll}\text { Chapter } 1 & \text { General introduction } & 7\end{array}$

Chapter 2 Conceptualizations of the societal perspective within 17 economic evaluations: a systematic review Published in: International Journal of Technology Assessment in Health Care (2017)

Chapter 3 Stakeholders' perception on including broader economic impact of vaccines in economic evaluations in low and middle income countries: a mixed methods study Published in: BMC Public Health (2015)

Chapter 4 Identification and prioritization of the broader economic impacts of vaccines

Published in: BioMed Research International (2016)

Chapter 5 Evidence-informed vaccine decision making:

The introduction of Human Papilloma Virus (HPV) vaccination in the Netherlands Submitted for publication

Chapter 6 General discussion

Addenda Summary

Samenvatting

Valorisation

Dankwoord

List of publications \& awards 
$\bullet \bullet$

-

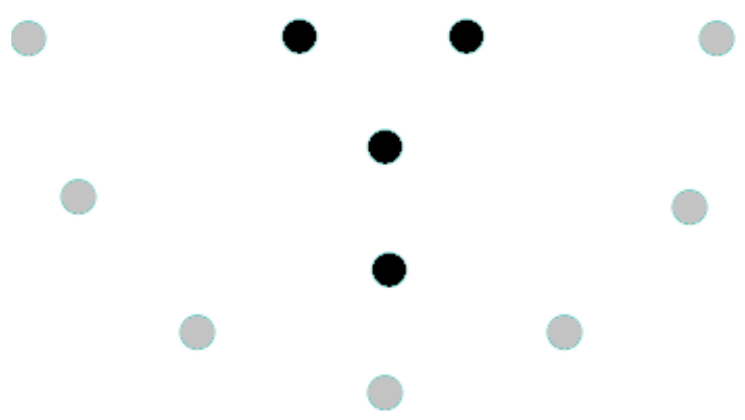


CHAPTER 1

General Introduction 


\section{Introduction}

This dissertation investigates evidence-informed decision making on the introduction of (new) vaccines. Chapter 1 provides a general background by describing the increasing need for information in making decisions on vaccination, as well as the need for information on the (economic) impact of vaccines. The chapter ends with a description of the objectives and an outline of this dissertation.

\section{Evidence-informed decision making on the introduction of vaccines}

Evidence-informed decision making can be defined as using different types of information in a variety of forms and from a variety of sources, reflective of and responsive to policy and practice [1]. In recent years, attention for evidence-informed decision making has been increasing, also with regard to decisions on the introduction of vaccines. Vaccine introduction can be described as the addition of a vaccine to the Expanded Program on Immunization (EPI) or National Vaccination Programmes (NVP), as the introduction of a new formulation of a product that is already part of the programme, as a new combination of vaccines, or as a new route of administration for a vaccine that is already covered [2]. In 20163.2 billion vaccination doses were purchased globally from 73 manufacturers, representing a total value of $\$ 9.3$ billion [3].

In high income countries (HICS), the growing need for evidence-informed decision making on the introduction of vaccines is often related to resource allocation decisions that must be made in times of growing health care costs, an ageing population and technological developments leading to scarcity [4, 5]. Proper decision making requires information on who receives what, when and at what costs [5]. In low and middle income countries (LMICS), the increased need for evidence-informed decision making on the introduction of vaccines is often related to the limited (financial) resources available for vaccines in situations where more (comprehensive) vaccine coverage is desired. It is estimated that an extra 4.2 million lives could be saved globally by ensuring access to comprehensive vaccine coverage [6]. However, for GAVI-eligible countries (i.e. poor countries that receive help from the Global Alliance for Vaccine Introduction), adding new vaccines to the EPI programme has increased the price of a full vaccination course from $\$ 1.37$ in the year 2001 to over $\$ 38.80$ in 2011 [7]. Accordingly, with limited resources at their disposal, LMIC governments and international donors must decide how to balance the introduction of vaccines against other investments in health care $[6,8]$. Currently, these decision processes are ad hoc, non-transparent and driven by interest groups; this makes the system inactive, and leads to misplaced priorities, wasted money and needless deaths [5]. This is especially apparent in LMICs where priorities are set haphazardly due to highly constrained budgets. Investments in health care, including vaccines, in these countries is often 
below the $5 \%$ of Gross Domestic Product (GDP) investment that is recommended by the World Health Organization (WHO) [9]. However investments in vaccines provide a great return on investment, with net returns estimated to amount to 44 times the costs [10]. To overcome these problems, the development of a more balanced decision process based on science, ethics and public interest and finding consensus is recommended [5]. Information (including evidence) can play an important role in this respect, as information can provide not only data that can support decision making, but also provide a basis for developing a framework or standard procedure for decision making on the introduction of vaccines $[11,12]$.

\section{Information on the impact of vaccines: from narrow to broad}

The importance of evidence-informed decision making on the introduction of vaccines is also recognized increasingly in practice and in science. During the $65^{\text {th }}$ World Health Assembly in 2012, for instance, the importance of using information (including evidence) in vaccine decision making was stipulated through the endorsement of the Global Vaccine Action Plan (GVAP) [13]. This plan states that "National legislation, policies and resource allocation decisions should be informed by credible and current evidence regarding the direct and indirect impact of immunization." [14]

Furthermore, several guidelines on economic evaluations of vaccines have been published by research groups and international organizations to strengthen evidencebased decision making on the introduction of vaccines [15-19]. The core components of these guidelines revolve around estimating the costs and benefits of vaccines, vaccination and immunization programmes. Benefit components traditionally include cost savings in health care or improvements in life expectancy and quality of life. Indirect benefits realized by caregivers and the greater community and/or the effectiveness of the vaccine, as part of a larger programme, are generally not included in these guidelines [20]. Others have investigated the role of different stakeholders (including experts, National Immunization Technical Advisory groups (NITAGs) or technical agencies such as the WHO, the United Nations International Children's Emergency Fund (UNICEF) and the Global Alliance for Vaccine Introduction (GAVI) in LMICs in the decision-making process [2, 21-29].

While the importance of evidence-informed decision making on the introduction of vaccines is being recognized increasingly, the question about which information is (more) relevant, which deserves higher priority, or is relevant towards aiding decision making is still under debate. In particular, information on the economic impact of vaccines has received specific attention in these debates. The main issue concerns the breadth of this impact [30-34]. In most studies, a narrow perspective is presented [34], as the impact of vaccines through vaccination and immunization programmes is presented in terms of immediate health gains and house-hold costs savings [31]. Other authors have suggested a perspective which focuses on the broader impact and benefits of vaccines [30-38]. The latter include "... potential benefits of vaccination 
aside from health effects, healthcare costs and short term productivity losses due to being ill or caring for someone ill. They typically involve longer term effects and/or wider externalities other than individuals vaccinated and their caregivers"[31] or the "...impacts that stem from the fact that immunization protects individuals not only against getting an illness per se, but also against the long-term effects of that illness on their physical, emotional, and cognitive development" [33]. As seen in these definitions the impact is not only based on vaccines as a technology but perceives vaccination of individuals and immunization programmes as an integral part of the health system and society. Examples of these impacts include behaviour-related productivity gains and community health externalities. Behaviour-related productivity gains resulting from improved child health and survival lead to economic benefits for families [32, 36]. Community health externalities occur among the unvaccinated community members such as the occurrence of herd immunity, in which the chance of becoming infected becomes lower when more individuals in the direct environment are vaccinated. Furthermore, vaccination can prevent antibiotic usage as children don't become sick in the first place, making vaccination part of the solution for antibiotic resistance prevention $[39,40]$.

In the ongoing debates on the narrow and broader impact of vaccines, both theoretical and practical arguments for using the broader economic impact of vaccines (instead of the narrow impact) in the decision-making process have been presented. From a theoretical (welfarist economic) point of view, it is often argued that a societal perspective is preferred for conducting an economic evaluation [41-43] as it includes "all costs and consequences regardless of who experiences these" [44, 45]. As the broader impact of vaccines better captures the overall impact of vaccinations and immunization programmes, including effects not directly related to the individual, this interpretation of the economic impact of vaccines seems to be more in line with the welfarist economic point of view and their definition of the societal perspective. From a practical point of view, others argue that the use of a broader perspective is preferable as it makes investment decisions more comparable with other social interventions [46], better reflecting the nature of vaccination in relation to the public good [30, 47], providing better justification with regard to current financing [48] and implementation schemes $[49,50]$ of vaccines, and possibly opposing the growing vaccine hesitancy movement [51].

Several attempts to provide frameworks for the economic impact of vaccines have therefore been made [30-38, 52]. Despite the relevancy from a theoretical and practical perspective, however, the usefulness of taking the information on the broader economic impact of vaccines into account for decision making on the introduction of vaccines has received little attention so far. 


\section{Objectives of the dissertation}

Within this context, the overall aim of this thesis is to investigate the use of information on the broader (economic) impact of vaccines in decision making on the introduction of vaccines. Four objectives have been formulated:

1. To determine how the broader perspective (i.e. the societal perspective) is applied in economic evaluations in general.

2. To identify which economic impacts seem relevant towards aiding decision making for vaccine introduction.

3. Based on stakeholders' perceptions, to determine the relative importance of the identified economic impacts.

4. To retrospectively analyse the role of information in vaccine decision making in a real life case.

\section{Outline of the dissertation}

The dissertation is structured around four main parts.

Chapter 2 explores the interpretation of the societal perspective within economic evaluations in general. By using a systematic literature review, the conceptualization of the social perspective is described, and the impact of using a broader perspective is assessed by looking at the impact of intersectoral costs and benefits on the results of economic evaluations.

Chapters 3 and 4 deal with the identification of (broader) economic impacts that are relevant towards aiding decision making on the introduction of a vaccine, and relative importance of these impacts with regard to different stakeholders. In Chapter 3 a mixed method, including interviews and a questionnaire is used, and in Chapter 4 a best-worst scaling questionnaire is used to collect the opinions of the different stakeholders.

In Chapter 5 a document analysis is performed to map the decision-making process on the introduction of the HPV vaccine in the Netherlands that took place from 2006-2009. Furthermore, we investigated what type of information (including evidence) was used during the decision-making process and to what extent (broader) economic evidence did play a role in this decision-making process.

Last, in Chapter 6, an overview is provided of the main findings and of the methodological and theoretical considerations of this dissertation. Furthermore, the implications for research and policy are discussed. 


\section{References}

1. Bowen S, Zwi AB. Pathways to "evidence-informed" policy and practice: a framework for action. PLoS Med. 2005;2(7):e166.

2. World Health Organization. Principles and considerations for adding a vaccine to a national immunization programme: from decision to implementation and monitoring. Geneva; Switserland: 2014.

3. World Health Organization. V3P: Global Fact Sheet. Geneva: World Health Organization, 2017.

4. Drummond MF, Sculpher MJ, Claxton K, Stoddart GL, Torrance GW. Methods for the economic evaluation of health care programmes: Oxford university press; 2015.

5. Glassman A, Chalkidou K. Priority-setting in health: building institutions for smarter public spending. Washington, DC: Center for Global Development. 2012.

6. Hauck K, Smith PC, Goddard M. The economics of priority setting for health care: a literature review. The International Bank for Reconstruction and Development/The World Bank. 2003;10:03-8.

7. MSF access campaign. The right shot. Geneva, Switzerland: Medecins Sans Frontieres, 2015.

8. Neumann PJ, Fang CH, Cohen JT. 30 years of pharmaceutical cost-utility analyses: growth, diversity and methodological improvement. Pharmacoeconomics. 2009;27(10):861-72.

9. Savedoff WD, Organization WH. How much should countries spend on health? 2003.

10. Ozawa S, Clark S, Portnoy A, Grewal S, Brenzel L, Walker DG. Return on investment from childhood immunization in low-and middle-income countries, 2011-20. Health Affairs. 2016;35(2):199-207.

11. Hanney SR, Gonzalez-Block MA, Buxton MJ, Kogan M. The utilisation of health research in policymaking: concepts, examples and methods of assessment. Health Res Policy Syst. 2003;1(1):2.

12. Hanney SR, Gonzalez-Block MA. Evidence-informed health policy: are we beginning to get there at last? Health Res Policy Syst. 2009;7:30.

13. Jauregui B, Janusz C, Felix G. 4.7 Evidence-based policy-making for national immunization programs. In: Family Gender and Life Course, editor. Washington D.C.: Pan American Health Organization; 2013.

14. World Health Organization. Global Vaccine Action Plan 2011-2020. Global Vaccine Action Plan 20112020. 2013.

15. Erickson L, De Wals P, Farand L. An analytical framework for immunization programs in Canada. Vaccine. 2005;23(19):2470-6.

16. Kimman TG, Boot HJ, Berbers GAM, Vermeer-de Bondt PE, Ardine de Wit G, de Melker HE. Developing a vaccination evaluation model to support evidence-based decision making on national immunization programs. Vaccine. 2006;24(22):4769-78.

17. Mansoor $O$, Shin S, Maher C, WPRO tIFo. Assessing new vaccines for national immunization programmes. A framework to assist decision makers. Manila: World Health Organization Regional Office for the Western Pacific Manila, 2000 2012/5/29. Report No.

18. Walker DG, Hutubessy R, Beutels P. WHO Guide for standardisation of economic evaluations of immunization programmes. Vaccine. 2010;28(11):2356-9.

19. Stratton KR, Durch JS, Lawrence RS. Vaccines for the 21st century: a tool for decisionmaking, Committee to Study Priorities for Vaccine Development. Division of Health Promotion and Disease Prevention, Institute of Medicine. National Academy of Sciences, Washington, DC. 1999:-.

20. Piso B, Wild C. Decision support in vaccination policies. Vaccine. 2009;27(43):5923-8.

21. Senouci K, Blau J, Nyambat B, Faye PC, Gautier L, Da Silva A, et al. The Supporting Independent Immunization and Vaccine Advisory Committees (SIVAC) initiative: a country-driven, multi-partner program to support evidence-based decision making. Vaccine. 2010;28:A26-A30.

22. Silva ML, Perrier L, Paget J, Mosnier A, Buthion V, Cohen JM, et al. Information Used in the DecisionMaking Process Regarding Influenza Vaccination Policy: Perceptions of Stakeholders in France and the Netherlands. Value in health : the journal of the International Society for Pharmacoeconomics and Outcomes Research. 2014;17(7):A329. 
23. Silva ML, Perrier L, Paget JW, Mosnier A, Buthion V, Cohen JM, et al. Influenza vaccination policymaking processes in France and The Netherlands: Framework and determinants. Health Policy. 2016;120(3):293-305.

24. Verweij MF, Houweling $\mathrm{H}$. What is the responsibility of national government with respect to vaccination? Vaccine. 2014;32(52):7163-6.

25. Welte R, Trotter CL, Edmunds WJ, Postma MJ, Beutels P. The role of economic evaluation in vaccine decision making: focus on meningococcal group $C$ conjugate vaccine. Pharmacoeconomics. 2005;23(9):855-74.

26. Wonodi C, Privor-Dumm L, Aina M, Pate A, Reis R, Gadhoke P, et al. Using social network analysis to examine the decision-making process on new vaccine introduction in Nigeria. Health policy and planning. 2012;27(suppl 2):ii27-ii38.

27. Burchett H, Mounier-Jack S, Griffiths U, Biellik R, Ongolo-Zogo P, Chavez E, et al. New vaccine adoption: qualitative study of national decision-making processes in seven low-and middle-income countries. Health policy and planning. 2012;27(suppl 2):ii5-ii16.

28. Burchett $\mathrm{H}$, Mounier-Jack S, Griffiths U, Mills A. National decision-making on adopting new vaccines: a systematic review. Health policy and planning. 2012;27(suppl 2):ii62-ii76.

29. Burns JE, Mitrovich RC, Jauregui B, Ruiz Matus C, Andrus JK. Descriptive analysis of immunization policy decision making in the Americas. Revista Panamericana de Salud Publica. 2009;26(5):398-404.

30. Bloom DE, Brenzel L, Cadarette D, Sullivan J. Moving beyond traditional valuation of vaccination: Needs and opportunities. Vaccine. 2017;35 Suppl 1:A29-a35.

31. Deogaonkar R, Hutubessy R, van der Putten I, Evers S, Jit M. Systematic review of studies evaluating the broader economic impact of vaccination in low and middle income countries. BMC public health. 2012;12(1):878.

32. Jit M, Hutubessy R, Ee PM, Sudaram N, Audilam J, Salim S, et al. The broader economic impact of vacination: reviewing and appraising the strength of evidence. BMC Med. 2015(13):209.

33. Bloom DE, Canning D, Weston M. The value of vaccination. World Economics. 2005;6(3):15-.

34. Ozawa S, Mirelman A, Stack ML, Walker DG, Levine OS. Cost-effectiveness and economic benefits of vaccines in low-and middle-income countries: A systematic review. Vaccine. 2012:96-108.

35. Barnighausen T, Berkley S, Bhutta ZA, Bishai DM, Black MM, Bloom DE, et al. Reassessing the value of vaccines. The Lancet Global health. 2014;2(5):e251-2.

36. Bärnighausen T, Bloom DE, Cafiero-Fonseca ET, O'Brien JC. Valuing vaccination. Proceedings of the National Academy of Sciences. 2014;111(34):12313-9.

37. Bärnighausen T, Bloom DE, Canning D, Friedman A, Levine OS, O'Brien J, et al. Rethinking the benefits and costs of childhood vaccination: The example of the Haemophilus influenzae type $b$ vaccine. Vaccine. 2011;29(13):2371-80.

38. Bärnighausen T, Bloom DE, Canning D, O'Brien J. Accounting for the full benefits of childhood vaccination in South Africa. South African Medical Journal. 2008;98(11):842-.

39. Beutels P, Scuffham PA, Maclntyre CR. Funding of drugs: do vaccines warrant a different approach? The Lancet Infectious Diseases. 2008;8(11):727-33.

40. Beutels P, Thiry N, Van Damme P. Convincing or confusing?: Economic evaluations of childhood pneumococcal conjugate vaccination-a review (2002-2006). Vaccine. 2007;25(8):1355-67.

41. Byford S, Raftery J. Perspectives in economic evaluation. BMJ : British Medical Journal. 1998;316(7143):1529-30.

42. Jonsson B. Ten arguments for a societal perspective in the economic evaluation of medical innovations. The European journal of health economics : HEPAC : health economics in prevention and care. 2009;10(4):357-9.

43. Knies S, Severens JL, Ament AJ, Evers SM. The transferability of valuing lost productivity across jurisdictions. differences between national pharmacoeconomic guidelines. Value in health : the journal of the International Society for Pharmacoeconomics and Outcomes Research. 2010;13(5):519-27. 
44. Weinstein MC, Siegel JE, Gold MR, Kamlet MS, Russell LB. Recommendations of the Panel on Costeffectiveness in Health and Medicine. Jama. 1996;276(15):1253-8.

45. Gold MR. Cost-effectiveness in health and medicine: Oxford university press; 1996.

46. Jit M, Hutubessy R. Methodological Challenges to Economic Evaluations of Vaccines: Is a Common Approach Still Possible? Applied health economics and health policy. 2016;14(3):245-52.

47. Chen LC, Evans TG, Cash RA. Health as a global public good. Global public goods. 1999:284-304.

48. Kallenberg J, Mok W, Newman R, Nguyen A, Ryckman T, Saxenian H, et al. Gavi's Transition policy: moving from development assistance to domestic financing of immunization Programs. Health Affairs. 2016;35(2):250-8.

49. Beeson JG, Simpson JA. The potential benefit of scaling up malaria prevention to reduce low birth weight in Africa. PLoS medicine. 2017;14(2):e1002244.

50. Walker PG, Floyd J, ter Kuile F, Cairns M. Estimated impact on birth weight of scaling up intermittent preventive treatment of malaria in pregnancy given sulphadoxine-pyrimethamine resistance in Africa: A mathematical model. PLoS medicine. 2017;14(2):e1002243.

51. van Boven M, van Lier A. Global trends in vaccination coverage. The Lancet Global Health.4(10):e670e1.

52. Bloom DE, Canning D, Shenoy ES. The effect of vaccination on children's physical and cognitive development in the Philippines. Applied Economics. 2012;44(21):2777-83. 

$\bullet \bullet$

$\bullet \bullet$

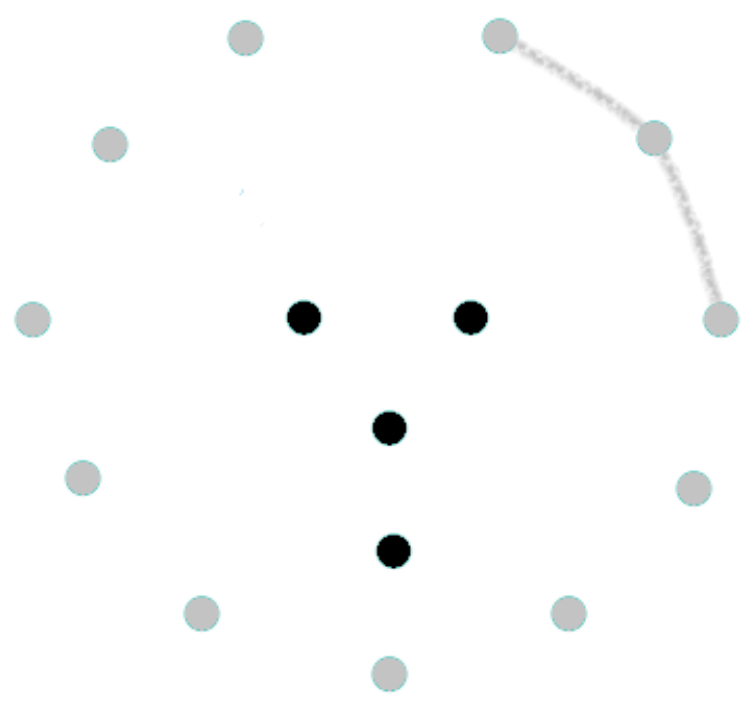




\section{CHAPTER 2}

\section{Conceptualizations of the societal perspective within economic evaluations: a systematic review}

Published as:

Drost MWA, van der Putten IM, Ruwaard D, Evers SMAA, and Paulus ATG. 2017.

Conceptualizations of the societal perspective within economic evaluations: a systematic review. International Journal of Technology Assessment in Health Care, 33(2): 1-10.

https://doi.org/10.1017/S0266462317000526 


\section{Abstract}

Objectives: The aim of this study was to investigate how the societal perspective is conceptualized in economic evaluations and to assess how intersectoral costs and benefits (ICBs), that is, the costs and benefits pertaining to sectors outside the healthcare sector, impact their results.

Methods: Based on a search in July 2015 using PubMed, Embase, CINAHL and PsychINFO, a systematic literature review was performed for economic evaluations which were conducted from a societal perspective. Conceptualizations were assessed in NVivo version 11 using conventional and directed content analysis. Trial-based evaluations in the fields of musculoskeletal and mental disorders were analysed further, focusing on the way ICBs impact the results of economic evaluations.

Results: A total of 107 studies were assessed, of which 74 (69.1\%) provided conceptualizations of the societal perspective. These varied in types of costs included and in descriptions of cost bearers. Labour productivity costs were included in 72 studies (67.3\%), while only 38 studies (35.5\%) included other ICBs, most of which entailed informal care and/or social care costs. ICBs within the educational and criminal justice sectors were each included five times. Most of the trial-based evaluations analysed further ( $n=21$ of 28 ) reported productivity costs. In nine, these took up more than $50 \%$ of total costs. In several studies, criminal justice and informal care costs were also important.

Conclusions: There is great variety in the way the societal perspective is conceptualized and interpreted within economic evaluations. Use of the term 'societal perspective' is often related to including merely productivity costs, while other ICBs could be relevant as well.

Keywords: Economic evaluation; Costs and cost analysis; Intersectoral costs and benefits; Societal perspective; Systematic literature review. 


\section{Introduction}

Increasingly, economic evaluations are being considered supportive for decision making on healthcare interventions [1,2]. Because financial resources are scarce and investment options are infinite, it is important that these programmes and interventions are effective not only in terms of health gains and improving quality of life, but that these effects also outweigh the costs of the intervention and the costs of service use in comparison with the best alternative investment in terms of costs for society as a whole. The analyses and reported results of such economic evaluations depend on the perspective from which the economic evaluation is conducted [3]. This perspective can be either narrow, in which a selection of costs and effects are measured and included in the analysis, or broad, comprising all costs and effects of the interventions under comparison.

Within economic evaluations, the most commonly used perspectives include 1) the payer perspective, in which only the costs and effects for a certain party, such as the patient, employer or insurer, are included, 2) the healthcare perspective, which comprises only the costs and effects within the healthcare sector, and 3) the societal perspective, in which the analyst considers all costs and effects that flow from the intervention, regardless of who experiences these [3]. Because the chosen perspective determines the outcome of the evaluation, economic evaluations should be explicit about the perspective they adopt ${ }^{4}$. Several guidelines on good research practices, such as reported in 'Principles of Good Practice for Budget Analysis: Report of the ISPOR Task Force on Good Research Practices - Budget Impact Analysis' and 'Consolidated Health Economic Evaluation Reporting Standards (CHEERS) Statement' (simultaneous publication in the International Journal of Technology Assessment in Health Care and nine other renowned journals, 2013), have adopted this statement [5-7].

The societal perspective is arguably preferable to the others $[4,8,9]$. This is because health economics is founded on welfare economics, which indicates that an economic evaluation should include the impact of an intervention on the whole of society [4]. Accordingly, a societal perspective is necessary for making optimal societal decisions [8]. In theory, the definition of the societal perspective, which states that 'all costs and effects should be included regardless of who experiences these', seems appropriate. In practice, however, this definition appears less straightforward; looking at costs, the first part of this definition in particular leaves considerable room for discussion as there is often uncertainty regarding which costs should be included in addition to healthcare costs [10]. As a result, the way the societal perspective is conceptualized and interpreted can differ among studies, and the choice of conceptualization can seriously affect the outcome of an economic analysis. 
While the leading health economic literature explicitly notes that informal care and productivity losses are potentially important [11-13], other costs outside the healthcare sector are given considerably less attention. Yet, the aforementioned definition does not limit researchers to value only informal care and productivity losses along with the use of health services. In fact, interventions within the healthcare sector can yield a wide array of costs and benefits in sectors outside the healthcare sector. These are also known as 'intersectoral costs and benefits (ICBs)' [14,15]. Drost et al. (2013) identified more than 70 ICBs of healthcare interventions; these ICBs were classified into five categories. These include the sectors 'Education' (e.g. special education), 'Labour and Social Security' (e.g. productivity), 'Household \& Leisure' (e.g. informal care) and 'Criminal Justice System' (e.g. police interventions), and a fifth category for 'Individual \& Family Effects' (e.g. family conflict), showing that health is connected with the welfare of society through various pathways [14].

Although it is clear that choices are being made when adopting a societal perspective, it is unclear whether choices to omit specific ICBs are made based on a misinterpretation of the societal perspective or measurement issues, and whether an ICB was deliberately omitted or not. There is a danger of leaving out important costs, which can lead to biased results $[10,16]$. This, in turn, could lead to poor investment and reimbursement decisions in the healthcare sector. It is, therefore, important that both researchers and policy makers have sound knowledge of how the societal perspective is conceptualized and interpreted in economic evaluations, and that both groups have a good understanding of possible discrepancies between these conceptualizations and interpretations. Prior research has already shown that including productivity losses in economic evaluations matters [17]. Unfortunately, little is known about the possible impact of other ICBs. Therefore, the main aim of this study is to find out how the societal perspective is conceptualized and interpreted in economic evaluations, and to assess which ICBs are included within these evaluations. A secondary aim is to illustrate how ICBs could determine the results of these evaluations.

\section{Methods}

\section{Literature search}

A systematic literature review was conducted focusing on economic evaluations performed from a societal perspective. The reporting of the systematic review was based on a combination of the Preferred Reporting Items for Systematic Reviews and Meta-Analyses (PRISMA) [18] and reporting requirements from the International Journal of Technology Assessment in Health Care. 
In July 2015, relevant studies were sought using a design derived from an exemplary literature review [19] and adapted from instructions for retrieving (economic) evaluations [20,21]. In addition, to increase the likelihood and efficiency of finding studies reporting the required information, the search was limited to studies which were published after the CHEERS statement was published in 2013. Since the publications of the CHEERS statement appeared between March and June of 2013, it was decided to include only studies published after 1 July 2013. This date was chosen to maximize the number of studies reporting on the perspective considered in the economic analysis - as per the CHEERS statement. Furthermore, the search was limited to full economic evaluation studies published in English, with the availability of the complete text, conducted on human subjects.

Databases and search terms were initially selected based on recommendations for retrieving relevant economic evaluation studies, which propose a combined search in PubMed and the National Health Service Electronic Evaluation Database (NHS EED) as an appropriate, cost-effective strategy [20]. However, since funding to produce NHS EED ceased at the end of March 2015, we replaced NHS EED with its principle sources: Embase, CINAHL and PsychINFO. Searches were conducted using the search term combination 'societal' AND 'economic evaluation' OR 'costs'. Adding the search term 'costs' was necessary to increase the sensitivity of the search, because 'economic evaluation' and equivalents are not consistently indexed with Medical Subject Heading terms [20].

\section{Postsearch article selection}

Of the studies found, all duplicates, reviews, design articles, and animal studies which passed the search filter were excluded. Two reviewers independently assessed all titles and abstracts (RD and IP). Titles were selected based on a recommendation in the first item of the CHEERS statement, which states that the study's title "identifies the study as an economic evaluation or uses more specific terms such as cost-effectiveness analysis" [5]. Subsequently, the abstracts were also checked for describing a economic evaluation. Furthermore, abstracts were checked for use of the word 'societal' in combination with either 'perspective' or 'costs' (or equivalents). Abstracts lacking this combination were excluded.

Finally, full texts (which were all retrieved) were examined for describing full economic evaluations conducted from a societal perspective. Eligibility criteria, framed around PICOS [22], included all non-institutionalized and institutionalized age groups of the population $(\mathrm{P})$, independently of the intervention (I), comparators $(\mathrm{C})$, and outcomes (O), set up as trial- or model-based full economic evaluations (comparing both costs 
and outcomes of both the intervention group and comparators), adopting a societal perspective as study design (S). Only these were included in our study.

\section{Data extraction and analysis}

In the second half of 2015, two reviewers (RD and IP) independently assessed all included studies, after which they compared the assessments. Differences in the results were discussed in author meetings with all authors until uniformity was reached. The data extracted and assessed included conceptualizations of the societal perspective, general study characteristics, and economic evaluation-specific characteristics.

\section{Conceptualizations of the societal perspective}

Conceptualizations of the societal perspective (if provided) were labelled as one or more of the following, which were not mutually exclusive: 1) provision of a general conceptualization, i.e. mention of broad categories such as 'direct costs' and 'indirect costs', 2) provision of a specific conceptualization, i.e. mention of cost types such as 'absenteeism costs' and 'general practitioner costs' or 3) citation of a health economic guideline, journal article or handbook. Furthermore, we also assessed whether studies specified their conceptualizations further to a specific country context, for example the Dutch or Danish societal perspective.

From here, all conceptualizations of the societal perspective were assessed using content analysis in NVivo version 11 [23,24]. This entails an analysis of quotes referring to the societal perspective (e.g. "this study was conducted from a societal perspective, which means...") and was done separately for general and specific conceptualizations. Quotes were defined as general conceptualizations if authors described the societal perspective in generic terms such as 'all relevant costs' and did not provide further specifications. If authors did specify relevant costs by mentioning different types of costs (e.g. criminal costs; productivity costs) and/or different cost categories matching the Drummond classification, then this was regarded as a specific conceptualization.

General conceptualizations were analysed using conventional content analysis, which means that for each new conceptualization a code was added to the overview [23]. Specific conceptualizations were analysed using directed content analysis. Costs were classified based on the $\mathrm{C}_{1}-\mathrm{C}_{4}$ classification of Drummond et al. (2015), which categorizes costs as healthcare costs $\left(C_{1}\right)$, costs in other sectors $\left(C_{2}\right)$, patient and family costs, such as out of pocket and travel expenses $\left(C_{3}\right)$, and productivity costs $\left(C_{4}\right)$ [1]. ICBs (category $C_{2}$ ) were further subdivided based on a classification scheme by Drost et al. (2013), which provides a sub-classification into the 'educational sector', 'the criminal justice system', and 'household and leisure' [14]. The latter covers ICBs related to informal care, social care, household help, leisure time and voluntary work. 


\section{General study characteristics}

The general study characteristics extracted from the full text included year of publication, country of study and the disease area targeted by the intervention, based on the International Statistical Classification of Diseases and Related Health Problems 10th Revision [25]. Interventions which did not target a specific disease, but overall health such as certain health behaviour interventions, were clustered in a separate group. Furthermore, we assessed the type of economic analysis (cost-minimization; cost-effectiveness; cost-utility; cost-benefit; combination), study design (trial; modelling), time horizon ( $\leq 1$ year; $\leq 2$ years; $\leq 5$ years; $\leq 10$ years; lifetime) and cost categories included in the evaluation. Types of costs were categorized using the classification schemes of Drummond et al. (2015) and Drost et al. (2013) mentioned earlier $[1,14]$. Costs which were reported as direct or indirect costs were reclassified based on the abovementioned classification schemes.

\section{Economic evaluation specific characteristics}

Specific characteristics of an economic evaluation were drawn from a subset of studies. Based on the general study characteristics, it was decided to restrict this extensive analysis to trial-based economic evaluations of interventions within the disease areas of 'musculoskeletal disorders/dysfunction' (13 studies) and 'mental and behavioural disorders' (15 studies). For all other disease areas, no more than three trial-based evaluations were identified per area. Furthermore, trial-based evaluations offered revealed (measured) costs, while costs in model-based economic evaluations are (largely) hypothetical. Therefore, and given the limited level of required information provided in these studies, model-based evaluations were not further assessed.

Specific characteristics of economic evaluations extracted from the full text included: the outcome measure (monetary; quality adjusted life years; other), outcome in the analysis conducted from the societal perspective, such as the net-monetary benefit, incremental cost-effectiveness ratio (ICER) and incremental cost-utility ratio (ICUR), whether the intervention was cost effective and/or had a positive net benefit from the societal perspective, specific types of $C_{2}$ and $C_{4}$ costs, whether a second economic analysis was conducted from a different perspective, whether the outcome of this second analysis was different from the one conducted from the societal perspective, and whether the author mentions cost types which were not included in the evaluation conducted from the societal perspective (and if this was considered to be a limitation of the study).

To illustrate how ICBs could impact ICERs/ICURs, for each of these studies and based on available information reported in the articles, we calculated the proportion of ICBrelated costs relative to total costs for the intervention condition(s) and control condition. From here, as has been done for productivity costs in earlier research [17], 
we recalculated incremental costs (i.e. costs in the intervention condition minus costs in the control condition) by leaving out costs in the educational sector and criminal justice sector. Only these two sectors were assessed, because little is known about the extent to which ICBs in these sectors determine the results of economic evaluations. Main economic evaluation-specific findings are presented and discussed in this paper. More detailed information on the trial-based studies can be obtained from the first author.

\section{Results}

Based on the searches in PubMed, CINAHL, PsychInfo and Embase, 725 unique studies were identified. Of these, 590 were excluded based on an assessment of the titles and abstracts. These were excluded on the basis of being design articles, reviews, not describing the study as being an economic evaluation or not mentioning the societal perspective. Of the 135 left, another 28 were excluded, of which 17 were excluded because they appeared to have been published before 1 July 2013. This resulted in 107 included studies (Figure 1).

\section{Conceptualizations of the societal perspective}

Of the 107 studies (Supplementary file 1), only 74 provided a conceptualization of the societal perspective. Further analysis showed that, of these 74 studies, 18 studies (24\%) provided a general conceptualization of the societal perspective, 50 studies (68\%) provided a specific conceptualization and six studies (8\%) provided both. The other 33 studies did not provide any conceptualization of the societal perspective in the text.

In total, 25 studies refer to a health economic guideline, journal article or handbook. Sources that were cited two or more times were Gold et al. (1996) [3], Byford (1998) [4], Drummond et al. (2005) [26], and the US Panel on 
Figure 1. PRISMA flow chart of electronic database search.

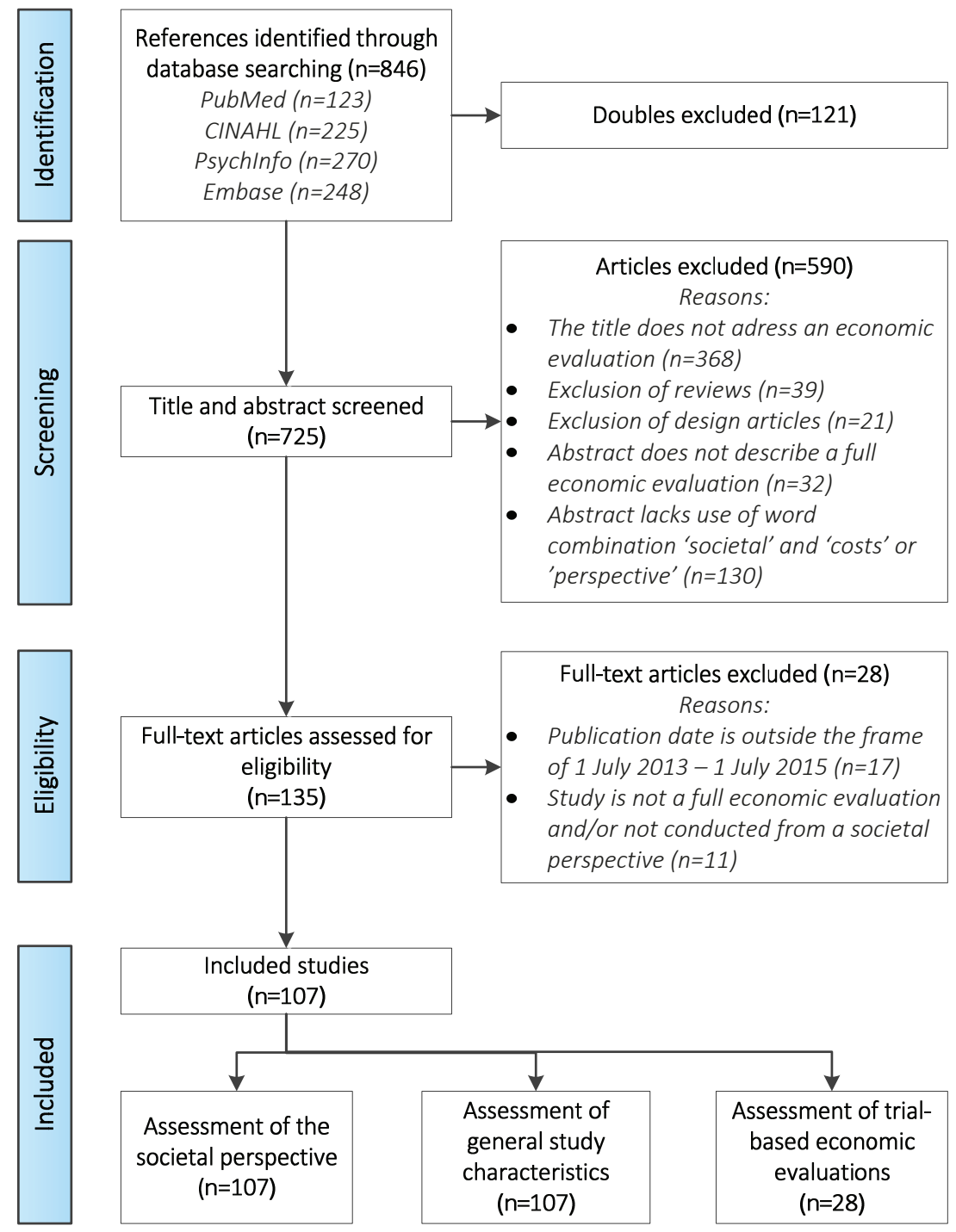

Looking at the 56 specific conceptualizations (Table 1), types of healthcare costs (34 studies) or productivity costs (33 studies) were named most. Patient and family costs were named in 19 of the conceptualizations, and 15 conceptualizations mentioned costs in other sectors. Costs in the educational sector were mentioned in one conceptualization, costs in the criminal justice sector in five and household and/or leisure costs in ten. Intervention costs were mentioned in only ten of the specific conceptualizations. Some specific costs could not be classified based on the specific classification scheme of Drummond (26 studies) and are, therefore, not presented in Table 1. Of these, 20 
studies mentioned direct costs, 18 indirect costs and one also added intangible costs in the equation. Another eight studies included non-medical or non-health(care) costs. Furthermore, one study divided the included costs into payer, participant and opportunity costs. Four studies mentioned the outcomes in their conceptualization of the societal perspective. Detailed information on the conceptualizations can be obtained from the first author.

Table 1. General and specific conceptualizations of the societal perspective ${ }^{a}$

\begin{tabular}{|c|c|c|c|}
\hline \multicolumn{3}{|l|}{ General } & $\mathbf{N}=\mathbf{2 4}$ \\
\hline \multicolumn{3}{|c|}{ All costs and benefits irrespective to whom } & 3 \\
\hline \multicolumn{3}{|c|}{ All costs irrespective of the payer } & 6 \\
\hline \multicolumn{3}{|c|}{ All costs to all individuals in society } & 2 \\
\hline \multicolumn{3}{|c|}{ All relevant costs for and effects on society } & 2 \\
\hline \multicolumn{3}{|c|}{ Costs shouldered by both provider and household } & 1 \\
\hline \multicolumn{3}{|c|}{ Any costs incurred by the patients } & 2 \\
\hline \multicolumn{3}{|c|}{ The overall societal benefits of the programme whether intended or not } & 1 \\
\hline \multicolumn{3}{|c|}{ All relevant costs associated with the burden of the disease } & 1 \\
\hline \multicolumn{3}{|c|}{ Costs associated with utilization of health care } & 2 \\
\hline \multicolumn{3}{|c|}{ All costs from whatever source } & 4 \\
\hline \multicolumn{3}{|l|}{ Specific } & $N=56$ \\
\hline Type & $\mathbf{N}$ & Type & $\mathbf{N}$ \\
\hline Intervention costs & 9 & Costs in other sectors & 0 \\
\hline Treatment costs & 1 & Educational sector & \\
\hline Health care costs & 9 & School absenteeism & 1 \\
\hline Community health & 2 & Criminal justice system & \\
\hline Day activity & 1 & Automobile accident & 1 \\
\hline Drug & 2 & Criminal activity & 2 \\
\hline Health care utilization & 1 & Criminal justice & 2 \\
\hline Health system & 5 & Victim & 2 \\
\hline Home care services & 1 & Household \& leisure & \\
\hline Hospital & 9 & Informal care & 6 \\
\hline Laboratory tests & 1 & Household cost & 1 \\
\hline Medical & 9 & Caregiver & 3 \\
\hline Medicare reimbursement & 3 & Housekeeping & 2 \\
\hline Nursing home care & 1 & Absenteeism normal activities & 1 \\
\hline Primary care & 2 & Unpaid work & 1 \\
\hline Provider & 2 & Patient and family costs & 6 \\
\hline Social care & 3 & Mortality & 2 \\
\hline Productivity costs & 25 & Out-of-pocket & 5 \\
\hline Absenteeism work & 8 & Patient time & 2 \\
\hline Disability payment & 1 & Respondent cost & 3 \\
\hline Lost income & 2 & Travel expenses & 6 \\
\hline Lost labour force & 1 & & \\
\hline Work time lost & 6 & & \\
\hline
\end{tabular}


It is important to mention that the costs named in these conceptualizations do not always represent the variety of costs taken into account, for many costs are mentioned elsewhere in the methods and results sections of the articles. For example, most studies included intervention costs in their analysis, while hardly any included these costs in the conceptualization of the societal perspective. This becomes evident when comparing the results in Table 1 and Table 3, the latter of which is discussed later on.

\section{General study characteristics}

Around half of the included studies ( $n=56$ ) covered trial-based economic evaluations and around half ( $n=51)$ covered modelling studies (Table 2 ). Approximately one-third of the 107 included studies were US-based $(n=36)$ and more than one-fifth were based in the Netherlands $(n=24)$. Sweden $(n=8)$ and Canada $(n=7)$ took third and fourth place in numbers of included studies. In contrast, a fairly limited number of studies from the UK $(n=5)$ were included. Although the societal perspective is preferred in international literature [4], it is recommended and commonplace in the UK to conduct economic evaluations from the perspective of the NHS [27]. The main focus in the US studies was on modelling ( $n=30,83.3 \%$ ), whereas most of the evaluations in the Netherlands were trial-based $(n=23,95.8 \%)$. The majority of studies $(n=60)$ covered interventions targeting musculoskeletal disorders/dysfunctions, mental and behavioural disorders, cardiovascular diseases, or infectious diseases. Most economic evaluations within the field of mental and behavioural disorders were trial-based (15 out of 17 studies), while in the fields of cardiovascular and infectious diseases model-based economic evaluations were more common (18 out of 21 studies).

In total, 79 studies were CUA-based, either as a standalone analysis or in combination with a CEA. Most CEAs were trial-based, while the majority of less common CBAs were model-based. The majority of the trial-based evaluations (78.6\%) had a follow-up of no longer than one year. Apart from one study, which assessed costs over a one-year timeframe 15 years post intervention, no trial-based evaluations were identified with a follow-up longer than five years. Most modelling studies (58.8\%) projected the lifetime costs and consequences of the intervention. 
Table 2. Study characteristics of the included economic evaluations ( $n, \%)$

\begin{tabular}{|c|c|c|c|c|}
\hline \multirow{2}{*}{$\begin{array}{l}\text { Study } \\
\text { characteristic }\end{array}$} & & \multirow[b]{2}{*}{ All } & \multicolumn{2}{|c|}{ Study design } \\
\hline & & & Trial & Modelling \\
\hline $\begin{array}{l}\text { Number of } \\
\text { studies }\end{array}$ & & 107 & $56(52)$ & $51(48)$ \\
\hline \multirow{8}{*}{$\begin{array}{l}\text { Country of } \\
\text { study }\end{array}$} & US & $36(34)$ & $6(11)$ & $30(59)$ \\
\hline & The Netherlands & $24(22)$ & $23(41)$ & $1(2)$ \\
\hline & Sweden & $8(8)$ & $5(9)$ & $3(6)$ \\
\hline & Canada & $7(7)$ & $4(7)$ & $3(6)$ \\
\hline & UK & $5(5)$ & $3(5)$ & $2(4)$ \\
\hline & Spain & $4(4)$ & $3(5)$ & $1(2)$ \\
\hline & Thailand & $4(4)$ & $0(0)$ & $4(8)$ \\
\hline & Other/multiple countries & $19(18)$ & $12(21)$ & $7(14)$ \\
\hline \multirow[t]{14}{*}{ Disease area } & Musculoskeletal disorders/dysfunction & $22(21)$ & $13(23)$ & $9(18)$ \\
\hline & Mental and behavioural disorders & $17(16)$ & $15(27)$ & $2(4)$ \\
\hline & Cardiovascular diseases & $11(10)$ & $2(4)$ & $9(18)$ \\
\hline & Infectious diseases & $10(9)$ & $1(1)$ & $9(18)$ \\
\hline & Cancer & $8(8)$ & $3(5)$ & $5(10)$ \\
\hline & Obesity and diabetes & $5(5)$ & $2(4)$ & $3(6)$ \\
\hline & Dental problems & $4(4)$ & $3(5)$ & $1(2)$ \\
\hline & Kidney and urinary tract diseases/dysfunction & $3(3)$ & $2(4)$ & $1(2)$ \\
\hline & Pain and fatigue & $3(3)$ & $3(5)$ & $0(0)$ \\
\hline & Lung diseases & $2(2)$ & $2(4)$ & $0(0)$ \\
\hline & Hearing disorders & $2(2)$ & $1(2)$ & $1(2)$ \\
\hline & Pregnancy and neonatal care & $2(2)$ & $1(2)$ & $1(2)$ \\
\hline & Non-specific (general health, health behaviour) & $8(8)$ & $5(9)$ & $3(6)$ \\
\hline & Other & $10(9)$ & $3(5)$ & $7(14)$ \\
\hline \multirow{6}{*}{$\begin{array}{l}\text { Type of } \\
\text { analysis }\end{array}$} & Cost-minimization analysis & $4(4)$ & $3(5)$ & $1(2)$ \\
\hline & Cost-effectiveness analysis & $16(15)$ & $12(21)$ & $4(8)$ \\
\hline & Cost-utility analysis & $55(51)$ & $21(38)$ & $34(67)$ \\
\hline & Cost-benefit analysis & $6(6)$ & $1(2)$ & $5(10)$ \\
\hline & Cost-effectiveness + cost-utility analysis & $24(22)$ & $17(30)$ & $7(14)$ \\
\hline & Other combination & $2(2)$ & $2(4)$ & $0(0)$ \\
\hline \multirow[t]{7}{*}{ Time horizon } & $\leq 1$ year & $51(48)$ & $44(79)$ & $7(14)$ \\
\hline & $\leq 2$ years & $6(6)$ & $6(11)$ & $0(0)$ \\
\hline & $\leq 5$ years & $9(8)$ & $3(5)$ & $6(12)$ \\
\hline & $\leq 10$ years & $1(1)$ & $0(0)$ & $1(2)$ \\
\hline & Lifetime & $30(28)$ & $0(0)$ & $30(59)$ \\
\hline & Multiple & $3(3)$ & $0(0)$ & $3(6)$ \\
\hline & Unspecified/unclear & $7(7)$ & $3(5)$ & $4(8)$ \\
\hline
\end{tabular}




\section{Types of costs included}

Nearly all studies clearly report having included intervention costs and healthcare costs (Table 3), of which some might have used these terms interchangeably for the same types of costs. Nearly half of the 107 included studies $(n=49)$ included patient and family costs such as out of pocket expenses, travel costs and/or living costs. The majority of the studies $(n=72,67 \%)$ included costs related to labour productivity, such as costs related to absenteeism, presenteeism and unemployment. However, productivity costs were more frequently included in studies on interventions targeting musculoskeletal dysfunctions/disorders (86\%) and mental and behavioural disorders $(94 \%)$ than in studies on interventions targeting cardiovascular diseases (36\%) and infectious diseases (60\%). Related to this finding, productivity costs were more often included in trial-based economic evaluations $(n=43,77 \%)$ than in model-based economic evaluations ( $n=29,57 \%$ ). Only 38 studies (36\%) included other ICBs, of which most included only costs related to informal care, household help and/or social care. Again, these were more frequently included in trial-based evaluations. Studies which included ICBs within the educational sector and criminal justice sector were scarce. Both types were included five times, of which one of the studies which included educational costs was in the field of infectious diseases and two of the studies which included criminal justice costs were in the field of mental and behavioural disorders.

\section{Impact of ICBs on economic evaluation results}

Of the thirteen trial-based economic evaluations in the disease area of musculoskeletal disorder/dysfunction, nine explicitly reported the follow-up costs for ICBs. All of these reported costs related to labour productivity, such as absenteeism and presenteeism costs. In six of these, (combined) productivity-related costs took up more than $50 \%$ of the total costs in both the intervention as well as the control arms. Two studies reported costs related to informal care. In one of these, informal care costs took up $18 \%$ of the costs in the control condition and $29 \%$ of the costs in the intervention condition. In the other study, the weight of these costs relative to the total costs was close to $0 \%$. Costs related to other ICBs were not explicitly reported. Seven studies conducted additional analyses from other perspectives: six were from the healthcare/health system perspective and one from the employer's perspective. Differences in results between the societal perspective and other perspectives underlined the important role of ICBs. Six studies explicitly mentioned cost types which were not included in the study, but could have been of importance. The types and number of cost items mentioned in the discussion sections varied per study. 


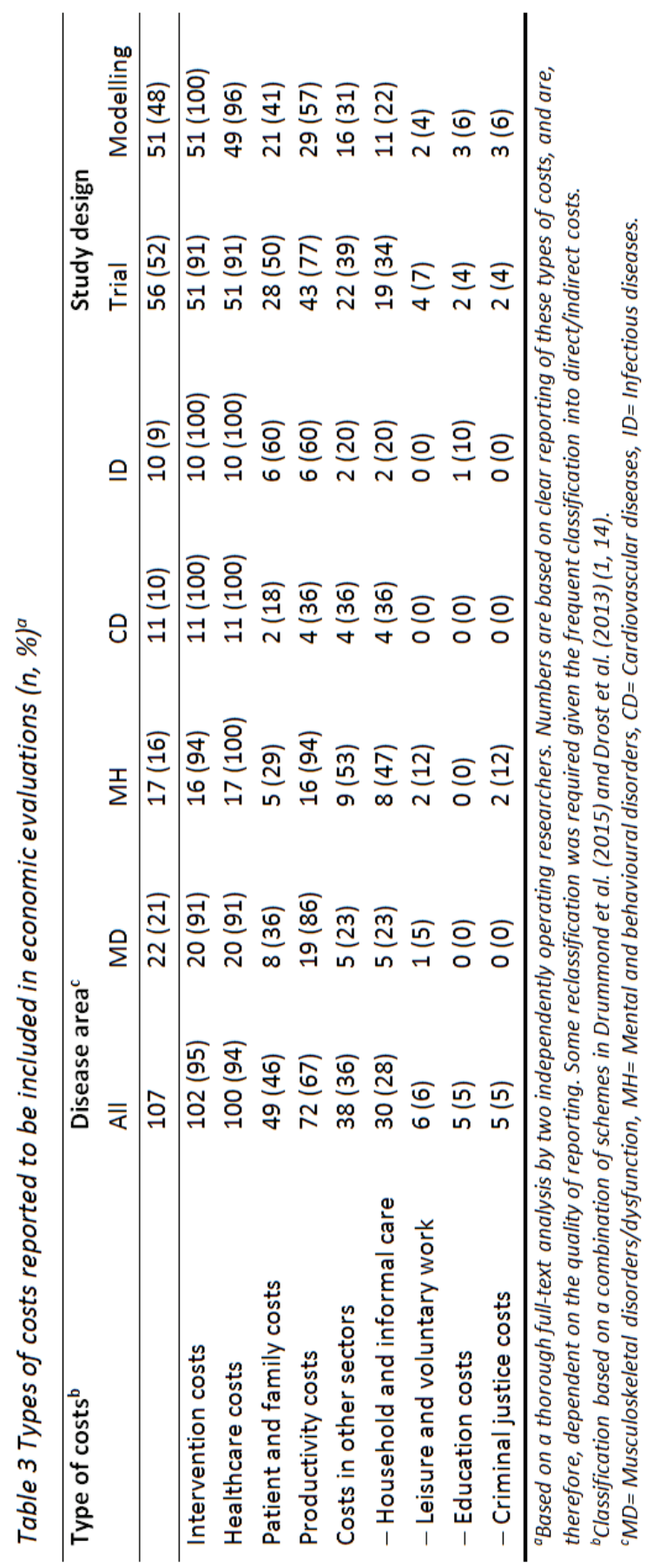


Of the fifteen mental/behavioural health trial-based economic evaluations, thirteen explicitly reported the follow-up costs for ICBs. Twelve of these reported costs related to labour productivity, such as costs of absenteeism and presenteeism. In three of these, productivity-related costs took up more than $50 \%$ of the total costs in both the intervention as well as the control arms and in all three, presenteeism costs outweighed absenteeism costs. Five studies reported costs related to informal care or domestic productivity. In one of these, informal care costs took up $66 \%$ of the costs in the control condition and $67 \%$ of the costs in the intervention condition. In the other five studies, the weight of these costs relative to the total costs was below $20 \%$.

Two studies in the field of mental/behavioural health reported costs within the criminal justice sector. In one, crime costs and criminal justice costs took up 25\% of the total costs in the intervention condition and $18 \%$ of the total costs in the control condition [28]. The recalculation without these costs shifted incremental costs from GBP -350 to GBP $-1,896$. In the other study, costs related to arrests, court, probation and jail/prison time took up $24 \%$ of the total costs in the intervention condition and $63 \%$ of the total costs in the control condition [29]. Here, the recalculation resulted in a shift from USD 1,630 to USD -423 . Costs related to other ICBs were not explicitly reported. Eight studies conducted additional analyses from other perspectives: five were from the healthcare/health system perspective, two from the employer's perspective and one from the criminal justice services' perspective. Differences in results between the societal perspective and other perspectives underlined the important role of ICBs. Three studies explicitly mentioned costs which were not included in the study, but could have been of importance.

As mentioned earlier, more detailed information on the trial-based studies can be obtained from the first author.

\section{Discussion}

\section{Conclusion}

Based on the results, it can be concluded that there is great variety in the way the societal perspective is conceptualized and executed within economic evaluations. Consequently, there is great variety in the types of costs included in the analyses of the assessed studies.

The authors of included studies who did pay attention to the conceptualization of the societal perspective $(n=74)$ used a general conceptualization, and/or used a specific conceptualization, by mentioning specific costs to describe their interpretation of the societal perspective. Both types were commonly used; eighteen studies used a general 
conceptualization, 50 studies used a specific conceptualization and six used both. Most of the authors who operationalized the societal perspective in a specific conceptualization explicitly mentioned productivity costs or related terms, which could have been their justification for using the term societal perspective. The classification of costs in (in)direct (non)-medical categories is also found to be widely used instead of the sector-based classification of Drummond.

The conceptualization of the societal perspective was not often mentioned and discussed in the discussion sections of studies. However, some studies did discuss this issue. Some studies regarded their interpretation of the societal perspective to be a weakness of the study $[30,31]$. Others perceived their interpretation of the societal perspective as a strength [32-35].

In trial-based evaluations within the field of musculoskeletal disorders/dysfunction, productivity costs more often took up a large proportion of the total costs than in evaluations in the field of mental and behavioural disorders. However, these costs were shown to be important in this field as well. The two of the mental health studies which explicitly reported costs related to ICBs within the criminal justice sector showed that restricting economic evaluations to healthcare costs and productivity costs alone could sometimes be insufficient. Despite the differences between disease areas and even between studies within these disease areas, this literature review shows that costs related to ICBs often take up a considerable proportion of the total costs of an intervention.

Although this evidence for ICBs other than those related to productivity is scarce, it is clear that, depending on the type of intervention, the disease area, and the target group, omitting ICBs from analyses conducted from the societal perspective could lead to biased results. Furthermore, when this leads to a biased ICER, ICUR or other important economic outcome, omitting ICBs may lead to poor decision making when choosing between care as usual and an alternative.

\section{Research and policy implications}

How the societal perspective is operationalized remains largely in the eye of the beholder (36). Referring to the classification scheme of Drost et al. (2013), it is clear that, even if the societal perspective is chosen, not all 70 ICBs can be or should be included [14]. Adopting the societal perspective raises measurement and valuation challenges $[10,37]$. Furthermore, not all ICBs may be considered important enough to be included in the economic evaluations of certain interventions. For example, it is clear that costs within the criminal justice sector are not important for the economic evaluation of blood pressure medication, while the results of this literature review 
show that they might be important for the field of mental and behavioural health. Although the decision regarding which ICBs to include will remain based on expectations on what are considered to be 'big tickets', the results of this literature review underline the importance of making well-informed and argued decisions on which costs to include and exclude from analysis.

Because ICBs are disease-specific, it is advised to always consult experts in the field to know which ICBs are relevant for specific diseases and, accordingly, the interventions targeting these. The ICB classification scheme of Drost et al. can be provided to these experts for them to consult during the process of deciding which ICBs should be measured and valued [14]. As mentioned earlier, wrong decisions lead to biased results [10]. Our findings affirm the earlier statement of the ISPOR Task Force on Good Research Practices about the wide misunderstanding and misuse of the term 'societal perspective' within economic evaluations [37]. Policy makers, therefore, should be vigilant concerning this matter.

The way the societal perspective is conceptualized and executed within economic evaluations is partly dependent on country-specific health economic guidelines. Looking at productivity costs, a review of Knies et al. (2010) showed that the majority of examined guidelines (22 of 30 ) recommend using the societal perspective, but vary in the way productivity costs should be valued [9]. However, the use of the term 'societal perspective' should not be justifiable merely based on the choice of including productivity costs. Concord with this can be found in the updated version of the Dutch guidelines for costing research, which was published and presented in February 2016. These state that ICBs within the educational sector and criminal justice sector could play a vital role in economic evaluations as well (38). This goes for all types of analysis, including CEA, CUA and CBA.

\section{Limitations}

The findings of this study need to be placed in the context of three limitations. First, the findings of the review were dependent on the quality of the reporting in included studies. The amount and quality of information which could be drawn from these studies varied. Some studies were less detailed and structured than others, which made it harder or impossible to retrieve the required information. Furthermore, some elements were harder to retrieve than others. For example, although a classification of costs into sectors is considered to provide more structure [1], the majority of studies ( $n=60,56.1 \%$ ) used the alternative of classifying costs into direct and indirect costs. Therefore, costs had to be reclassified. However, the chance of errors in retrieving and reclassifying information has been minimized through a double and independent analysis by two of the authors. Furthermore, the choice to include only papers which 
were published after publication of the CHEERS might have helped. Notwithstanding, what is not reported in papers might be more interesting than what is, and our study was limited due to this (un)deliberate reporting bias. This limitation shows the value of and need for reporting guidelines such as the CHEERS and the Consolidated Standards of Reporting Trials [5,39].

Second, our search for and inclusion of literature was restricted to published research articles, whereas unpublished or grey literature could have provided additional valuable findings. However, it is assumed that the selection made for a broad and sensitive search, and that 107 studies which were included are representative of the way the societal perspective is nowadays conceptualized and interpreted in health economic studies.

Third, several methodological choices needed to be made for feasibility and practical reasons, of which some could be important for future studies. The included studies were not assessed for methodological quality. Furthermore, costs were classified based on the classification schemes of Drummond et al. (2015) and Drost et al. (2013) [1,14], while other ways of classifying costs could have influenced results. Last, the in-depth analysis on ICBs was restricted to trial-based economic evaluations on interventions targeting musculoskeletal disorders/dysfunction and mental/behavioural disorders. The number of studies in other disease areas was limited. Recalculation of ICERs was done merely on reported information, not based on the original datasets containing individual patient data, which were not accessible to the authors. Model-based evaluations were not assessed, given the fact that the majority of the model-based studies did not offer a detailed overview of costs. Furthermore, trial-based evaluations offered revealed (measured) costs, while costs in model-based economic evaluations are (largely) hypothetical. 


\section{References}

1. Drummond M, Sculpher MJ, Claxton K, Stoddart G, Torrance GW. Methods for the Economic Evaluation of Health Care Programmes. New York: Oxford University Press; 2015.

2. Hutubessy R, Chisholm D, Edejer TT. Generalized cost-effectiveness analysis for national-level priority-setting in the health sector. Cost Eff Resour Alloc. 2003;1(1):8.

3. Gold MR, Siegel JE, Russel LB, Weinstein MC. Cost-Effectiveness in Health and Medicine. New York: Oxford University Press; 1996.

4. Byford S, Raftery J. Perspectives in economic evaluation. BMJ. 1998;316(7143):1529-30.

5. Husereau D, Drummond M, Petrou S, Carswell C, Moher D, Greenberg D, et al. Consolidated Health Economic Evaluation Reporting Standards (CHEERS) statement. Int J Technol Assess Health Care. 2013;29(2):117-22.

6. ISPOR. Health Economic Evaluation Publication Guidelines (CHEERS): Good Reporting Practices 2016 [Available from website ISPOR: http://www.ispor.org/Health-Economic-Evaluation-PublicationCHEERS-Guidelines.asp.

7. Mauskopf JA, Sullivan SD, Annemans L, Caro J, Mullins CD, Nuijten M, et al. Principles of good practice for budget impact analysis: report of the ISPOR Task Force on good research practices-budget impact analysis. Value Health. 2007;10(5):336-47.

8. Jonsson B. Ten arguments for a societal perspective in the economic evaluation of medical innovations. Eur J Health Econ. 2009;10(4):357-9.

9. Knies S, Severens $\mathrm{JL}$, Ament AJ, Evers SM. The transferability of valuing lost productivity across jurisdictions. Differences between national pharmacoeconomic guidelines. Value Health. 2010; 13(5):519-27.

10. Evers SM, Hiligsmann M, Adarkwah CC. Risk of bias in trial-based economic evaluations: identification of sources and bias-reducing strategies. Psychology \& health. 2015;30(1):52-71.

11. Koopmanschap MA, Rutten FF, van Ineveld BM, van Roijen L. The friction cost method for measuring indirect costs of disease. J Health Econ. 1995;14(2):171-89.

12. Koopmanschap MA, van Exel JN, van den Berg B, Brouwer WB. An overview of methods and applications to value informal care in economic evaluations of healthcare. Pharmacoeconomics. 2008;26(4):269-80.

13. Weisbrod BA. Economics of Public Health: Measuring the Economic Impact of Diseases: University of Pennsylvania Press; 1961.

14. Drost RMWA, Paulus ATG, Ruwaard D, Evers SMAA. Inter-sectoral costs and benefits of mental health prevention: towards a new classification scheme. J Ment Health Policy Econ. 2013;16(4):17986.

15. Weatherly H, Drummond M, Claxton K, Cookson R, Ferguson B, Godfrey C, et al. Methods for assessing the cost-effectiveness of public health interventions: key challenges and recommendations. Health Policy. 2009;93(2-3):85-92.

16. Drummond M, Sculpher M. Common methodological flaws in economic evaluations. Med Care. 2005;43(7 Suppl):5-14.

17. Krol M, Papenburg J, Koopmanschap M, Brouwer W. Do Productivity Costs Matter?: the impact of including productivity costs on the incremental costs of interventions targeted at depressive disorders. Pharmacoeconomics. 2011;29(7):601-19.

18. Moher D, Liberati A, Tetzlaff J, Altman DG, Group P. Preferred reporting items for systematic reviews and meta-analyses: the PRISMA statement. PLoS medicine. 2009;6(7):e1000097.

19. Alayli-Goebbels AF, Evers SM, Alexeeva D, Ament AJ, de Vries NK, Tilly JC, et al. A review of economic evaluations of behavior change interventions: setting an agenda for research methods and practice. J Public Health (Oxf). 2014;36(2):336-44.

20. Alton V, Eckerlund I, Norlund A. Health economic evaluations: how to find them. Int J Technol Assess Health Care. 2006;22(4):512-7. 
21. Aveyard H. Doing a literature review in health and social care: a practical guide (3rd edition). Berkshire: Open University Press: McGraw - Hill Education; 2014.

22. Schardt C, Adams MB, Owens T, Keitz S, Fontelo P. Utilization of the PICO framework to improve searching PubMed for clinical questions. BMC Med Inform Decis Mak. 2007;7:16.

23. Hsieh HF, Shannon SE. Three approaches to qualitative content analysis. Qual Health Res. 2005;15(9):1277-88.

24. QSR. 2016 [Available from: http://www.qsrinternational.com/what-is-nvivo.

25. WHO. International Statistical Classification of Diseases and Related Health Problems 10th Revision 2016 [Available from: http://apps.who.int/classifications/icd10/browse/2016/en.

26. Drummond M, O'Brien BJ, Stoddart G, Torrance GW. Methods for the Economic Evaluation of Health Care Programmes. New York: Oxford University Press; 2005.

27. NICE. Developing NICE guidelines: the manual 2014 [Available from: https://www.nice.org.uk/ article/pmg20/chapter/7-incorporating-economic-evaluation.

28. Barrett B, Waheed W, Farrelly S, Birchwood M, Dunn G, Flach C, et al. Randomised controlled trial of joint crisis plans to reduce compulsory treatment for people with psychosis: economic outcomes. PLoS One. 2013;8(11):e74210.

29. Herman PM, Mahrer NE, Wolchik SA, Porter MM, Jones S, Sandler IN. Cost-benefit analysis of a preventive intervention for divorced families: reduction in mental health and justice system service use costs 15 years later. Prev Sci. 2015;16(4):586-96.

30. Christensen A, Hoy K, Bunger C, Helmig P, Hansen ES, Andersen T, et al. Transforaminal lumbar interbody fusion vs. posterolateral instrumented fusion: cost-utility evaluation along side an RCT with a 2-year follow-up. European spine journal : official publication of the European Spine Society, the European Spinal Deformity Society, and the European Section of the Cervical Spine Research Society. 2014;23(5):1137-43.

31. Lewis DJ, Attiah MA, Malhotra NR, Burnett MG, Stein SC. Anterior surgical management of singlelevel cervical disc disease: a cost-effectiveness analysis. Spine. 2014;39(25):2084-92.

32. Golsteijn RH, Peels DA, Evers SM, Bolman C, Mudde AN, de Vries H, et al. Cost-effectiveness and cost-utility of a Web-based or print-delivered tailored intervention to promote physical activity among adults aged over fifty: an economic evaluation of the Active Plus intervention. The international journal of behavioral nutrition and physical activity. 2014;11:122.

33. Imaz I, Rubio B, Cornejo AM, Gonzalez-Enriquez J. Budget impact and cost-utility analysis of universal infant rotavirus vaccination in Spain. Prev Med. 2014;61:116-21.

34. Marsh J, Hoch JS, Bryant D, MacDonald SJ, Naudie D, McCalden R, et al. Economic evaluation of webbased compared with in-person follow-up after total joint arthroplasty. The Journal of bone and joint surgery American volume. 2014;96(22):1910-6.

35. van Apeldoorn FJ, Stant AD, van Hout WJ, Mersch PP, den Boer JA. Cost-effectiveness of CBT, SSRI, and CBT+SSRI in the treatment for panic disorder. Acta Psychiatr Scand. 2014;129(4):286-95.

36. Sculpher $\mathrm{M}$, editor How Should a Societal Perspective in Economic Evaluation be Implemented? ISPOR; 2014; Amsterdam.

37. Garrison LP, Jr., Mansley EC, Abbott TA, 3rd, Bresnahan BW, Hay JW, Smeeding J. Good research practices for measuring drug costs in cost-effectiveness analyses: a societal perspective: the ISPOR Drug Cost Task Force report--Part II. Value Health. 2010;13(1):8-13.

38. ZiNL. De nieuwe richtlijn Economische Evaluaties in Nederland: Verschillen en verbeteringen ten opzichte van de vorige richtlijn. Nieuwe richtlijn economische evaluaties: "Verduidelijking en verdieping". Amsterdam; 2016.

39. Moher D, Schulz KF, Altman DG. The CONSORT statement: revised recommendations for improving the quality of reports of parallel-group randomised trials. Lancet. 2001;357(9263):1191-4. 


\section{Supplementary file 1}

1. Aboagye EK, M. L.; Hagberg, J.; Jensen, I. Cost-effectiveness of early interventions for non-specific low back pain: a randomized controlled study investigating medical yoga, exercise therapy and selfcare advice. Journal of rehabilitation medicine : official journal of the UEMS European Board of Physical and Rehabilitation Medicine, 2015;47(2):167-73.

2. Achelrod DS, T. Cost-utility analysis comparing heavy-weight and light-weight mesh in laparoscopic surgery for unilateral inguinal hernias. Applied health economics and health policy, 2014;12(2):15163.

3. Alkoshi SM, N.; Dahlui, M. Cost-effectiveness analysis of rotavirus vaccination among Libyan children using a simple economic model. The Libyan journal of medicine, 2014;9:26236.

4. Annemans LB, M.; Druais, S.; De Pauw, A.; Gauthier, A.; Demyttenaere, K. Cost-effectiveness analysis of pharmaceutical treatment options in the first-line management of major depressive disorder in Belgium. Pharmacoeconomics, 2014;32(5):479-93.

5. Arends IB, Ute; van Rhenen, Willem; Groen, Henk; van der Klink, Jac J. L. Economic evaluation of a problem solving intervention to prevent recurrent sickness absence in workers with common mental disorders. PLoS ONE, 2013;8(8).

6. Armstrong KS, John L.; Coyte, Peter C. Replacing ambulatory surgical follow-up visits with mobile app home monitoring: Modeling cost-effective scenarios. Journal of medical Internet research, 2014; Vo 16(9):262-70.

7. Baltzer HB, P. A. Cost-effectiveness in the management of Dupuytren's contracture: A Canadian costutility analysis of current and future management strategies. Bone \& Joint Journal (British), 2013;95$B(8): 1094-100$.

8. Barbosa CC, Alexander; Bray, Jeremy; Aldridge, Arnie. The cost-effectiveness of alcohol screening, brief intervention, and referral to treatment (SBIRT) in emergency and outpatient medical settings. Journal of substance abuse treatment, 2015;53:1-8.

9. Barrett BW, W.; Farrelly, S.; Birchwood, M.; Dunn, G.; Flach, C.; Henderson, C.; Leese, M.; Lester, H.; Marshall, M.; Rose, D.; Sutherby, K.; Szmukler, G.; Thornicroft, G.; Byford, S. Randomised controlled trial of joint crisis plans to reduce compulsory treatment for people with psychosis: economic outcomes. PLoS One, 2013;8(11):e74210.

10. Chen H-HC, William Tzu-Liang; Lee, Hsin-Chung; Lin, Jen-Kou; Fang, Chuan-Yin; Chou, Yenn-Hwei; Lin, Peng-Chan; Lin, Bo-Wen; Huang, Chi-Chou; Yeh, Chung-Hung; Hsu, Hsi-Hsien; Chen, Hung-Chang; Ting, Wen-Chien; Yang, Ming-Chin; Tan, Elise Chia-Hui. Health-related quality of life and cost comparison of adjuvant capecitabine versus 5-fluorouracil/leucovorin in stage III colorectal cancer patients. Quality of Life Research: An International Journal of Quality of Life Aspects of Treatment, Care \& Rehabilitation, 2015;24(2):473-84.

11. Chhagan MKVdB, J.; Luabeya, K. K.; Mpontshane, N.; Bennish, M. L. Cost of childhood diarrhoea in rural South Africa: exploring cost-effectiveness of universal zinc supplementation. Public Health Nutr, 2014;17(9):2138-45.

12. Christensen AH, K.; Bunger, C.; Helmig, P.; Hansen, E. S.; Andersen, T.; Sogaard, R. Transforaminal lumbar interbody fusion vs. posterolateral instrumented fusion: cost-utility evaluation along side an RCT with a 2-year follow-up. European spine journal : official publication of the European Spine Society, the European Spinal Deformity Society, and the European Section of the Cervical Spine Research Society, 2014;23(5):1137-43.

13. Delgado MKS, Kristan L.; Wang, N. Ewen; Spain, David A.; Weir, Sharada; Owens, Douglas K.; Goldhaber-Fiebert, Jeremy D. Cost-effectiveness of helicopter versus ground emergency medical services for trauma scene transport in the United States. Annals of emergency medicine, 2013;62(4):351-64.e19.

14. Demaerschalk BMS, Jeffrey A.; Jipan, Xie; Liangyi, Fan; Villa, Kathleen F.; Wu, Eric Q. Cost Utility of Hub-and-Spoke Telestroke Networks From Societal Perspective. American Journal of Managed Care, 2013;19(12):976-10. 
15. Dugas AFC, S.; Gaydos, C. A.; Rothman, R. E.; Frick, K. D. Cost-utility of rapid polymerase chain reaction-based influenza testing for high-risk emergency department patients. Annals of emergency medicine, 2013;62(1):80-8.

16. Echebiri NCM, M. aya; Pullen, Jessica A.; Aalto, Meaghan M.; Patel, Natasha N.; Doyle, Nora M. Placental alpha-microglobulin-1 and combined traditional diagnostic test: a cost-benefit analysis. American Journal of Obstetrics \& Gynecology, 2015;212(1):77.e1-.e10.

17. Epstein LHP, R. A.; Wrotniak, B. H.; Daniel, T. O.; Kilanowski, C.; Wilfley, D.; Finkelstein, E. Costeffectiveness of family-based group treatment for child and parental obesity. Childhood obesity, 2014;10(2):114-21.

18. Erickson KFC, Glenn M.; Goldhaber-Fiebert, Jeremy D. Cost-effectiveness of tolvaptan in autosomal dominant polycystic kidney disease. Annals of Internal Medicine, 2013;159(6):382-9.

19. Eriksson JKK, J. A.; Bratt, J.; Petersson, I. F.; van Vollenhoven, R. F.; Ernestam, S.; Geborek, P.; Neovius, M. Cost-effectiveness of infliximab versus conventional combination treatment in methotrexate-refractory early rheumatoid arthritis: 2-year results of the register-enriched randomised controlled SWEFOT trial. Ann Rheum Dis, 2015;74(6):1094-101.

20. Eveleigh RG, J.; Muskens, E.; Oude Voshaar, R.; van Weel, C.; Speckens, A.; Lucassen, P. Cost-utility analysis of a treatment advice to discontinue inappropriate long-term antidepressant use in primary care. Fam Pract, 2014;31(5):578-84.

21. Fangjun ZS, Abigail; Wenger, Jay; Messonnier, Mark; Li Yan, Wang; Lopez, Adriana; Moore, Matthew; Murphy, Trudy V.; Cortese, Margaret; Rodewald, Lance. Economic Evaluation of the Routine Childhood Immunization Program in the United States, 2009. Pediatrics, 2014;133(4):577-85.

22. Florence CS, Jonathan; Brennan, lain; Simon, Thomas R. An economic evaluation of anonymised information sharing in a partnership between health services, police and local government for preventing violence-related injury. Injury Prevention, 2014;20(2):108-14.

23. Garcia AL, Terrence H.; Victorino, Gregory P. Cost-utility analysis of prehospital spine immobilization recommendations for penetrating trauma. Journal of Trauma \& Acute Care Surgery, 2014;76(2):53441.

24. Geraedts ASvD, Johanna M.; Kleiboer, Annet M.; Wiezer, Noortje M.; van Mechelen, Willem; Cuijpers, Pim; Bosmans, Judith E. Economic evaluation of a web-based guided self-help intervention for employees with depressive symptoms: Results of a randomized controlled trial. Journal of Occupational and Environmental Medicine, 2015;57(6):666-75.

25. Ghomrawi HME, Ashley A.; Pearle, Andrew D. Effect of age on cost-effectiveness of unicompartmental knee arthroplasty compared with total knee arthroplasty in the u.s. Journal of Bone \& Joint Surgery, American Volume, 2015;97(5):396-402.

26. Golsteijn RHJP, Denise A.; Evers, Silvia M. A. A.; Bolman, Catherine; Mudde, Aart N.; de Vries, Hein; Lechner, Lilian. Cost-effectiveness and cost-utility of a web-based or print-delivered tailored intervention to promote physical activity among adults aged over fifty: An economic evaluation of the Active Plus intervention. The international journal of behavioral nutrition and physical activity, 2014;11.

27. Goorden MM, A.; van Marwijk, H.; Spinhoven, P.; Ader, H.; van Balkom, A.; van der Feltz-Cornelis, C.; Hakkaart-van Roijen, L. Cost utility analysis of a collaborative stepped care intervention for panic and generalized anxiety disorders in primary care. Journal of psychosomatic research, 2014;77(1):57-63.

28. Goorden MV, M. C.; Anema, J. R.; van Mechelen, W.; Beekman, A. T.; Hoedeman, R.; van der FeltzCornelis, C. M.; Hakkaart-van Roijen, L. Cost-utility analysis of a collaborative care intervention for major depressive disorder in an occupational healthcare setting. J Occup Rehabil, 2014;24(3):555-62.

29. Hannemann PFWE, B. A. B.; Schots, J. P. M.; Dullaert, K.; Poeze, M.; Brink, P. R. G. Functional outcome and cost-effectiveness of pulsed electromagnetic fields in the treatment of acute scaphoid fractures: A cost-utility analysis Orthopedics and biomechanics. 1 ed. United Kingdom: BioMed Central Ltd.; 2015.

30. Hedman EEA, S.; Lindefors, N.; Andersson, E.; Ruck, C.; Ghaderi, A.; Kaldo, V.; Lekander, M.; Andersson, G.; Ljotsson, B. Clinical effectiveness and cost-effectiveness of Internet- vs. group-based 
cognitive behavior therapy for social anxiety disorder: 4-year follow-up of a randomized trial. Behaviour research and therapy, 2014;59:20-9.

31. Henriksson MN, E.; Ohna, A.; Wallentin, L.; Janzon, M. Ticagrelor treatment in patients with acute coronary syndrome is cost-effective in Sweden and Denmark. Scandinavian cardiovascular journal : SCJ, 2014;48(3):138-47.

32. Herman PMM, Nicole E.; Wolchik, Sharlene A.; Porter, Michele M.; Jones, Sarah; Sandler, Irwin N. Cost-benefit analysis of a preventive intervention for divorced families: Reduction in mental health and justice system service use costs 15 years later. Prevention Science, 2015;16(4):586-96.

33. Herman PMS, O.; Cooley, K.; Seely, D. A naturopathic approach to the prevention of cardiovascular disease: cost-effectiveness analysis of a pragmatic multi-worksite randomized clinical trial. J Occup Environ Med, 2014;56(2):171-6.

34. Imaz IR, B.; Cornejo, A. M.; Gonzalez-Enriquez, J. Budget impact and cost-utility analysis of universal infant rotavirus vaccination in Spain. Prev Med, 2014;61:116-21.

35. Ising HKS, F.; Veling, W.; Rietdijk, J.; Dragt, S.; Klaassen, R. M. C.; Savelsberg, N. S. P.; Boonstra, N.; Nieman, D. H.; Linszen, D. H.; Wunderink, L.; van der Gaag, M. Cost-effectiveness of preventing firstepisode psychosis in ultra-high-risk subjects: Multi-centre randomized controlled trial. Psychol Med, 2015;45(7):1435-46.

36. Ito KA, J.; Shrank, W. H.; Toscano, M.; Spettel, C.; Brennan, T.; Choudhry, N. K. Long-term costeffectiveness of providing full coverage for preventive medications after myocardial infarction. 3 ed. United States: Lippincott Williams and Wilkins; 2015. p. 252-9.

37. Jarungsuccess ST, Satadon. Cost-Utility Analysis of Oral Anticoagulants for Nonvalvular Atrial Fibrillation Patients at the Police General Hospital, Bangkok, Thailand. Clinical Therapeutics, 2014;36(10):1389-94.e4.

38. Joling KJB, J. E.; van Marwijk, H. W.; van der Horst, H. E.; Scheltens, P.; MacNeil Vroomen, J. L.; van Hout, H. P. The cost-effectiveness of a family meetings intervention to prevent depression and anxiety in family caregivers of patients with dementia: a randomized trial. Trials, 2013;14:305.

39. Kazi DSG, Alan M.; Shah, Rashmee U.; Dudley, R. Adams; Mell, Matthew W.; Rhee, Ceron; Moshkevich, Solomon; Boothroyd, Derek B.; Owens, Douglas K.; Hlatky, Mark A. Cost-effectiveness of genotype-guided and dual antiplatelet therapies in acute coronary syndrome. Annals of Internal Medicine, 2014;160(4):221-32.

40. Khazeni NH, David W.; Collins, Cassandra I. F.; Garber, Alan M.; Owens, Douglas K. Health and Economic Benefits of Early Vaccination and Nonpharmaceutical Interventions for a Human Influenza A (H7N9) Pandemic: A Modeling Study. Annals of Internal Medicine, 2014;160(10):684-94.

41. Klop KWK, N. F.; Dols, L. F.; d'Ancona, F. C.; Adang, E. M.; Grutters, J. P.; I. Jzermans JN. Costeffectiveness of hand-assisted retroperitoneoscopic versus standard laparoscopic donor nephrectomy: a randomized study. Transplantation, 2013;96(2):170-5.

42. Kohn CGP, M. W.; Limone, B. L.; Coleman, C. I. Cost-effectiveness of ranolazine added to standard-ofcare treatment in patients with chronic stable angina pectoris. Am J Cardiol, 2014;113(8):1306-11.

43. Konopka JFG, A. H.; Thornhill, T. S.; Katz, J. N.; Losina, E. The cost-effectiveness of surgical treatment of medial unicompartmental knee osteoarthritis in younger patients: a computer model-based evaluation. The Journal of bone and joint surgery. American volume, 2015;97(10):807-17.

44. Lachaine JB, Catherine; Mathurin, Karine; Gilbert, Dominique; Beillat, Maud. Cost-effectiveness of asenapine in the treatment of bipolar disorder in Canada. BMC psychiatry, 2014;14.

45. Lazzaro CL, Leonardo; Cocito, Dario. Subcutaneous vs intravenous administration of immunoglobulin in chronic inflammatory demyelinating polyneuropathy: An Italian cost-minimization analysis. Neurological Sciences, 2014;35(7):1023-34.

46. Le QAD, J. N.; Zoellner, L. A.; Feeny, N. C. Cost-effectiveness of prolonged exposure therapy versus pharmacotherapy and treatment choice in posttraumatic stress disorder (the Optimizing PTSD Treatment Trial): a doubly randomized preference trial. The Journal of clinical psychiatry, 2014;75(3):222-30. 
47. Lee BYS, Ashima; Bartsch, Sarah M.; Muder, Robert R. An Economic Model: Value of AntimicrobialCoated Sutures to Society, Hospitals, and Third-Party Payers in Preventing Abdominal Surgical Site Infections. Infection Control \& Hospital Epidemiology, 2014;35(8):1013-20.

48. LeFevre AES, S. D.; Waters, H. R.; Haider, S.; El Arifeen, S.; Mannan, I.; Seraji, H. R.; Shah, R.; Darmstadt, G. L.; Wall, S. N.; Williams, E. K.; Black, R. E.; Santosham, M.; Baqui, A. H. Economic evaluation of neonatal care packages in a cluster-randomized controlled trial in Sylhet, Bangladesh. Bull World Health Organ, 2013;91(10):736-45.

49. Leppert MHC, J. D.; Simpson, J. R.; Burke, J. F. Cost-Effectiveness of Intra-Arterial Treatment as an Adjunct to Intravenous Tissue-Type Plasminogen Activator for Acute Ischemic Stroke. Stroke; a journal of cerebral circulation, 2015;46(7):1870-6.

50. Lewis DJA, Mark A.; Malhotra, Neil R.; Burnett, Mark G.; Stein, Sherman C. Anterior Surgical Management of Single-Level Cervical Disc Disease: A Cost-effectiveness Analysis. Spine (03622436), 2014;39(25):2084-92.

51. Littlewood KJO, Mario J. N. M.; Sauboin, Christophe; Tehard, Bertrand; Alain, Sophie; Denis, François. Cost-Effectiveness of Routine Varicella Vaccination Using the Measles, Mumps, Rubella and Varicella Vaccine in France: An Economic Analysis Based on a Dynamic Transmission Model for Varicella and Herpes Zoster. Clinical Therapeutics, 2015;37(4):830-41.

52. Liu SW, Daena; Holodniy, Mark; Goldhaber-Fiebert, Jeremy D. Sofosbuvir-based treatment regimens for chronic, genotype 1 hepatitis C virus infection in u.s. Incarcerated populations: a costeffectiveness analysis. Annals of Internal Medicine, 2014;161(8):546-53.

53. Luciano JVDA, F.; Cerda-Lafont, M.; Penarrubia-Maria, M. T.; Knapp, M.; Cuesta-Vargas, A. I.; Serrano-Blanco, A.; Garcia-Campayo, J. Cost-utility of cognitive behavioral therapy versus U.S. Food and Drug Administration recommended drugs and usual care in the treatment of patients with fibromyalgia: an economic evaluation alongside a 6-month randomized controlled trial. Arthritis research \& therapy, 2014;16(5):451.

54. Luciano JVS-F, R.; Cardenosa, E.; T. Penarrubia-Maria M; Fernandez-Vergel, R.; Garcia-Campayo, J.; Knapp, M.; Serrano-Blanco, A. Cost-utility of a psychoeducational intervention in fibromyalgia patients compared with usual care: an economic evaluation alongside a 12-month randomized controlled trial. The Clinical journal of pain, 2013;29(8):702-11.

55. Maes IHC, R. F.; Anteunis, L. J.; Scheijen, D. J.; Baguley, D. M.; El Refaie, A.; Vlaeyen, J. W.; Joore, M. A. Cost-effectiveness of specialized treatment based on cognitive behavioral therapy versus usual care for tinnitus. Otology \& neurotology : official publication of the American Otological Society, American Neurotology Society [and] European Academy of Otology and Neurotology, 2014;35(5):787-95.

56. Mangham-Jefferies LW, V.; Achonduh, O. A.; Drake, T. L.; Cundill, B.; Onwujekwe, O.; Mbacham, W. Economic evaluation of a cluster randomized trial of interventions to improve health workers' practice in diagnosing and treating uncomplicated malaria in Cameroon. Value Health, 2014;17(8):783-91.

57. Manning VLK, B.; Ratcliffe, J.; Scott, D. L.; Choy, E.; Hurley, M. V.; Bearne, L. M. Economic evaluation of a brief education, self-management and upper limb exercise training in people with rheumatoid arthritis (EXTRA) programme: a trial-based analysis. Rheumatology (Oxford, England), 2015;54(2):302-9.

58. Marra CAG, M.; Cibere, J.; Grindrod, K. A.; Woolcott, J. C.; Gastonguay, L.; Esdaile, J. M. Cost-utility analysis of a multidisciplinary strategy to manage osteoarthritis of the knee: economic evaluation of a cluster randomized controlled trial study. Arthritis care \& research, 2014;66(6):810-6.

59. Marsh JH, J. S.; Bryant, D.; MacDonald, S. J.; Naudie, D.; McCalden, R.; Howard, J.; Bourne, R.; McAuley, J. Economic evaluation of web-based compared with in-person follow-up after total joint arthroplasty. The Journal of bone and joint surgery. American volume, 2014;96(22):1910-6.

60. Mason JMT, K. S.; Crook, A. M.; Foster, K. A.; Chalmers, J. R.; Nunn, A. J.; Williams, H. C. Prophylactic antibiotics to prevent cellulitis of the leg: economic analysis of the PATCH I \& II trials. PLoS One, 2014;9(2):e82694. 
61. Mather 3rd RCK, Lane; Acevedo, Daniel; Dall, Timothy M.; Gallo, Paul; Romeo, Anthony; Tongue, John; Williams Jr, Gerald. The societal and economic value of rotator cuff repair. Journal of Bone \& Joint Surgery, American Volume, 2013;95(22):1993-2000.

62. Mather 3rd RCK, Lane; Kocher, Mininder S.; Dall, Timothy M.; Gallo, Paul; Scott, Daniel J.; Bach Jr, Bernard R.; Spindler, Kurt P. Societal and economic impact of anterior cruciate ligament tears. Journal of Bone \& Joint Surgery, American Volume, 2013;95(19):1751-9.

63. Mather RC, 3rd; Hug, K. T.; Orlando, L. A.; Watters, T. S.; Koenig, L.; Nunley, R. M.; Bolognesi, M. P. Economic evaluation of access to musculoskeletal care: the case of waiting for total knee arthroplasty. BMC musculoskeletal disorders, 2014;15:22.

64. Meeuwsen EM, R.; van der Aa, G.; Goluke-Willemse, G.; de Leest, B.; van Raak, F.; Scholzel-Dorenbos, C.; Verheijen, D.; Verhey, F.; Visser, M.; Wolfs, C.; Adang, E.; Olde Rikkert, M. Cost-effectiveness of one year dementia follow-up care by memory clinics or general practitioners: economic evaluation of a randomised controlled trial. PLoS One, 2013;8(11):e79797.

65. Meng HF, F.; Castora-Binkley, M. Cost-effectiveness of chronic fatigue self-management versus usual care: a pilot randomized controlled trial. BMC family practice, 2014;15:184.

66. Metzelthin SFVR, Erik; Hendriks, Marike R. C.; Dewitte, Luc P.; Hobma, Sjoerd O.; Sipers, Walther; Kempen, Gertrudis I. J. M. Reducing disability in community-dwelling frail older people: costeffectiveness study alongside a cluster randomised controlled trial. Age \& Ageing, 2015;44(3):390-6.

67. Muennig PAE, Michael; Guohua, Li; DiMaggio, Charles. The Cost-Effectiveness of New York City's Safe Routes to School Program. Am J Public Health, 2014;104(7):1294-9.

68. Najafzadeh MA, Karin; Shrank, William H.; Krumme, Alexis A.; Matlin, Olga S.; Brennan, Troyen; Avorn, Jerry; Choudhry, Niteesh K. Cost-effectiveness of novel regimens for the treatment of hepatitis C virus. Annals of Internal Medicine, 2015;162(6):407-19.

69. Nielsen RK, H.; Bjermer, L.; Lange, P.; Arnetorp, S.; Hedegaard, M.; Stenling, A.; Mittmann, N. Cost effectiveness of adding budesonide/formoterol to tiotropium in COPD in four Nordic countries. Respiratory medicine, 2013;107(11):1709-21.

70. Noben CS, Filip; Nieuwenhuijsen, Karen; Ketelaar, Sarah; Gärtner, Fania; Boon, Brigitte; Sluiter, Judith; Evers, Silvia. Comparative cost-effectiveness of two interventions to promote work functioning by targeting mental health complaints among nurses: Pragmatic cluster randomised trial. International journal of nursing studies, 2014;51(10):1321-31.

71. Nohlert EH, A. R.; Tillgren, P.; Tegelberg, A.; Johansson, P. Comparison of the cost-effectiveness of a high- and a low-intensity smoking cessation intervention in Sweden: a randomized trial. Nicotine \& tobacco research : official journal of the Society for Research on Nicotine and Tobacco, 2013;15(9):1519-27.

72. Oestergaard LGC, F. B.; Nielsen, C. V.; Bunger, C. E.; Fruensgaard, S.; Sogaard, R. Early versus late initiation of rehabilitation after lumbar spinal fusion: economic evaluation alongside a randomized controlled trial. Spine, 2013;38(23):1979-85.

73. Ostensson EH, A. C.; Hellman, K.; Gustavsson, I.; Gyllensten, U.; Wilander, E.; Zethraeus, N.; Andersson, S. Projected cost-effectiveness of repeat high-risk human papillomavirus testing using self-collected vaginal samples in the Swedish cervical cancer screening program. Acta obstetricia et gynecologica Scandinavica, 2013;92(7):830-40.

74. Pershing SE, Eva A.; Matesic, Brian; Owens, Douglas K.; Goldhaber-Fiebert, Jeremy D. Costeffectiveness of treatment of diabetic macular edema. Annals of Internal Medicine, 2014;160(1):1829.

75. Petraroli AS, V.; Di Paola, N.; Barbarino, A.; Bova, M.; Spano, R.; Marone, G.; Triggiani, M. Home Therapy with Plasma-Derived C1 Inhibitor: A Strategy to Improve Clinical Outcomes and Costs in Hereditary Angioedema. International archives of allergy and immunology, 2015;166(4):259-66.

76. Pinto DR, M. C.; Abbott, J. H.; Hansen, P.; Campbell, A. J. Manual therapy, exercise therapy, or both, in addition to usual care, for osteoarthritis of the hip or knee. 2: economic evaluation alongside a randomized controlled trial. Osteoarthritis and cartilage / OARS, Osteoarthritis Research Society, 2013;21(10):1504-13. 
77. Purtle JR, Linda J.; Bloom, Sandra L.; Rich, John A.; Corbin, Theodore J. Cost-benefit analysis simulation of a hospital-based violence intervention program. Am J Prev Med, 2015;48(2):162-9.

78. Rubio-Valera MB, J.; Fernandez, A.; Penarrubia-Maria, M.; March, M.; Trave, P.; Bellon, J. A.; SerranoBlanco, A. Cost-effectiveness of a community pharmacist intervention in patients with depression: a randomized controlled trial (PRODEFAR Study). PLoS One, 2013;8(8):e70588.

79. Saha SC, K. S.; Gerdtham, U. G.; Eriksson, M. K.; Hagberg, L.; Eliasson, M.; Johansson, P. Are lifestyle interventions in primary care cost-effective?--An analysis based on a Markov model, differences-indifferences approach and the Swedish Bjorknas study. PLoS One, 2013;8(11):e80672.

80. Sangmala PC, U.; Tanwandee, T.; Pongchareonsuk, P. Economic evaluation and budget impact analysis of the surveillance program for hepatocellular carcinoma in Thai chronic hepatitis B patients. Asian Pac J Cancer Prev, 2014;15(20):8993-9004.

81. Schilp JB, J. E.; Kruizenga, H. M.; Wijnhoven, H. A.; Visser, M. Is dietetic treatment for undernutrition in older individuals in primary care cost-effective? Journal of the American Medical Directors Association, 2014;15(3):226 e7- e13.

82. Schulz DNS, E. S.; Stanczyk, N. E.; Kremers, S. P.; de Vries, H.; Evers, S. M. Economic evaluation of a web-based tailored lifestyle intervention for adults: findings regarding cost-effectiveness and costutility from a randomized controlled trial. Journal of medical Internet research, 2014;16(3):e91.

83. Seidl HH, M.; Leidl, R.; Meisinger, C.; Wende, R.; Kuch, B.; Holle, R. Cost-effectiveness of nurse-based case management versus usual care for elderly patients with myocardial infarction: results from the KORINNA study. 6 ed. Germany: Springer Verlag; 2015. p. 671-81.

84. Semenov YRY, Susan T.; Seshamani, Meena; Wang, Nae-Yuh; Tobey, Emily A.; Eisenberg, Laurie S.; Quittner, Alexandra L.; Frick, Kevin D.; Niparko, John K. Age-dependent cost-utility of pediatric cochlear implantation. Ear \& Hearing (01960202), 2013;34(4):402-12.

85. Sjostrom MU, G.; Lindholm, L.; Samuelsson, E. Cost-effectiveness of an Internet-based treatment program for stress urinary incontinence. Neurourology and urodynamics, 2015;34(3):244-50.

86. Spijker-Huiges AV, K.; Winters, J. C.; van Wijhe, M.; van der Meer, K. Costs and cost-effectiveness of epidural steroids for acute lumbosacral radicular syndrome in general practice: an economic evaluation alongside a pragmatic randomized control trial. Spine, 2014;39(24):2007-12.

87. Spijker-Huiges AV, K.; Winters, J. C.; van Wijhe, M.; van der Meer, K. Epidural steroids for lumbosacral radicular syndrome compared to usual care: quality of life and cost utility in general practice. Archives of physical medicine and rehabilitation, 2015;96(3):381-7.

88. Stanczyk NES, E. S.; Schulz, D. N.; De Vries, H.; Bolman, C.; Muris, J. W. M.; Evers, S. M. A. A. An economic evaluation of a video- and text-based computer-tailored intervention for smoking cessation: A cost-effectiveness and cost-utility analysis of a randomized controlled trial. 10 ed. United States: Public Library of Science; 2014.

89. Stey AMD, M.; Qiu, S.; Yin, S.; Divino, C. M. Cost-utility analysis of repair of reducible ventral hernia. Surgery, 2014;155(6):1081-9.

90. Tantai NC, U.; Tanwandee, T.; Werayingyong, P.; Teerawattananon, Y. A cost-utility analysis of drug treatments in patients with HBeAg-positive chronic hepatitis B in Thailand. United Kingdom; 2014. p. 170.

91. Thoma AK, M. N.; Tsoi, B.; Ziolkowski, N.; Duku, E.; Goldsmith, C. H. Cost-effectiveness analysis parallel to a randomized controlled trial comparing vertical scar reduction and inverted T-shaped reduction mammaplasty. Plastic and reconstructive surgery, 2014;134(6):1093-107.

92. Tynelius GEL-K, E.; Petren, S. A cost-minimization analysis of an RCT of three retention methods. European journal of orthodontics, 2014;36(4):436-41.

93. van Apeldoorn FJS, A. D.; van Hout, W. J.; Mersch, P. P.; den Boer, J. A. Cost-effectiveness of CBT, SSRI, and CBT+SSRI in the treatment for panic disorder. Acta Psychiatr Scand, 2014;129(4):286-95.

94. van den Hurk CJvdA-vM, M. Elske; Breed, Wim P.; van de Poll-Franse, Lonneke V.; Nortier, Johan W.; Coebergh, Jan W. Cost-effectiveness analysis of scalp cooling to reduce chemotherapy-induced alopecia. Acta Oncologica, 2014;53(1):80-7. 
95. van Dongen TMS, A. G.; Venekamp, R. P.; de Wit, G. A.; van der Heijden, G. J. Cost-effectiveness of treatment of acute otorrhea in children with tympanostomy tubes. Pediatrics, 2015;135(5):e1182-9.

96. van Haalen HGP, M.; Bergenheim, K.; McEwan, P.; Townsend, R.; Roudaut, M. Cost effectiveness of adding dapagliflozin to insulin for the treatment of type 2 diabetes mellitus in the Netherlands. Clinical drug investigation, 2014;34(2):135-46.

97. van Hees FH, J. Dik F.; Meester, Reinier G.; Lansdorp-Vogelaar, Iris; van Ballegooijen, Marjolein; Zauber, Ann G. Should colorectal cancer screening be considered in elderly persons without previous screening?: a cost-effectiveness analysis. Annals of Internal Medicine, 2014;160(11):750-9.

98. Vavrek DAS, R.; Haas, M. Cost analysis related to dose-response of spinal manipulative therapy for chronic low back pain: outcomes from a randomized controlled trial. Journal of manipulative and physiological therapeutics, 2014;37(5):300-11.

99. Vermaire JHvL, C.; Brouwer, W. B.; Krol, M. Value for money: economic evaluation of two different caries prevention programmes compared with standard care in a randomized controlled trial. Caries research, 2014;48(3):244-53.

100. Wantanee KS, Sompitak; Saengsuree, Jootar; Kanchana, Chansung; Yot, Teerawattananon. CostUtility Analysis of Dasatinib and Nilotinib in Patients With Chronic Myeloid Leukemia Refractory to First-Line Treatment With Imatinib in Thailand. Clinical Therapeutics, 2014;36(4):534-43.

101. Wilson ECFS, L.; Cahn, A. P.; Chilvers, E. R.; Parfrey, H.; Clark, A. B.; Twentyman, O. P.; Wilson, A. M. Treating idiopathic pulmonary fibrosis with the addition of co-trimoxazole: An economic evaluation alongside a randomised controlled trial. 1 ed. New Zealand: Adis International Ltd; 2014. p. 87-99.

102. Wilson KJB, H. Shelton, III; Bastida, Elena. Cost-effectiveness of a community-based weight control intervention targeting a low-socioeconomic-status Mexican-origin population. Health Promotion Practice, 2015;16(1):101-8.

103. Wong FKS, C.; Chau, J.; Law, A. K.; Tam, S. K.; McGhee, S. Economic evaluation of the differential benefits of home visits with telephone calls and telephone calls only in transitional discharge support. Age and ageing, 2015;44(1):143-7.

104. Wong FLB, Smita; Landier, Wendy; Francisco, Liton; Leisenring, Wendy; Hudson, Melissa M.; Armstrong, Gregory T.; Mertens, Ann; Stovall, Marilyn; Robison, Leslie L.; Lyman, Gary H.; Lipshultz, Steven E.; Armenian, Saro H. Cost-Effectiveness of the Children's Oncology Group Long-Term Followup Screening Guidelines for Childhood Cancer Survivors at Risk for Treatment-Related Heart Failure. Annals of Internal Medicine, 2014;160(10):672-83.

105. Yeh JMN, Anju; Diller, Lisa. Routine echocardiography screening for asymptomatic left ventricular dysfunction in childhood cancer survivors: a model-based estimation of the clinical and economic effects. Annals of Internal Medicine, 2014;160(10):661-71.

106. Younhee KJ-Y, Park; Sun-Young, Park; Sung-Hee, Oh; YeaJi, Jung; Ji-Min, Kim; Soo-Yeon, Yoo; SeongKyun, Kim. Economic Evaluation of Single-Tooth Replacement: Dental Implant Versus Fixed Partial Denture. International Journal of Oral \& Maxillofacial Implants, 2014;29(3):600-7.

107. Zhang YS, J.; Pang, Z.; Gao, W.; Sintonen, H.; Kapur, A.; Qiao, Q. Evaluation of two screening methods for undiagnosed diabetes in China: an cost-effectiveness study. Primary care diabetes, 2013;7(4):275-82. 
$\bullet \bullet \bullet$

-

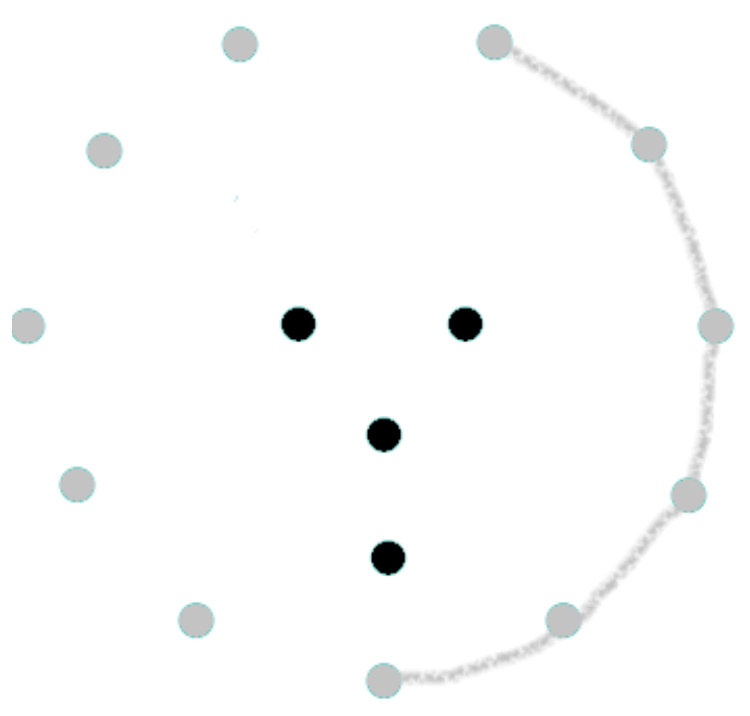




\section{CHAPTER 3}

\section{Stakeholders' perception on including}

broader economic impact of vaccines in economic evaluations in low and middle income countries: a mixed methods study

Published as:

Van der Putten I.M., Evers S.M.A.A., Deogaonkar R, Jit M, and Hutubessy R.C.W. 2015.

Stakeholders' perception on including broader economic impact of vaccines in economic evaluations in low and middle income countries: a mixed methods study.

BMC Public Health, 15 (356). https://doi.org/10.1186/s12889-015-1638-0 


\section{Abstract}

Background: Current economic evaluation guidelines mainly concentrate on immediate health gains and cost savings for the individual involved in the intervention. However, it has been argued that these guidelines are too narrow to capture the full impact of vaccination and immunization programmes in low and middle income countries. The inclusion of broader economic impact of vaccines (BEIVs) has therefore been proposed. Some examples of these are productivity-related gains, macro-economic impact, and different externalities. Despite their potency, the extent to which such benefits can and should be incorporated into economic evaluations of vaccination is still unclear. This mixed methods study aims to assess the relevance of BEIVs to different stakeholders involved in the decision making on the introduction of vaccines.

Methods: In this mixed method study an internet based survey was sent to attendees of the New and Underutilized Vaccines Initiative meeting in Montreux, Switzerland in 2011. Additionally, semi-structured interviews of 15 minutes each were conducted during the meeting. Study participants included decision makers, experts and funders of vaccines and immunization programmes in low and middle income countries. Descriptive analysis of the survey, along with identification of common themes and factors extracted from the interviews and open survey questions was undertaken.

Results: Evidence on macro-economic impact, burden of disease and ecological effects were perceived as being most valuable towards aiding decision making for vaccine introduction by the 26 survey respondents. The 14 interviewees highlighted the importance of burden of disease and different types of indirect effects. Furthermore, some new interpretations of BEIVs were discussed, such as the potential negative impact of wastage during immunization programmes and the idea of using vaccines as a platform for delivering other types of health interventions. Interviewees also highlighted the importance of using a broader perspective in connection to measuring economic impacts, particularly when attempting to derive the value of newer, more expensive vaccines.

Conclusion: According to participants, BEIVs were seen as being equally important as traditional outcome measures used in cost-effectiveness analyses. Such insight can be used to shape research agendas within this field and to eventually create broader, more inclusive practical guidelines for economic evaluations of vaccines.

Keywords: Mixed methods, Economic evaluations, Externalities, Vaccines, Immunization, Decision making, Low and middle income countries, Developing countries. 


\section{Background}

It is estimated that in 2013, 6.3 million children worldwide died before turning five, equal to almost 17.000 children every day [1]. The leading causes of under-five mortality among children have been found to be pneumonia, other acute respiratory infections, and childhood diarrhea [1,2]. Despite a commendable average reduction of 49\% from 1990 to 2013 [1], the decrease in current mortality rate will need to be quadrupled in order to reach the Millennium Development Goal of a two-thirds reduction in child mortality by 2015 [2]. It is estimated that an extra 4.2 million lives could be saved by ensuring access to comprehensive vaccine coverage [3]. However, low and middle income countries (LMICs) and international donors alike only have limited resources at their disposal. Hence, governments and donors have to trade off purchasing vaccines against other health care investment decisions [4,5]. Economic tools such as cost-benefit (CBA) and cost-effectiveness analysis (CEA) have the potential to strengthen the use of evidence in such a decision making context [6], hence creating a more transparent framework for vaccine introduction. Vaccine introduction can be interpreted as the addition of a vaccine to the Expanded Programme on Immunization (EPI programme), the introduction of a new product formulation that was already part of the programme, a new combination vaccine, or a new route of administration for an already covered vaccine [7].

One of the key issues during vaccine introduction, besides issues related to the disease and the strength of the immunization programme and the health system, is the vaccine itself in terms of safety, efficacy and the economic and financial consequences of introducing the vaccine [7]. Several guidelines on economic evaluations of vaccines have been published by research groups and international organizations to strengthen evidence-based decision making on the introduction of vaccines [8-12]. The core components of these guidelines revolve around estimating the costs and benefits of vaccines and immunization programmes. Benefit components traditionally include health care cost savings or improvements in life expectancy and quality of life. Indirect benefits realized by caregivers and the greater community and/or effectiveness of the vaccine, as part of a larger programme, are generally not included in these guidelines [13].

A report developed for the World Bank's Human Development Network (Health, Nutrition and Population Family series) suggests that policy makers do not base their decision solely on the CEA results currently prescribed due to a lack of transparency and inability to factor in country specific contextual factors [4]. Moreover, it has been argued that the use of CEA alone may be too narrow to capture the overall impact of vaccination [14-18] and other child health programmes [19]. In line with this report several initiatives, such as the Pan American Health Organization's (PAHO) ProVac 
Initiative in Latin America $[6,20]$, strengthen the process of national decision making by providing better infrastructure and tools for economic analysis, including training, data collection and analysis and general advocacy for the use of economic evidence in decision making [6]. Their programme ProVac trains national teams to develop policy briefs using a framework with technical, financial, operational and social criteria.

Recent reviews of the broader economic impact of vaccines (BEIVs) have identified several domains that are not adequately captured by traditional metrics such as morbidity, mortality and generic health utility measures such as Disability Adjusted Life Years (DALY) and Quality Adjusted Life years (QALY) (see Table 1) [4,14,16,19,21-28]. However, some of the broader domains discussed (e.g. behavior-related productivity gains), are based on theoretical concepts and have not been subject to adequate empirical quantification. It is therefore important to assess the relevance of including some of these broader economic considerations in economic evaluation studies for various stakeholders, prior to their inclusion in research and practical guidelines. Hence, the goal of this study is to gauge the importance of the various BEIVs from a stakeholder perspective, and clarify the extent to which BEIVs can and should be incorporated into the guidelines for economic evaluations of vaccines to support policymakers and external funders in making decisions on vaccine introduction.

\section{Methods}

Our study utilized a mixed method triangulation convergence model design [29]. This design allowed for simultaneous collection of both quantitative and qualitative data but also permitted separate analysis of the two components prior to comparing their respective results. The rationale for choosing this approach was to allow our qualitative findings to elucidate the quantitative data [29] The qualitative component consisted of face-to-face interviews (further referred to as interviews with interviewees) and the quantitative component involved the use of an internet based survey (further referred to as survey with respondents). Both interviews and survey were concurrently conducted among the participants of the New and Underutilized Vaccines Initiative (NUVI) meeting in Montreux (Switzerland) in May 2011. This meeting was selected because of good representation from all major stakeholders involved in vaccine introduction. A wide range of stakeholder groups were represented including donor programmes such as Global Alliance for Vaccines and Immunization (GAVI alliance) and the Bill and Melinda Gates Foundation, international organizations such as United Nations International Children's Emergency Fund (UNICEF) and World Health Organization (WHO), pharmaceutical companies, research institutes, national managers for the EPI programme, and other government or non-government (PATH, AMP, etc.) representatives. 
Table 1. Categorized list of the benefits of vaccination.

\begin{tabular}{|c|c|}
\hline Category & Definition \\
\hline \multicolumn{2}{|l|}{ A. Burden of disease } \\
\hline 1. Morbidity & Cases averted [14] \\
\hline 2. Mortality & Deaths averted [14] \\
\hline 3. Quality of life measures & DALYs and QALYs $[14,16]$ \\
\hline 4. Health care cost savings & $\begin{array}{l}\text { Reduction in cost of health care borne by the public sector } \\
\text { or private individuals }[16,23]\end{array}$ \\
\hline 5. Governmental savings & Reduction in overall costs of government expenses [21] \\
\hline \multicolumn{2}{|l|}{ B. Productivity-related gains $[14,22]$} \\
\hline 1. Care-related productivity gains & $\begin{array}{l}\text { Reduction in lost days of work due to sickness or caring for } \\
\text { a sick patient }\end{array}$ \\
\hline $\begin{array}{l}\text { 2. Outcome-related productivity } \\
\text { gains }\end{array}$ & $\begin{array}{l}\text { Increased lifetime productivity due to better health } \\
\text { improves cognition, educational attainment and physical } \\
\text { strength }\end{array}$ \\
\hline $\begin{array}{l}\text { 3. Behaviour-related productivity } \\
\text { gains }\end{array}$ & $\begin{array}{l}\text { Economic improvements due to changes in household } \\
\text { choices such as fertility and consumption/saving as a result } \\
\text { of improved child health and survival }\end{array}$ \\
\hline \multicolumn{2}{|l|}{ C. Ecological effects } \\
\hline 1. Prevalence of drug resistance & $\begin{array}{l}\text { Vaccination can prevent disease and thus obviate the need } \\
\text { for antibiotic use, reducing the prevalence of antibiotic } \\
\text { resistant strains [22] }\end{array}$ \\
\hline 2. Serotype replacement effects & $\begin{array}{l}\text { After the introduction of vaccine, non-vaccine serotypes } \\
\text { may well replace vaccine serotypes, leading to a smaller } \\
\text { reduction in disease burden over time }[14,24] \text {. }\end{array}$ \\
\hline 3. Herd effect & $\begin{array}{l}\text { Benefits accruing because vaccination improves outcomes } \\
\text { among unvaccinated community members [21] }\end{array}$ \\
\hline \multicolumn{2}{|l|}{ D. Indirect effects } \\
\hline 1. Equity & More equal distribution of health outcomes $[4,19]$. \\
\hline $\begin{array}{l}\text { 2. Interaction with other } \\
\text { interventions }\end{array}$ & $\begin{array}{l}\text { Events happening during the evaluation period not related } \\
\text { the intervention }[4,25] \text {. }\end{array}$ \\
\hline 3. Health resources & $\begin{array}{l}\text { Impact of vaccine programmes on amount of health } \\
\text { resources available (time, availability) }[4,25]\end{array}$ \\
\hline 4. Priority of interventions & $\begin{array}{l}\text { Overlooking importance of social determinants of health } \\
\text { by focusing on 'silver bullets' and 'mass campaigns' } \\
\text { instead of adapting interventions to the prevailing culture } \\
\text { and socioeconomic conditions, which generate the felt } \\
\text { needs [23] }\end{array}$ \\
\hline \multicolumn{2}{|l|}{ E. Macro-economic impact } \\
\hline 1. Burden on other sectors & $\begin{array}{l}\text { Macro-economic effect of vaccines on other sectors during } \\
\text { epidemics [26] }\end{array}$ \\
\hline 2. School absenteeism & Amount of schooldays missed due to illness $[16,27,28]$. \\
\hline
\end{tabular}




\section{Ethical clearance}

According to the Maastricht Ethical Review Committee (METC) "no ethical approval was required as the study is not concerned with medical research".

\section{Quantitative data collection and analysis}

An email was sent to the respondents one week prior to the NUVI meeting inviting them to participate in an online survey consisting of three parts: (i) introductory questions about the professional background of the respondents and expertise (ii) questions using a 5-point Likert-scale on the importance of different organizations involved in the decision-making process, types of evidence used and scenarios gauging the importance of availability of BEIVs for decision making, (iii) three open questions about the importance of different types of evidence currently used for decision making on the introduction of vaccines. The different scenarios were based on various types of effects and outcomes documented in the literature (see Table 1) [4,14,16,19,21-28]. These types were categorized into five domains, i.e. burden of disease, productivityrelated gains, ecological effects, indirect effects and macroeconomic impact (Supplementary file 1).

First, among all respondents, a median was calculated for every identified impact separately. Second, medians were calculated for every domain by first calculating the means for every respondent separately per domain. These means were used to calculate the median per domain among all respondents. Medians of 5 were regarded as very important, 4 as important, 3 as more or less important, 2 as somewhat important and 1 as not important. The calculated medians per domain were visualized by using box plots to give insight in their relative importance. Third, subgroup analysis was conducted to compare medians per domain from different geographical working areas (global, low income, middle income) and by institutional affiliation (government, international organization, research institution). The geographical working areas were based on the World Bank GDP classification of countries in 2011 [30].

\section{Qualitative data collection and analysis}

Respondents of the quantitative survey were offered the opportunity to self-select themselves into the interview sample. Interviewees were also personally recruited by $\mathrm{RH}, \mathrm{IvdP}, \mathrm{MPVA}$ and MJ during meeting breaks. The interview questions were exploratory in nature and based on themes covered in the survey. Interviewees were first asked to describe the current decision-making process in the country(ies) or region(s) they were responsible for. Subsequent questions covered the applicability of BEIVs to their jurisdiction; any known economic evaluation cases wherein evidence alluding to a BEIV has been included and the methodology utilized for its measurement; the relevance of BEIVs when applied to both traditional EPI vaccines and newer, next 
generation vaccines (Additional file 2). Representatives from all relevant stakeholder groups were interviewed by either one or two interviewers.

The interview transcripts, interviewer notes and answers to the open-ended survey questions were summarized and analyzed by IP using a qualitative data analysis program (Nvivo). This was done by extracting basic themes from each of the different sources, using the theoretical framework underlying the survey as a reference point. Per effect, the specific information mentioned in the interviews was listed and quotes were selected. New topics were added into the framework if one interviewee mentioned a topic that was not previously captured. All authors discussed accuracy of the analyses and consensus was obtained in case of disagreement.

\section{Merging of separate analyses}

Survey responses and interview comments were combined for each domain. Interviewee comments were used to explain results or to elucidate outcomes by giving practical examples of specific BEIVs.

\section{Results}

Out of 140 respondents invited, 26 completed the survey in full while 11 respondents commenced but did not complete any of the analyzed open or Likert-scale questions. Of the 26 surveys included in the final analysis, 10 contained at least one or more questions with a missing response (see Figure 1 ).

Figure 1. Flowchart participants of survey.

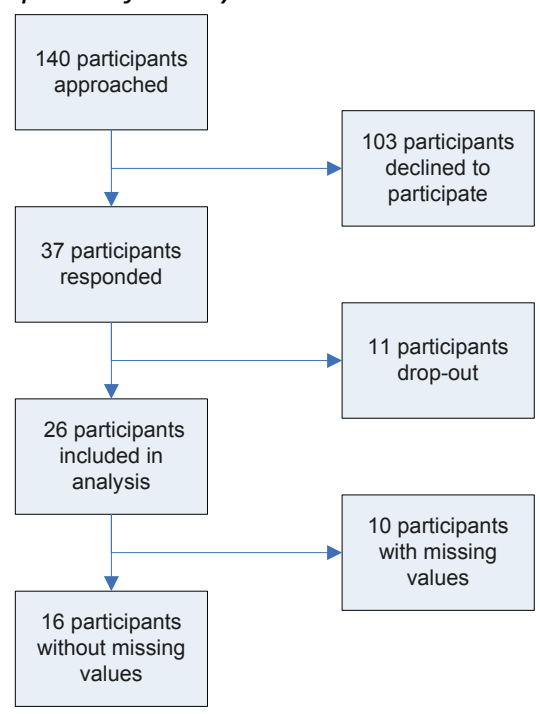


Survey respondents were of an average age of 45 years (SD 8.34), with an equal gender split. The average work experience of respondents in the field of immunization was 14.6 years (SD 10.75). Four worked exclusively in low income countries (LICs) and seven in middle income countries (MIC). Fifteen respondents worked in a mixed LMICs environment. In total, all respondents belonged to one of five stakeholder groups being represented at the meeting (see Table 2).

Table 2. Distribution of institutional background $(N=26)$

\begin{tabular}{lll}
\hline Institutional background & $\mathbf{N}=\mathbf{2 6}$ & Percentage (\%) \\
\hline Government & 4 & $15.4 \%$ \\
\hline International Organization & 12 & $46.2 \%$ \\
\hline Research institute & 5 & $19.2 \%$ \\
\hline Donor & 3 & $11.5 \%$ \\
\hline Vaccine manufacturer & 2 & $7.7 \%$ \\
\hline
\end{tabular}

Seven interviewees volunteered to be interviewed for the qualitative portion of our study. A further 7 attendees agreed to participate after being approached during the NUVI meeting. Members of all stakeholder groups were interviewed (see Table 3). All continents, except Australia, were represented in the qualitative interviews. Specifically, two interviewees worked exclusively with LICs, six with MICs and six with LMICs.

Table 3: Background characteristics of interviewees

\begin{tabular}{llll}
\hline Gender & Continent & Area of core interest & Stakeholder group \\
\hline $\mathrm{M}^{*}$ & Africa & Low income country & International Organization \\
\hline $\mathrm{F}$ & South America & Middle income country & Vaccine Manufacturer \\
\hline $\mathrm{M}$ & Europe & Global & International Organization \\
\hline $\mathrm{M}$ & Europe & Middle income country & Government \\
\hline $\mathrm{M}^{*}$ & Europe & Global & Research Institute \\
\hline $\mathrm{M}^{*}$ & North America & Global & International Organization \\
\hline $\mathrm{M}^{*}$ & South America & Middle income country & Research Institute \\
\hline $\mathrm{F}^{*}$ & Africa & Global & Donor \\
\hline $\mathrm{M}$ & Asia & Middle income country & Government \\
\hline $\mathrm{F}$ & Asia & Global & Research Institute \\
\hline $\mathrm{M}$ & Asia & Global & Donor \\
\hline $\mathrm{M}^{*}$ & South America & Middle income country & International Organization \\
\hline $\mathrm{M}$ & Asia & Low income country & Government \\
\hline $\mathrm{F}^{*}$ & South America & Middle income country & Government \\
\hline $\mathrm{Intew}$ & completed survey & voluntered be interviewed &
\end{tabular}

* Interviewee completed the survey and volunteered to be interviewed 


\section{Current decision-making process}

Survey respondents identified the Ministry of Health, Ministry of Finance and special expert advisory groups, such as National Immunization Technical Advisory Groups (NITAGs - named by thirteen respondents) [31] and Inter-agency Coordinating Committees (ICCs - named by four respondents), as being most important during the decision-making process around new vaccines. One interviewee also underlined the increased role of NITAGs in decision making by providing government with recommendations based on all available vaccine specific evidence. The decision-making process has thus become more formal and scientific than before due to the inclusion of NITAGs. Survey respondents also cited the importance of local advisory groups (mostly professional associations). The parliament, international organizations such as Medicines Sans Frontier (MSF), UNICEF and WHO were seen as more or less important (median of 3).

Survey respondents stated that effectiveness data, burden of disease, costeffectiveness data, overall costs of immunization programme, public sector budget impact and evidence of vaccine safety were all seen as being very important considerations for making a well-balanced decision. Accessibility, applicability, credibility, the availability of other interventions, and equity/fairness were also worth considering (medians between 3 and 4) but in the context of decision making were viewed as being not as important as the other types of evidence above.

Interviewees stated that the decision-making process around vaccine implementation in LMICs is quite diverse per country. According to a non-governmental organization (NGO) representative working in Africa, most African countries use data on mortality rates, cases averted and absenteeism as the core for decision making. Absenteeism numbers are collected together with evidence on vaccine coverage in Brazil as well. No evidence on QALYS or DALYs as an isolated measure is believed to be used for decision making in most LMICs. In one Asian LIC, evidence on disease burden (mortality, morbidity and DALYs) and health sector impact are used to convince the Minister of Finance to invest in new vaccines. Next to disease burden, impact on productivity was observed by looking at school attendance or working days lost. However, no set decision threshold is used. Vaccine costs and safety also play a role. For example, the Human Papillomavirus (HPV) vaccine targets an area of high disease burden but is also very costly and is therefore not implemented. Lastly, the importance of "herd effects" was acknowledged but no explicit mechanisms for their inclusion were declared. 


\section{Relative importance of domains}

Macro-economic impact, burden of disease and ecological effects were observed to be the most valuable domains according to the quantitative survey (Figure 2). All scored above four on the Likert-scale, which indicates very important. Specifically, evidence on herd effects was viewed as most important, closely followed by governmental cost savings, deaths averted and burden on other sectors. Productivity-related gains and indirect effects were seen to be somewhat valuable. The relatively low Likert-scores for productivity-related gains can be partly attributed to the low score for productivity outcomes relating to household behavior. For the indirect effects domain, the effects measured were all observed to be somewhat valuable. Detailed results providing an account of the importance of specific effects within each domain follow.

Figure 2. Boxplots importance of providing evidence on vaccine related issues per domain.

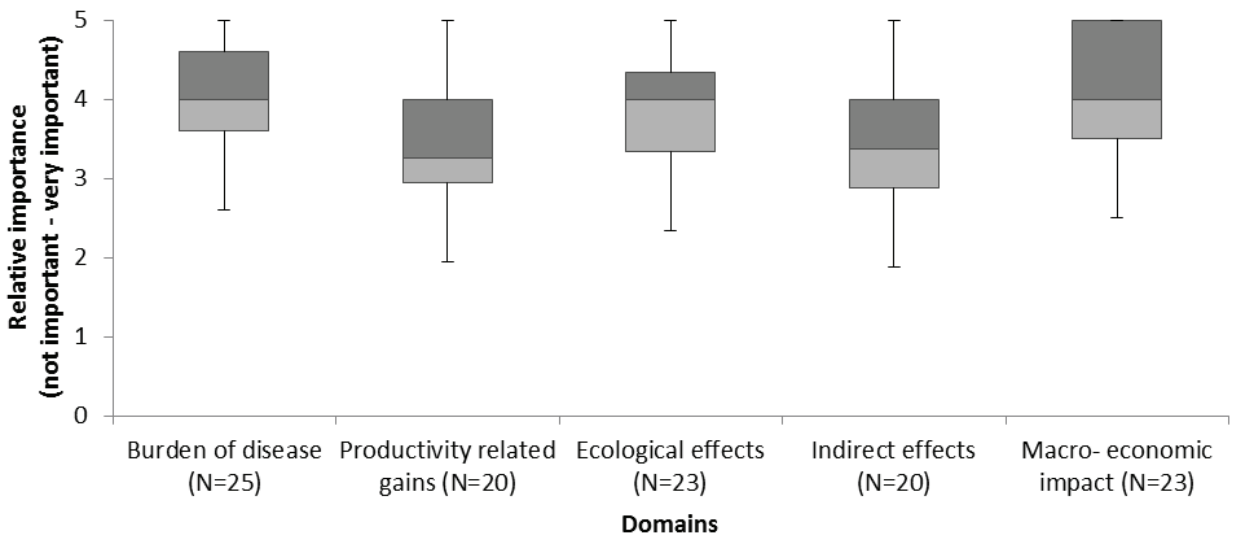

\section{Burden of disease}

Overall survey responses and four interviewees asserted the importance of burden of disease as being the most powerful evidence type in support of vaccine implementation. Two interviewees regarded burden of disease to be the primary basis for implementation with other evidence types being included for purposes of balanced appraisals. Another interviewee expressed that outcomes demonstrating a reduction in burden of disease, such as reduction in under-five mortality, as compelling evidence capable of attracting further investment by potential funders outside the health sector. Similarly, evidence on deaths averted was viewed as being more important than the amount of cases averted. The fourth interviewee highlighted the general importance of burden of disease but did not elaborate on its higher relevance. Three interviewees mentioned the importance of morbidity together with mortality as they are often used in CEA studies. However, one interviewee did not consider morbidity to be a very important outcome as it "only reflects reduction in contraction of the disease" (sic). 
Survey respondents generally ranked QALYs as being very important. During the interviews most of the interviewees talked about QALYS or DALYs interchangeably. Interviewees mentioned that the use of QALYs or DALYs depends on the country specific availability of such type of indicators. Measuring them was seen as valuable, but capacity building of local expertise to measure and value quality of life indicators was also needed. One interviewee also mentioned the complicated nature of using QALYs and DALYs in decision making, as the outcomes are difficult to explain to decision makers not trained in economics and public health.

Providing evidence on the impact of vaccines on health care costs was seen as being just as important as evidence on morbidity. One participant asserted that a reduction in disease-related health expenditures could be a possible effect of vaccine implementation. Two interviewees considered budgetary impact to be one of the main ways of convincing decision makers to invest in immunization programmes, while a third interviewee saw evidence of vaccine impact on the health care budget as an aim for conducting CEA research. To underline its importance, one of the interviewees mentioned that budget impact analysis was considered to be the most important type of economic evidence in MICs such as India and Indonesia.

Governmental cost savings was another factor. The impact of a vaccine on the national budget was mentioned by one of the survey respondents. Only one interviewee discussed the importance of impact on the entire govern- mental budget. He regarded it to be valuable evidence as ultimately the department for development and planning and Minister of Finance makes the final decision.

\section{Productivity-related gains}

Seven out of fourteen interviewees alluded towards the possibilities of measuring productivity gains. Only one interviewee said something about all three types of effects included within this domain, while the others only elaborated on outcome-related productivity gains.

Compared with the other types of productivity gains mentioned in the survey, outcome-related productivity gains were viewed as being most relevant. One interviewee reflected on how a polio outbreak in his country also led to a loss of production over time due to the cognitive impact of the disease on patients. Importantly, interviewees were aware of some issues limiting the relevance of outcome-related productivity gains. Firstly, one interviewee recognized that despite its theoretical validity, the argument that child immunization could lead to increased productivity later in life was hardly ever brought up during discussions with Ministries of Health. Secondly, two other interviewees acknowledged the added value of such evidence but also pointed to difficulties in measuring such an effect due to insufficient 
data. Thirdly, another interviewee only partly agreed on the applicability of outcomerelated productivity gains as they felt that it could only be used to evaluate benefits of certain vaccines targeting diseases, such as Japanese Encephalitis, which leads to some sort of cognitive damage in a third of the infected children. A further three interviewees were less convinced about the applicability of outcome-related productivity gains, stating that these gains were already implicitly included in the calculation of benefits and that it only provides a parental perspective rather than a governmental one.

Care-related productivity gains were acknowledged by 3 interviewees and further discussed by one of them. This interviewee mentioned that care-related productivity gains could be more relevant in the context of high income countries (HICs) rather than LMICs. For example, the introduction of the chicken pox (varicella) vaccine in the United States is primarily based on this effect. The similar impact is harder to establish in LMICs, as not all parents work full time and hence will not be absent from work.

Survey results showed that behavior-related productivity gains were considered to be least valuable for decision making. One possible explanation cited by an interviewee is that behavior-related productivity gains are very difficult to measure. There are also many social and cultural issues that can confound this relationship. For example: "In Brazil there is high vaccine coverage and high participation of women in the job market than next door to Bolivia with bit lower vaccine coverage and probably much lower participation in the job market. But then Bolivia's economy is not so strong, culturally women's have another position in society. Female education is lower in Bolivia, Types of work for [women] and kind of work is less. Is that because of vaccines or something else?" (sic).

\section{Ecological effects}

The impact of herd immunity on cost-effectiveness was seen as the most important ecological effect to measure. This is underlined by the fact that six respondents named it as a potential BEIV in the open questions. All three interviewees who discussed herd immunity thought it was an important ecological externality to measure in economic evaluations. Two cited the polio vaccine as an example where herd immunity is considered during the decision-making process in their country.

The effect of vaccination on reducing antimicrobial drug resistance was seen as the next most valuable outcome of an ecological effect. One survey respondent specified this effect in the open questions. Although, one interviewee reported that inclusion of the impact of a vaccine on drug resistance is only valuable in some cases, as in the malaria vaccine. 
Serotype replacement was also deemed important albeit accompanied by a negative intonation with respect to vaccine advocacy. As one interviewee suggested, evidence demonstrating an eventual increase in detected cases of non-vaccine serotype cases (irrespective of occurrence of true replacement) would work against calls for increased vaccine provision and uptake.

\section{Indirect effects}

From the overall survey results, we found that indirect effects were one of the least important domains. Evidence of impact on equity, health resource utilization and priority of interventions were all scored with a median of three. Only evidence on the possibility of interaction with other interventions was considered important. However, in the open questions many respondents referred to different indirect effects. One interviewee stated that inaccurate calculation of costs and not accounting for hidden or unanticipated costs involved with vaccine implementation could be a potential issue.

The interplay between health rights and equity was also discussed by one interviewee, who stated "When implementing immunization programmes it is very important to reach the lower socio-economic classes as the largest health gains can be obtained in this group".

Positive externalities of immunization programmes in strengthening other health services were also mentioned during the interviews and in the open questions. Nine respondents indicated vaccines as an entry point or platform for providing a wide range of other public health interventions such as school-based and maternal health interventions. One interviewee gave some examples on how vaccine programmes can improve health in other areas. "For example, when rotavirus vaccine was introduced in diarrheal disease surveillance and monitoring was improved. This had a positive effect on other disease surveillance in terms of training and education of staff in monitoring and evaluation etc." Another interviewee also stressed that vaccines are normally not implemented as a single solution but are supported by other health interventions that target other causes of the disease. This possibility was also mentioned by three respondents of the survey.

Moreover, four interviewees saw the possibility of capacity building through education and training for health care workers. However, one interviewee warned against rolling out interventions without ensuring availability of trained personnel as this can create an additional burden on health care workers.

None of the interviewees or survey respondents thought investing in vaccines would result in a misdirection of focus, for example, using cholera vaccines as a quick and easy 
fix in place of investing in tackling a more fundamental health hazard such as clean drinking water and sanitation.

\section{Macro-economic impact}

Survey results showed that the potential burden stemming from preventable outbreaks of disease on other non-health sectors of the wider economy is highly relevant information. The education sector and the effect of school absenteeism was regarded to be important and could be one example of a non-health sector in a certain sense.

However none of the respondent mentioned economic impact on other sectors in the open questions and only one interviewee gave examples of the impact that vaccines may have on other sectors. Examples given were a hepatitis $A$ virus and measles outbreak in an Eastern European country and an outbreak of polio virus, negatively affecting local fruit and vegetable markets.

Nonetheless, both survey respondents and interviewees reflected on the importance of evidence on school absenteeism of children. Two interviewees reported that the impact of vaccines on absenteeism offers a strong argument in favor of vaccine implementation, especially in the case of malaria. Furthermore, one interviewee testified towards a relationship between an NGO financed immunization programme and reduced school absenteeism, eventually resulting in a positive impact on the overall economy of African countries. However, another interviewee did not agree with this point and doubted the validity of such a causal relationship.

\section{Other BEIVs}

Interviewees mentioned some other possible positive effects of vaccination that are not usually discussed. One is the establishment of wide service network for children in the region. Another is the overall strengthening of local health care systems. Certain social goals can also be framed into becoming good rationales for vaccine uptake. For example, the HPV vaccine has been introduced in South America as it reduces mortality of young women of child-bearing age and hence the likelihood of orphaned children in the community.

One of the interviewees expressed concern that positive externalities are disproportionately measured in economic evaluation studies. This is a valid criticism considering, as one interviewee pointed out, that improper disposal of medical waste generated by the EPI programme is a main issue in Africa. Sometimes used needles can be found on sites, which can potentially transfer pathogens from sick to healthy children. 


\section{New tools for estimating BEIVs}

None of the survey respondents or interviewees were able to propose new methods of evaluation. However, some interviewees and respondents advised on using some tools not included in the survey. These include PATH guidelines on economic evaluation of vaccines, the return on investment approach informing Ministry of Finance or Planning Departments on cost-effectiveness of vaccines and evaluating the effectiveness of vaccines in an individual country context during implementation. Furthermore, one interviewee mentioned vaccines should be evaluated in relation with social determinants of health. This idea is rooted in the belief that children do not die only from vaccine-preventable diseases but are also exposed to other risk factors.

\section{Area of core interest}

Table 4 illustrates that in general, stakeholders working in LICs value evidence on burden of disease, ecological effects and macro-economic impact more highly than professionals working in MICs. For productivity-related gains, no differences could be found based on geographical working area. For the indirect effects, some differences could be identified between professionals working within a global context compared to professionals working in LICs, such as equity principles, which are more valued in LICs. However, only macro-economic impact is scored above four by the stakeholders working within a global context whilst representatives from MICs have scored ecological effects as a four.

Table 4. Median scores by domain by geographical working area of core interest

\begin{tabular}{lllllll}
\hline \multirow{2}{*}{ Domains } & \multicolumn{2}{l}{$\begin{array}{l}\text { Low income } \\
\text { countries }\end{array}$} & \multicolumn{2}{l}{$\begin{array}{l}\text { Middle income } \\
\text { countries }\end{array}$} & \multicolumn{2}{l}{ Global } \\
\cline { 2 - 7 } & $\mathbf{n}$ & score & $\mathbf{n}$ & score & $\mathbf{n}$ & score \\
\hline Burden of disease & 4 & 4.70 & 7 & 3.60 & 14 & 3.90 \\
\hline Productivity-related gains & 3 & 3.25 & 7 & 3.25 & 10 & 3.25 \\
\hline Ecological effects & 3 & 5.00 & 7 & 4.00 & 13 & 3.66 \\
\hline Indirect effects & 4 & 3.50 & 5 & 3.50 & 11 & 3.25 \\
\hline Macro-economic impact & 4 & 4.50 & 7 & 3.50 & 12 & 4.25 \\
\hline
\end{tabular}

\section{Different stakeholder groups}

Table 5 gives an overview of the calculated importance of each domain specific to stakeholder group. Due to a lack of data on donors and manufacturers, scores for these stakeholders were not calculated. Respondents working in governmental bodies were seen to give higher scores to burden of disease, ecological effects and macro-economic impact. A similar trend was observed for respondents from international organizations and research institutes, although none of the domains were scored as very important for the latter group. 
Table 5. Median scores by domain by institutional background

\begin{tabular}{lllllll}
\hline Domains & \multicolumn{2}{l}{ Government } & \multicolumn{2}{l}{$\begin{array}{l}\text { International } \\
\text { Organization }\end{array}$} & \multicolumn{2}{l}{$\begin{array}{l}\text { Research } \\
\text { institute }\end{array}$} \\
\cline { 2 - 7 } & $\mathbf{n}$ & score & $\mathbf{n}$ & score & $\mathbf{n}$ & score \\
\hline Burden of disease & 4 & 4.50 & 12 & 4.10 & 5 & 3.60 \\
\hline Productivity-related gains & 4 & 3.88 & 9 & 3.25 & 5 & 3.00 \\
\hline Ecological effects & 3 & 4.33 & 11 & 4.00 & 5 & 3.67 \\
\hline Indirect effects & 4 & 3.25 & 10 & 3.38 & 4 & 3.25 \\
\hline Macro-economic impact & 4 & 4.25 & 11 & 4.38 & 5 & 3.50 \\
\hline
\end{tabular}

\section{Applicability to new versus traditional EPI vaccines}

Four interviewees conveyed challenges with regards to the measurement of BEIVs for newer vaccines. Due to paucity in data, some interviewees recommended measuring BEIVs in older vaccines as the relevant economic and clinical data may be unavailable for new vaccines. There are also some inherent problems related to the type of diseases being targeted by newer vaccines. For example, benefits from the HPV and Hepatitis B Virus vaccines only occur much later in life. This increases the complexity of models involved and technical expertise required. In the case of rotavirus and pneumonia, reductions in mortality can only be observed at a global level as the disease is still widely prevalent at an individual or local level and utilizes many of the same resources (i.e health care workers, antibiotics). This factor affirms the relevance of including BEIVs in conveying the true value of new vaccines. Additionally, traditional EPI vaccines were also viewed as having a greater societal impact as they targeted diseases with greater incidence rates and which affected a greater proportion of children.

\section{Discussion}

This study offers unique insight into the reasoning and justification employed by decision makers, funders and experts in the field of vaccine introduction.

According to respondents, the Ministries of Health, Finance and NITAGs play a crucial role in the current decision-making process around new vaccine introductions. Although the numbers of NITAGs globally have been growing, the level of expertise in health economics has been limited and lacking in most LMICs [31]. Hence, explicit guidance on the inclusion of BEIVs by international organizations such as WHO would be most timely and well received.

Our study results indicate that evidence on burden of disease, safety and costeffectiveness is regarded as most important for vaccine introduction decisions. This is in contrast to findings from another qualitative study which reported that only burden of 
disease evidence, and on occasion affordability and safety, was essential for immunization programme decision making in seven LMICs [32]. More importantly, our study affirms that BEIVs belonging to ecological effects and macro-economic impact domains are considered to be equally as important as the more traditional outcome measures. Indirect effects and care-related productivity gains were considered less important to include in economic evaluation. Quite similarly, Burchett et al. [32] also reported that serotype replacement effects and, impact on non-health outcomes were rarely mentioned whereas equity considerations were only acknowledged in South Africa. Although productivity gains have often been cited in other studies $[14,15,18,22,33]$, one explanation why this domain ranks lower on some studies [17] could be its relatively high importance to economists rather than clinicians and public sector officials who may be less familiar with its causal relationship. Cultural and contextual differences could be another possible explanation [4]. Indeed we observe that respondents dealing in an LIC context and representatives of government bodies tend to give higher importance to BEIVs than other stakeholders.

Considerations not covered by the survey were also brought up by interviewees. For example, the potential negative impact of wastage during immunization programmes or the idea of using vaccines as a platform for providing other health interventions. The concept of combining vaccination with other interventions is not new [23]. However it remains difficult to translate the potential benefits of this synergistic effect into economic terms. Furthermore, interviewees highlighted the importance of using a broader perspective particularly when deriving the value of newer and costlier vaccines. This can be explained by the substantially higher list prices for new developed vaccines [34]. Several interviewees also reported the existence of different audiences. This finding underlines the necessity for flexible guidelines and the importance of combining different evaluation techniques to accommodate different needs and evaluation perspectives.

There are also several limitations to our study worth highlighting. Firstly, as most of the NUVI participants are actively involved in vaccine advocacy at a global as well as country level, the results may reflect biased viewpoints in favour of promoting the wider benefits of vaccines. Since this study was exploratory in nature, it was important to select a group that was actively engaged in decision making. It may be useful to conduct the survey within a more neutral group in the future. Secondly, the study suffered from a low response rate. Only 26 out of 140 respondents participated, which could be explained by the estimated 30 minute completion time. As a result none of the subgroup analyses performed were statistically significant. Future versions should attempt to be shorter. Offering rewards to attract participants could also be considered. Furthermore, the data collection could be organized in another setting. For example, the survey could be performed in workshop setting with direct feedback to 
the audience. Thirdly, the placement of the different types of impacts in the framework can be discussed. This is especially the case with school absenteeism which can also be placed under productivity-related gains and governmental savings which can be interpreted as a macro-economic impact. A separate analysis was performed to give insight in the outcomes for this alternative framework. It was found it would not change the results except for the macro-economic impact, which would be valued as even more important. Fourthly, using a Likert-scale has several methodological disadvantages [35]. These can be overcome by using a discrete choice experiment which would allow for a more explicit analysis of trade-offs between the various BEIVs and might offer greater discriminatory power than Likert-scales [36]. Finally, the qualitative part was supposed to add a layer on top of the survey findings, by providing illustrative anecdotal experiences and thoughts on feasibility of including BEIVs in economic evaluation studies. However, it was difficult to conduct a sound comparison of the qualitative and quantitative part of the research, because not all interviewees filled out the survey. This may have resulted in recall bias as participants that contributed to both were already familiar with the different types of BEIVs outlined in the survey. To get more insight in this bias we checked for overrepresentation of both components in the results. No indications of this were to be found.

\section{Conclusion}

Notwithstanding the limitations of this study, the uniqueness of this project should be considered as the study results will contribute to a better understanding by decision and policy makers regarding the usefulness of BEIVs information for vaccine introduction decisions at national level. Furthermore, these insights can also be used to shape upcoming research agendas in this field to facilitate creation of more comprehensive guidelines on economic evaluations of vaccines. However, several country-level studies should be conducted to test the proposed BEIVs on their ability to address the needs of different stakeholders and applicability to inform different audiences. 


\section{References}

1. World Health Organization. Global Health Observatory: Under Five Mortality 2012 [updated 2012/7/30]. -]. Available from: http://www.who.int/gho/child_health/mortality/mortality_under_ five_text/en/index.html.

2. Save the Children Fund. No child born to die: Closing the gaps. Londen: Save the Children UK, 2011.

3. GAVI Alliance. Investing in immunisation through the GAVI Alliance; The evidence base. Geneva: GAVI Alliance, 2010.

4. Hauck K, Smith PC, Goddard M. The economics of priority setting for health care: a literature review. The International Bank for Reconstruction and Development/The World Bank. 2003;10:03-8.

5. Neumann PJ, Fang CH, Cohen JT. 30 years of pharmaceutical cost-utility analyses: growth, diversity and methodological improvement. Pharmacoeconomics. 2009;27(10):861-72.

6. Jauregui B, Sinha A, Clark AD, Bolanos BM, Resch S, Toscano CM, et al. Strengthening the technical capacity at country-level to make informed policy decisions on new vaccine introduction: Lessons learned by PAHO's ProVac Initiative. Vaccine. 2011;29(5):1099-106.

7. WHO. Principles and considerations for adding a vaccine to a national immunization programme: from decision to implementation and monitoring. Geneva; Switserland: 2014.

8. Erickson L, De Wals P, Farand L. An analytical framework for immunization programs in Canada. Vaccine. 2005;23(19):2470-6.

9. Kimman TG, Boot HJ, Berbers GAM, Vermeer-de Bondt PE, Ardine de Wit G, de Melker HE. Developing a vaccination evaluation model to support evidence-based decision making on national immunization programs. Vaccine. 2006;24(22):4769-78.

10. Mansoor O, Shin S, Maher C, WPRO tIFo. Assessing new vaccines for national immunization programmes. A framework to assist decision makers. Manila: World Health Organization Regional Office for the Western Pacific Manila, 2000 2012/5/29. Report No.

11. Stratton KR, Durch JS, Lawrence RS. Vaccines for the 21st century: a tool for decisionmaking, Committee to Study Priorities for Vaccine Development. Division of Health Promotion and Disease Prevention, Institute of Medicine. National Academy of Sciences, Washington, DC. 1999:-.

12. Walker DG, Hutubessy R, Beutels P. WHO Guide for standardisation of economic evaluations of immunization programmes. Vaccine. 2010;28(11):2356-9.

13. Piso B, Wild C. Decision support in vaccination policies. Vaccine. 2009;27(43):5923-8.

14. Bärnighausen T, Bloom DE, Canning D, Friedman A, Levine OS, O'Brien J, et al. Rethinking the benefits and costs of childhood vaccination: The example of the Haemophilus influenzae type $b$ vaccine. Vaccine. 2011;29(13):2371-80.

15. Bloom DE, Canning D, Weston M. The value of vaccination. World Economics. 2005;6(3):15-39.

16. Ozawa S, Mirelman A, Stack ML, Walker DG, Levine OS. Cost-effectiveness and economic benefits of vaccines in low-and middle-income countries: A systematic review. Vaccine. 2012:96-108.

17. Deogaonkar R, Hutubessy R, van der Putten I, Evers S, Jit M. Systematic review of studies evaluating the broader economic impact of vaccination in low and middle income countries. BMC public health. 2012;12(1):878.

18. Bärnighausen T, Bloom DE, Cafiero-Fonseca ET, O'Brien JC. Valuing vaccination. Proceedings of the National Academy of Sciences. 2014;111(34):12313-9.

19. Belli PC, Bustreo F, Preker A. Investing in children's health: what are the economic benefits? Bulletin of the World Health Organization. 2005;83(10):777-84.

20. Burns JE, Mitrovich RC, Jauregui B, Ruiz Matus C, Andrus JK. Descriptive analysis of immunization policy decision making in the Americas. Revista Panamericana de Salud Publica. 2009;26(5):398-404.

21. Culyer AJ. Handbook of health economics: North Holland; 2000.

22. Bärnighausen T, Bloom DE, Canning D, O'Brien J. Accounting for the full benefits of childhood vaccination in South Africa. South African Medical Journal. 2008;98(11):842-8. 
23. Banerji D. Serious crisis in the practice of International health by the World Health Organization: The Commission on Social Determinants of Health. International Journal of Health Services. 2006;36(4):637-50.

24. Beutels P, Thiry N, Van Damme P. Convincing or confusing?: Economic evaluations of childhood pneumococcal conjugate vaccination-a review (2002-2006). Vaccine. 2007;25(8):1355-67.

25. Shearley AE. The societal value of vaccination in developing countries. Vaccine. 1999;17:S109-S12.

26. Holmes C. Swine Flu Prompts A World Of Different Reactions: NPR; 2009. -]. Available from: http://www.npr.org/templates/story/story.php?storyld=103614016.

27. Dickson R, Awasthi S, Williamson P, Demellweek C, Garner P. Effects of treatment for intestinal helminth infection on growth and cognitive performance in children: systematic review of randomised trials. BMJ. 2000;320(7251):1697-701.

28. Sakti H, Nokes C, Hertanto W, Hendratno S, Hall A, Bundy DAP. Evidence for an association between hookworm infection and cognitive function in Indonesian school children. Tropical Medicine \& International Health. 1999;4(5):322-34.

29. Creswell JW, Clark VLP. Designing and conducting mixed methods research: Wiley Online Library; 2007.

30. World Bank. World Bank list of economies 18 july 2011.

31. Duclos P, Ortynsky S, Abeysinghe N, Cakmak N, Janusz CB, Jauregui B, et al. Monitoring of progress in the establishment and strengthening of national immunization technical advisory groups. Vaccine. 2012.

32. Burchett H, Mounier-Jack S, Griffiths U, Biellik R, Ongolo-Zogo P, Chavez E, et al. New vaccine adoption: qualitative study of national decision-making processes in seven low-and middle-income countries. Health policy and planning. 2012;27(suppl 2):ii5-ii16.

33. Bloom DE, Canning D, Shenoy ES. The effect of vaccination on children's physical and cognitive development in the Philippines. Applied Economics. 2012;44(21):2777-83.

34. Beutels P, Edmunds WJ, Smith RD. Partially wrong? Partial equilibrium and the economic analysis of public health emergencies of international concern. Health economics. 2008;17(11):1317-22.

35. Dawis RV. Scale construction. Journal of Counseling Psychology. 1987;34(4):481.

36. Ryan M, Scott D, Reeves C, Bate A, van Teijlingen E. Eliciting public preferences for healthcare: a systematic review of techniques. Health Technology Assessment. 2001;5(5):186. 


\section{Supplementary file 1 - Survey}

\section{Survey on the broader economic impact of vaccines and immunization programmes}

Dear participant,

The WHO Immunization Vaccines and Biologicals Department in collaboration with Maastricht University, the University of Birmingham and the Health Protection Agency is conducting a study on the broader economic impact of vaccines and immunization programmes. We would be very grateful if you could fill out this survey, which should take about 15 minutes of your time. Information provided by you will be treated confidentially and will be analyzed anonymously.

In middle and low income countries the resources to fund immunization programmes are limited due to budget and other constraints. Currently, most economic evaluations of vaccination focus on their cost-effectiveness (i.e. how much it costs to obtain a certain amount of healthcare gain, such as a disability adjusted life year or DALY). In this study we want to investigate if broader economic considerations besides costeffectiveness (e.g. budget impact, implementation issues, equity considerations) are important to decision makers and funders of immunization programmes in low and middle income countries.

After completing the survey the printed version can be handed in by Ms Inge van der Putten during the NUVI meeting.

For questions please contact: impactvaccines@who.int 
Part 1: In the first part of this questionnaire you will be asked some information about your personal background.

\section{Gender}

$\square \quad$ Male

口 Female

2. Age

...... years

3. How long have you been working ${ }^{1}$ in the field of vaccination?

...... years

4. What is the name of the organization that you work for?

If you work for more than one organization, please choose the one which is most relevant to this survey.

5. What are your most important duties in the organization you work for? Please provide a short job description.

6. In which of the following WHO region(s) do you work?

More than one answer is possible.

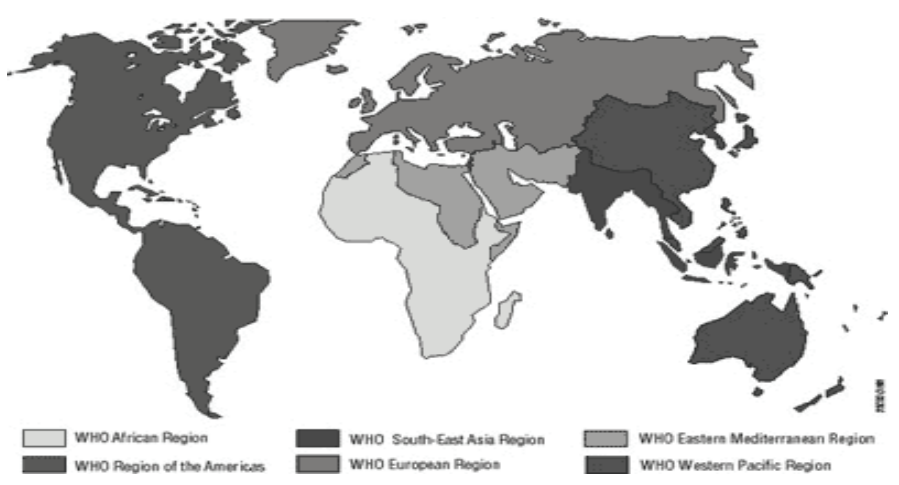

WHO African Region

WHO Region of the Americas

WHO South-East Asia Region

$\square \quad$ WHO European Region

$\square \quad$ WHO Eastern Mediterranean Region

WHO Western Pacific Region

${ }^{1}$ Excluding postgraduate research and/or medical residency (graduate medical training). 
Part 2: In this part, you will be asked about the priority setting process in your country or the organization you represent in the country you work for.

\section{How important are the following organizations in the decision-making process for} implementing immunization programmes?

If you work in a high income country, please answer this question based on the low/middle income country most relevant to your work.

If any of the options are not applicable please circle " $n / a$ ".

If you are not familiar with any of the following organizations please circle "?".

The "others" option is to enable you to fill in any organizations not covered in options 1-6. If you cannot think of any more, please circle " $n / a$ ".

\begin{tabular}{|c|c|c|c|c|c|c|c|}
\hline & \multicolumn{3}{|c|}{ Not important } & \multicolumn{3}{|c|}{ Very important } & \\
\hline 1. Parliament & 1 & 2 & 3 & 4 & 5 & $\mathrm{n} / \mathrm{a}$ & ? \\
\hline 2. Ministry of Health & 1 & 2 & 3 & 4 & 5 & $\mathrm{n} / \mathrm{a}$ & ? \\
\hline 3. Ministry of Finance & 1 & 2 & 3 & 4 & 5 & $\mathrm{n} / \mathrm{a}$ & ? \\
\hline 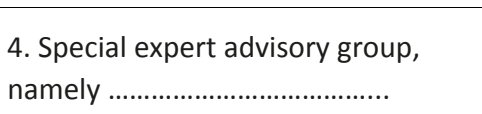 & 1 & 2 & 3 & 4 & 5 & $\mathrm{n} / \mathrm{a}$ & ? \\
\hline 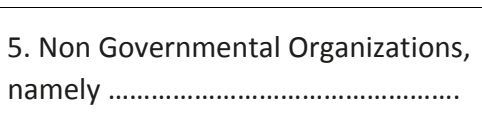 & 1 & 2 & 3 & 4 & 5 & $\mathrm{n} / \mathrm{a}$ & ? \\
\hline 6. Local advocacy groups ${ }^{2}$, namely & 1 & 2 & 3 & 4 & 5 & $\mathrm{n} / \mathrm{a}$ & ? \\
\hline 7. Others, namely & 1 & 2 & 3 & 4 & 5 & $\mathrm{n} / \mathrm{a}$ & ? \\
\hline 8. Others, namely & 1 & 2 & 3 & 4 & 5 & $\mathrm{n} / \mathrm{a}$ & ? \\
\hline 9. Others, namely & 1 & 2 & 3 & 4 & 5 & $\mathrm{n} / \mathrm{a}$ & ? \\
\hline
\end{tabular}

${ }^{2}$ e.g. patient groups.

\section{How important are the following types of evidence when making decisions about} immunization programmes?

If you work in a high income country, please answer this question based on the low/middle income country most relevant to your work.

If any of the options are not applicable please circle " $n / a$ ".

If you are not familiar with any of the following types please circle "?".

The "others" option is to enable you to fill in any types not covered in options 1-6. If you cannot think of any more, please circle " $n / a$ ". 
Not important

\begin{tabular}{|c|c|c|c|c|c|c|c|}
\hline 1. Effectiveness data ${ }^{3}$ & 1 & 2 & 3 & 4 & 5 & $\mathrm{n} / \mathrm{a}$ & ? \\
\hline 2. Cost-effectiveness data ${ }^{4}$ & 1 & 2 & 3 & 4 & 5 & $\mathrm{n} / \mathrm{a}$ & ? \\
\hline 3. Burden of disease ${ }^{5}$ & 1 & 2 & 3 & 4 & 5 & $\mathrm{n} / \mathrm{a}$ & ? \\
\hline $\begin{array}{l}\text { 4. Overall costs of an immunization } \\
\text { programme }\end{array}$ & 1 & 2 & 3 & 4 & 5 & $\mathrm{n} / \mathrm{a}$ & ? \\
\hline 5. Public sector budget impact & 1 & 2 & 3 & 4 & 5 & $\mathrm{n} / \mathrm{a}$ & $?$ \\
\hline 6. Accessibility ${ }^{6}$ & 1 & 2 & 3 & 4 & 5 & $\mathrm{n} / \mathrm{a}$ & ? \\
\hline 7. Safety ${ }^{7}$ & 1 & 2 & 3 & 4 & 5 & $\mathrm{n} / \mathrm{a}$ & ? \\
\hline 8. Applicability ${ }^{8}$ & 1 & 2 & 3 & 4 & 5 & $\mathrm{n} / \mathrm{a}$ & ? \\
\hline 9. Credibility $^{9}$ & 1 & 2 & 3 & 4 & 5 & $\mathrm{n} / \mathrm{a}$ & ? \\
\hline 10. Equity, fairness ${ }^{10}$ & 1 & 2 & 3 & 4 & 5 & $\mathrm{n} / \mathrm{a}$ & ? \\
\hline $\begin{array}{l}\text { 11. Availability of other } \\
\text { interventions }^{11}\end{array}$ & 1 & 2 & 3 & 4 & 5 & $\mathrm{n} / \mathrm{a}$ & $?$ \\
\hline 12. Others, namely & 1 & 2 & 3 & 4 & 5 & $\mathrm{n} / \mathrm{a}$ & ? \\
\hline 13. Others, namely & 1 & 2 & 3 & 4 & 5 & $\mathrm{n} / \mathrm{a}$ & ? \\
\hline 14. Others, namely & 1 & 2 & 3 & 4 & 5 & $\mathrm{n} / \mathrm{a}$ & $?$ \\
\hline
\end{tabular}

3. Vaccine effectiveness as reported in clinical trials, observational studies and post-marketing surveillance.

${ }^{4}$ Results from studies comparing the cost of an immunization programme with its benefits (measured in units such cases avoided, deaths prevented or DALYs gained).

${ }^{5}$ Estimates of total morbidity and mortality due to the disease.

${ }^{6}$ Availability of the vaccine, taking into account social, cultural, economic and geographical barriers to being vaccinated.

${ }^{7}$ Reported adverse effects of the vaccine.

${ }^{8}$ Whether the evidence presented was generated in a setting comparable to that in your own country (in terms of disease epidemiology, economic status and cultural norms/values).

${ }^{9}$ Whether the authors and/or institutions generating or publishing the evidence are regarded as objective, unbiased and respected.

${ }^{10}$ The extent to which an immunization programme will improve the health of everyone equally.

${ }^{11}$ Whether or not other interventions exist besides vaccination that may reduce the incidence and/or severity of the disease. 
Part 3: This part involves questions about the effects of an immunization programme other than the direct health benefits to the people being vaccinated. Such effects can be either beneficial or harmful.

9. Are there any effects of an immunization programme that you consider to be important, other than the direct health benefits to the people being vaccinated?

Please make a list of the effects from most important to least important 
10. Suppose the following statements about burden of disease are made about the impact an immunization programme being considered in your country. In your opinion, how important is each piece of information to such a decision?

If you work in a high income country, please answer this question based on the low/middle income country most relevant to your work.

If any of the options are not applicable please circle " $n / a$ ".

If you are not familiar with any of the following scenarios please circle "?".

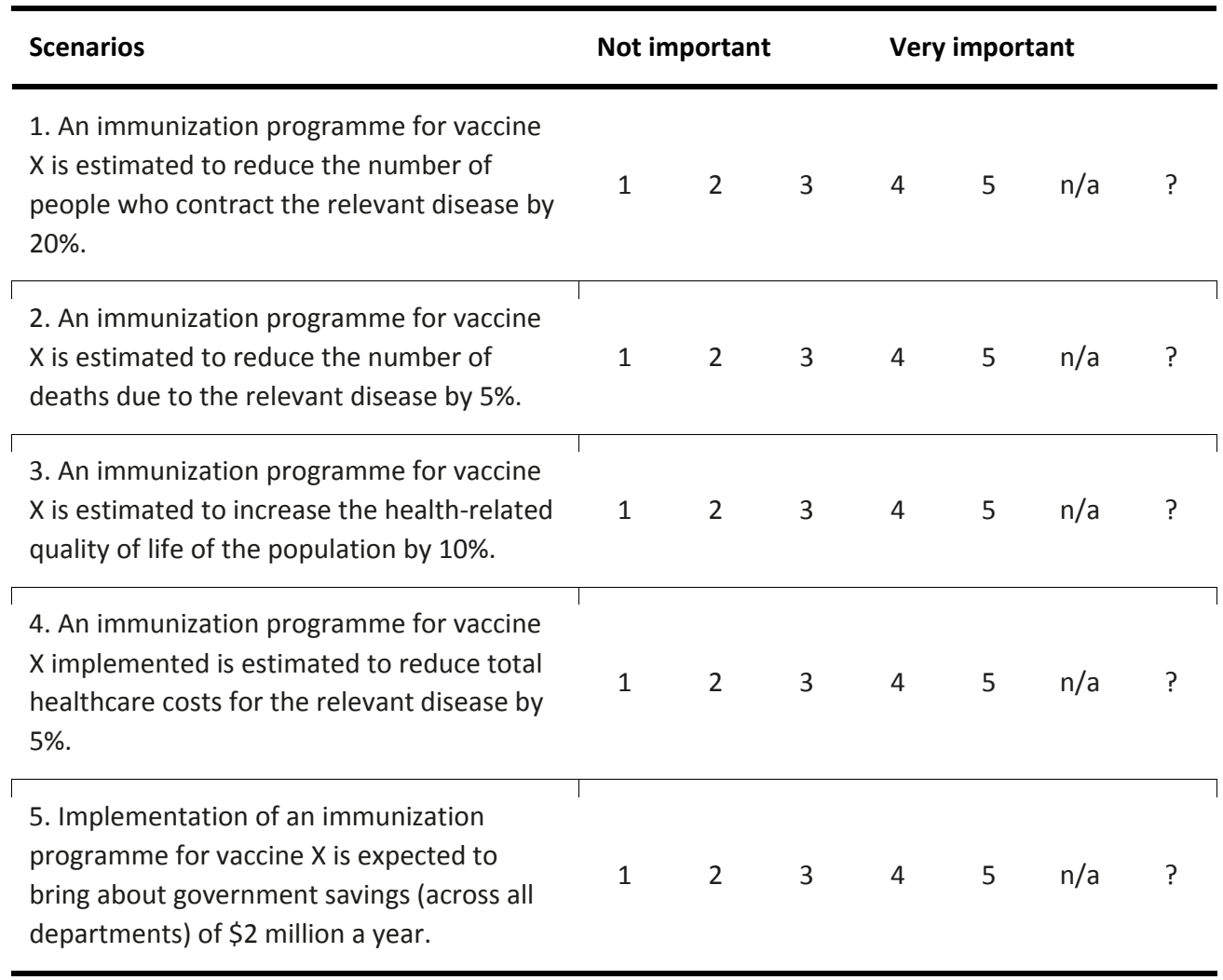


11. Suppose the following statements are made about the productivity gains of a vaccine which is being considered in your country. In your opinion, how important is each piece of information to such a decision?

If you work in a high income country, please answer this question based on the low/middle income country most relevant to your work.

If any of the options are not applicable please circle " $n / a$ ".

If you are not familiar with any of the following scenarios please circle "?".

\begin{tabular}{|c|c|c|c|c|c|c|c|}
\hline Scenarios & \multicolumn{3}{|c|}{ Not important } & \multicolumn{4}{|c|}{ Very important } \\
\hline $\begin{array}{l}\text { 1. When an immunization programme for } \\
\text { vaccine } X \text { is implemented, the average } \\
\text { parent or caregiver may save } 6 \text { hours a year } \\
\text { by avoiding the need to take care of a sick } \\
\text { child. }\end{array}$ & 1 & 2 & 3 & 4 & 5 & $n / a$ & ? \\
\hline
\end{tabular}

2. The implementing of an immunization programme for vaccine $X$ may increase the lifetime labour productivity of vaccinated children because vaccination will improve their cognition and physical strength, as well $\begin{array}{lllllll}1 & 2 & 3 & 4 & 5 & \text { n/a }\end{array}$ as school enrolment, attendance and attainment.

3. The implementing of an immunization programme for vaccine $X$ may eventually influence choices on fertility and hence $\begin{array}{lllllll}1 & 2 & 3 & 4 & 5 & \text { n/a }\end{array}$ improve participation of women in the labour market.

4. The implementing of an immunization programme for vaccine $X$ may influence choices on fertility and hence improve the nutrition, health and educational attainment 1 of children. This can in turn increase the child's labour productivity as an adult. 
12. Suppose the following statements are made about the ecological effects of a vaccine which is being considered in your country. In your opinion, how important is each piece of information to such a decision?

If you work in a high income country, please answer this question based on the low/middle income country most relevant to your work.

If any of the options are not applicable please circle " $n / a$ ".

If you are not familiar with any of the following scenarios please circle "?".

\begin{tabular}{|c|c|c|c|c|c|c|c|}
\hline Scenarios & \multicolumn{3}{|c|}{ Not important } & \multicolumn{4}{|c|}{ Very important } \\
\hline $\begin{array}{l}\text { 1. Implementing an immunization } \\
\text { programme for vaccine } X \text { may reduce/delay } \\
\text { the emergence of drug resistant strains in } \\
\text { the region. }\end{array}$ & 1 & 2 & 3 & 4 & 5 & $\mathrm{n} / \mathrm{a}$ & ? \\
\hline $\begin{array}{l}\text { 2. Implementing an immunization } \\
\text { programme for vaccine } X \text { may lead serotype } \\
\text { replacement effects in the population i.e. an } \\
\text { increase in disease caused by serotypes not } \\
\text { covered by the vaccine. }\end{array}$ & 1 & 2 & 3 & 4 & 5 & $\mathrm{n} / \mathrm{a}$ & ? \\
\hline $\begin{array}{l}\text { 3. Implementing an immunization } \\
\text { programme for vaccine } X \text { may reduce the } \\
\text { risk that non-vaccinated individuals will } \\
\text { acquire the disease. }\end{array}$ & 1 & 2 & 3 & 4 & 5 & $\mathrm{n} / \mathrm{a}$ & ? \\
\hline
\end{tabular}


13. Suppose the following statements are made about the indirect effects of a vaccine which is being considered in your country. In your opinion, how important is each piece of information to such a decision?

If you work in a high income country, please answer this question based on the low/middle income country most relevant to your work.

If any of the options are not applicable please circle " $n / a$ ".

If you are not familiar with any of the following scenarios please circle "?".

\begin{tabular}{|c|c|c|c|c|c|c|c|}
\hline Scenarios & \multicolumn{3}{|c|}{ Not important } & \multicolumn{4}{|c|}{ Very important } \\
\hline $\begin{array}{l}\text { 1. Implementing an uptake for vaccine } X \\
\text { may be highest in protecting people with } \\
\text { lowest risk of disease (due to their } \\
\text { socioeconomic and educational advantage } \\
\text { over non-vaccinated people). }\end{array}$ & 1 & 2 & 3 & 4 & 5 & $\mathrm{n} / \mathrm{a}$ & ? \\
\hline $\begin{array}{l}\text { 2. Other preventative or therapeutic } \\
\text { interventions for the same disease may be } \\
\text { introduced, which would reduce the benefit } \\
\text { of an immunization programme for vaccine } \\
\text { X. }\end{array}$ & 1 & 2 & 3 & 4 & 5 & $\mathrm{n} / \mathrm{a}$ & ? \\
\hline $\begin{array}{l}\text { 3. Implementing an immunization } \\
\text { programme for vaccine } X \text { would reduce the } \\
\text { time that healthcare workers have. }\end{array}$ & 1 & 2 & 3 & 4 & 5 & $n / a$ & ? \\
\hline $\begin{array}{l}\text { 4. Implementing an immunization } \\
\text { programme for vaccine } X \text { may reduce the } \\
\text { priority given to wider public health } \\
\text { interventions to reduce disease incidence } \\
\text { (such as sanitation, maternal health } \\
\text { improvement and provision of clean water). }\end{array}$ & 1 & 2 & 3 & 4 & 5 & $\mathrm{n} / \mathrm{a}$ & ? \\
\hline
\end{tabular}


14. Suppose the following statements are made about the impact of a vaccine on other sectors, which is being considered in your country. In your opinion, how important is each piece of information to such a decision?

If you work in a high income country, please answer this question based on the low/middle income country most relevant to your work.

If any of the options are not applicable please circle " $n / a$ ".

If you are not familiar with any of the following scenarios please circle "?".

\begin{tabular}{l|llllllll}
\hline Scenarios & Not important & \multicolumn{3}{l}{ Very important } \\
\hline $\begin{array}{l}\text { 1. Implementing an immunization } \\
\text { programme for vaccine X may reduce the } \\
\text { financial burden on other sectors besides } \\
\text { healthcare. }\end{array}$ & 1 & 2 & 3 & 4 & 5 & $\mathrm{n} / \mathrm{a}$ & ? \\
$\begin{array}{l}\text { 2. Implementing an immunization } \\
\text { programme for vaccine X may reduce school } \\
\text { absenteeism. }\end{array}$ & 1 & 2 & 3 & 4 & 5 & n/a ? ? \\
\hline
\end{tabular}

15. Do you know of any information about the broader impact of vaccines and / or immunization programmes in your country?

$\begin{array}{ll}\square & \text { No } \\ \square & \text { Yes, namely }\end{array}$

16. Can you think of any original methods to measure the broader impact of vaccines and / or immunization programmes?

$\square \quad$ No

$\square \quad$ Yes, namely 
17. Are there any other examples of the broader impact of vaccines and/or immunization programmes that have not been mentioned in questions 9-14?

$\square \quad$ No

$\square \quad$ Yes, namely

It would be very helpful if we could interview you about your thoughts on this subject, to obtain greater insight about the considerations underlying your answers to this questionnaire, and how different kinds of vaccines may merit different considerations.

Interviews will be conducted during the NUVI meeting in Montreux on 22-23 June, and will take about 20 minutes. If you are happy to be interviewed, please fill out the contact information below:

18. Name

\section{E-mail address}

If you like to be informed about the results of this survey, please leave your e-mail address so that we can contact you.

\section{E-mail address}

Thank you for the time taken to fill out this questionnaire. The information provided will help the WHO to understand key considerations in vaccine implementation, and to develop its work programme around these issues. The printed version of the survey can be handed in by Ms Inge van der Putten during the NUVI meeting.

If you still have any questions or comments on the research please contact; impactvaccines@who.int 


\section{Supplementary File 2 - Questions interviews}

Introduction:

Master students Maastricht University, Global health Health, Policy and Innovation Management. Maastricht University works on this project in collaboration with WHO Immunization Vaccines and Biologicals department in University of Birmingham and the Health Protection Agency

Need:

In middle and low income countries the resources to fund immunization programmes are limited due to budget and other constraints. Currently, most economic evaluations of vaccinations focus on their cost-effectiveness. In this study we want to investigate if any other considerations besides cost-effectiveness (e.g. budget impact, implementation issues, equity considerations) are important to decision makers and funders of immunization programmes in low and middle income countries.

Timeframe interview: $15 \mathrm{~min}$

Is it okay to record the interview?

Interview (start with 1 if more time is available, ask next question):

1. Additional information on external effects (question 10-14 \& did we miss some types of effects)

a. Do you want to further elaborate on a few things you filled out in the survey and that you think need some more explanation?

b. Did you miss a type of effect in the survey that you came across in the years you worked in the field of vaccines?

2. Any considerations on methods to measure effects for in the future

a. Can you give us some recommendations on how to measure some sort of external effects in the future?

b. Is there as far as you know any data/literature available that we can use for further research

3. Differences between vaccines (traditional vs new developed)

a. Are there different issues important for different vaccines? 

$\bullet \bullet$

-

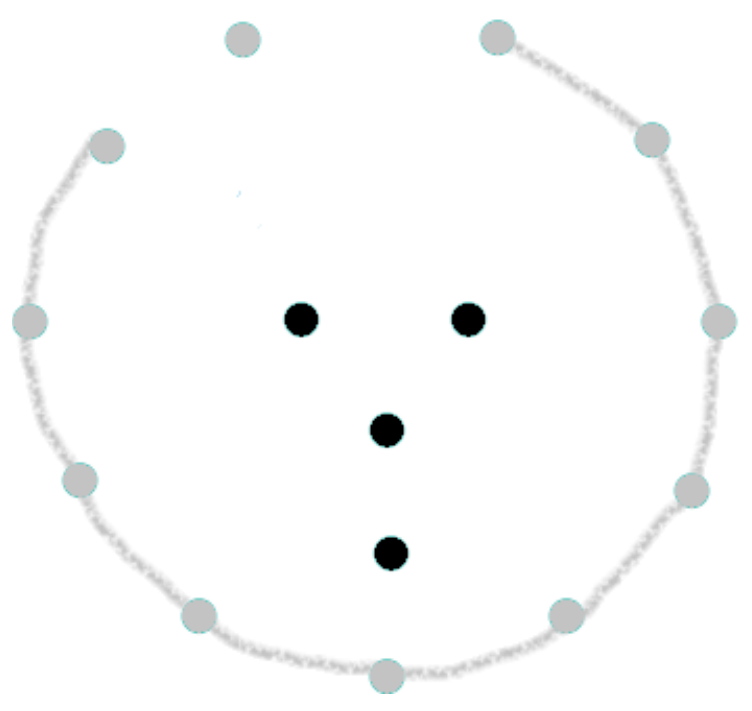




\section{CHAPTER 4}

\section{Identification and Prioritization of the Broader Economic Impact of vaccines}

Published as:

Van der Putten IM, Paulus ATG, Evers SMAA, Hutubessy RCW, and Hiligsmann M. 2016. Identification and Prioritization of the Economic Impacts of Vaccines. Biomed Research International, Volume 2016, article ID: 6267343.

http://dx.doi.org/10.1155/2016/6267343 


\begin{abstract}
Understanding the most important economic impacts of vaccines can provide relevant information to stakeholders when selecting vaccine immunization strategies from a broader perspective. This study was therefore designed to first identify economic impacts to vaccinated individuals, and second, to assess the relative importance of these economic impacts. A four-step approach was used, including a review of the literature, a pilot study and expert consultation. As a fourth step, a survey utilizing a best-worst scaling was conducted among 26 different stakeholders to assess the relative importance of the identified economic impacts. In each of the 15 choice tasks, participants were asked to choose the most important and the least important economic impact from a set of four from the master list. We identified 23 economic impacts relevant for vaccine introduction. Four domains were identified, namely, health-related benefits to vaccinated individuals, short- and long-term productivity gains, community or health systems externalities and broader economic indicators. The first domain was seen as especially important with mortality, health care expenditure, and morbidity ranking in the top three overall. In conclusion, our study suggests that domain A "health-related benefits to vaccinated individuals" are valued more important than the other economic impacts.
\end{abstract}

Keywords: Economic evaluations; Externalities; Vaccines; Immunization; Decision making. 


\section{Introduction}

Globally, the introduction of vaccines has had an important impact on the reduction of communicable diseases [1]. This can be seen in the reduction of the under-5 mortality rate from 12.7 million in 1990 to 6.3 million children in 2013 [2]. Currently, it is estimated that immunization averts 2 to 3 million deaths every year [3]. Furthermore, vaccination is believed to be one of the most cost-effective interventions [4]. Consequently, many countries have introduced national vaccine programmes, often referred to as an Expanded Programme of Immunization (EPI), to prevent the most common and deadly diseases. However, such programmes are not static, but are developing over time.

Before a new or improved vaccine is added to such a programme, the vaccine first has to be evaluated. In this process called vaccine introduction, one of the steps is to look at the economic and financial consequences of introducing the vaccine [5]. This step has become increasingly important as government resources have become less available. As a result, governments have to choose among many competing interventions inside and outside the health care sector [6]. For instance, governments must decide whether they want to invest in free primary education, sanitation programmes, housing, vaccination or other healthcare interventions.

For vaccine introduction decisions the following economic and financial considerations are important. First, stakeholders are in need of decision-supportive information, such as the outcomes of economic evaluations [7-9]. Second, to expand the budget available for vaccines, instead of merely redistributing the existing budget, other stakeholders get involved, such as people from the department of finance, parliamentarians, civil society and media [10].

Currently, many economic evaluations of immunization programmes concentrate on immediate health gains and household cost-savings. However, to better inform all the stakeholders involved in vaccine introduction decisions, outcomes should also include the broader economic impact of vaccines, which have long-term effects $[11,12]$. These effects are experienced by those who are vaccinated and society as a whole, including non-vaccinated community members [13].

Several attempts to provide frameworks for the broader economic impact of vaccines have been performed [13-15]. However, it is largely unknown how stakeholders value these kinds of economic impacts [16] (i.e., which impacts do stakeholders find most and least important). Van der Putten et al. (2015) tested an initial framework to gain insight into the viewpoints of different stakeholders in low and middle income countries (LMIC) [17]. In this mixed-method study, it was found that the broader economic 
impact of vaccines was seen to be as important as measuring the burden of disease. However, this framework needed to be updated to incorporate new insights that were developed in the field [13-15,18] and further validation among a larger group of different stakeholders. In addition, it was suggested that different audiences need different messages because of differences in culture and context [17]. Furthermore, a more detailed prioritization of the economic impact of vaccines would be important to steer research investments into the most valued areas.

To assess the broader economic impact of vaccines and prioritize different types of economic impacts, rankings are needed by different stakeholders, such as policy makers, providers of immunization services, health advocates and researchers. Given the above-mentioned limitations of prior studies and the importance of gaining insight into the preferences of different stakeholders, this study was designed with the aim to: (1) identify what kind of economic information could be important for stakeholders when making decisions on introducing vaccines in general; (2) to assess the relative importance of economic impact of vaccines by ranking them most important and least important in a best-worst scaling; (3) to find out if context (availability and relevance), type of stakeholder group or working in a low and middle income countries (LMIC) vs. high income countries (HIC) influence preferences stated.

\section{Methods}

To identify and prioritize the broader economic impact of vaccines, a four-step process was used (as shown in figure 1). The first three steps were undertaken to come up with a renewed framework for the economic impact of vaccines, while the fourth step prioritized the identified economic impacts using a best-worst scaling.

\section{Identification}

In the first step, we reviewed the literature and used the outcomes of several papers, including three literature reviews [13-15] and a mixed-method study [17] to identify a list of the economic impacts of vaccines. The mixed-method study consisted of a survey among participants of the New and Underutilized Vaccine Initiative (NUVI) meeting $2011(n=26)$ and interviews with stakeholders $(n=14)$ [17]. More detailed descriptions of the methods can be found in the referenced articles [13-15,17]. A total of 23 different short-term effects of vaccines, long-term effects of vaccines and the effects experienced by society as a whole were included in the framework. This framework was first used to design a version of the questionnaire, which consisted of 25 individual items. Then, this version was pilot tested by a convenient sample of 12 colleagues. The pilot revealed that the questionnaire was too time consuming. Furthermore, the comparison of the different types of impacts was difficult for several reasons: the 
questionnaire consisted of too many items; the used economic impacts were not all from the same level; and, the used impacts were not totally exclusive. To overcome these problems, we decided to add a third step to validate the framework using individual consultations with experts $(n=8)$ via Skype or telephone interviews. In these interviews, we provided the experts with the initial framework and asked them if all included economic impacts were relevant, if some economic impacts could be combined, if any economic impacts should be added, and if the proposed items for the survey were correctly formulated. Based on these results, a renewed framework of 23 economic impacts of vaccines was formulated. In a consensus meeting with the authors, three criteria were established to formulate the final questionnaire: (1) all items should be measured on the same level; (2) items should not overlap; and (3) it should be possible to calculate the item in monetary terms.

Figure 1. Steps in the identification and prioritization of the economic impacts.

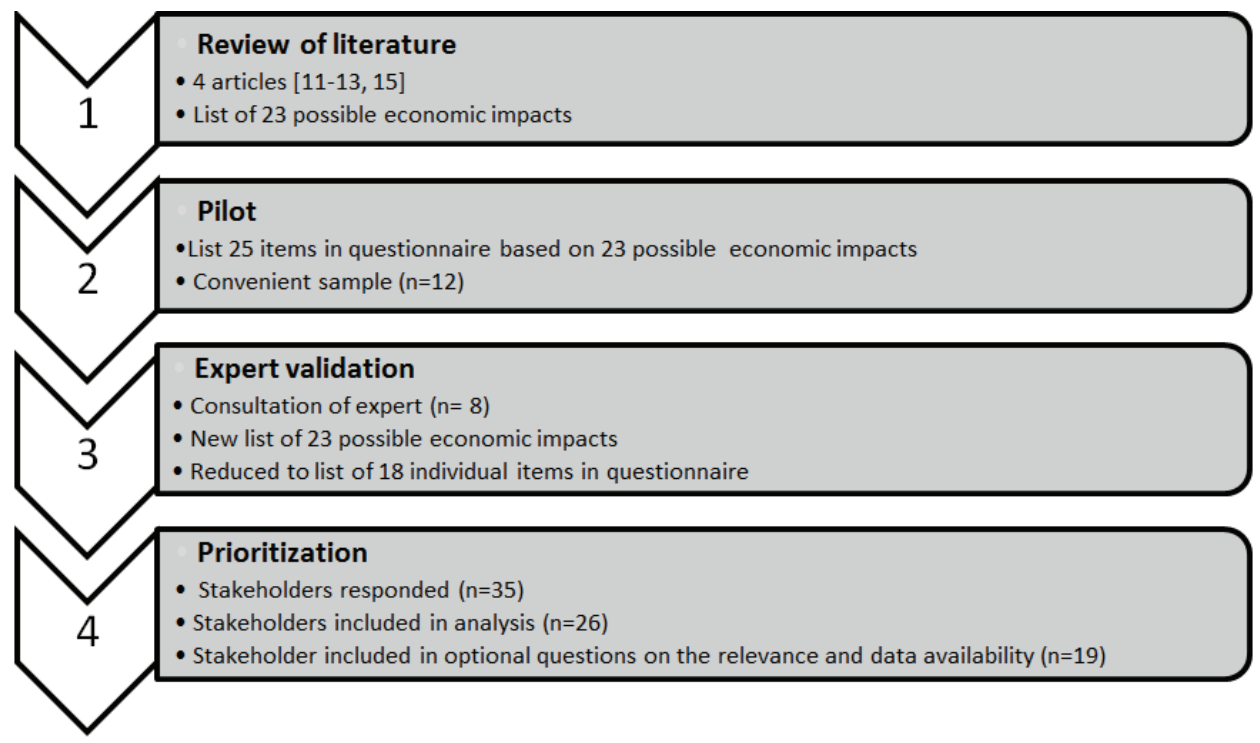

As a result, the final framework consisted of 18 items for the questionnaire. An overview of how the framework of 23 economic impacts of vaccines was reduced to 18 individual items is provided in supplementary materials (Supplementary file 1 and available online at http://dx.doi.org/10.1155/2016/62627343).

\section{Prioritization}

To prioritize the 18 individual items, a survey was conducted (Fourth step). Policy makers, providers of immunization services, health advocates, researchers, and other participants were actively recruited by using personal contacts, the Supporting 
Independent Immunization and Vaccine Advisory Committees (SIVAC) Initiative database, internet searches for collaborative initiatives for vaccines, among participants at the WHO Broad Economic Impact of Vaccines Meeting (24-25 November 2014, Bangkok, Thailand); and Annual European Congress - ISPOR, (8-12 November 2014 Amsterdam, Netherlands); World Health Forum, (22-24 November 2015, The Hague); Advancing The Value Of Vaccines Research Agenda, (26-27 April 2016 Boston, US,) and snowballing via personal contacts, the contacts of the eight experts, the participants at the meeting in Bangkok and the meeting in Boston.

Table 1. Lists of all economic impacts of vaccines.

\begin{tabular}{ll}
\hline Impacts & Individual item \\
\hline A. Health-related benefits to vaccinated individuals \\
\hline 1. Mortality & Health benefits achieved by reducing number of deaths. \\
\hline 2. Morbidity & $\begin{array}{l}\text { Health benefits achieved by reducing morbidity and } \\
\text { improving quality of life. }\end{array}$ \\
\hline 3. Health care expenditure & Reduction in medical expenditures for health care system. \\
\hline B. Short-term and long-term productivity gains \\
\hline 4. School absenteeism & Reduction in amount of schooldays missed due to illness. \\
\hline 5. Care-related productivity & $\begin{array}{l}\text { Increased individual productivity due to reduction in lost } \\
\text { w. Outcome-related }\end{array}$ \\
\hline productivity & $\begin{array}{l}\text { Increased individual lifetime productivity and participation } \\
\text { due to improved health. }\end{array}$
\end{tabular}

C. Community or health systems externalities

\begin{tabular}{ll}
\hline 7. Impact on other diseases & $\begin{array}{l}\text { Impact on incidence numbers of closely related diseases not } \\
\text { vaccinated for. }\end{array}$ \\
\hline $\begin{array}{l}\text { 8. Community health } \\
\text { externalities }\end{array}$ & Externalities among the unvaccinated community members. \\
\hline 9. Outbreak prevention costs & Impact on disease outbreak investigations and prevention. \\
\hline 10. Equity & Impact on equity issues in the society. \\
\hline 11. Risk reduction & $\begin{array}{l}\text { Impact on welfare of households due to reduced uncertainty } \\
\text { in future outcomes and health expenditures. }\end{array}$
\end{tabular}

\begin{tabular}{|c|c|}
\hline 12. Economies of scale & $\begin{array}{l}\text { Impact on per dose price of vaccine due to changes in } \\
\text { demand. }\end{array}$ \\
\hline \multicolumn{2}{|l|}{ D. Broader economic indicators } \\
\hline $\begin{array}{l}\text { 13. Behaviour-related } \\
\text { productivity }\end{array}$ & $\begin{array}{l}\text { Economic benefits for families as a result of improved child } \\
\text { health and survival. }\end{array}$ \\
\hline 14. Demographic dividend & $\begin{array}{l}\text { Economic effects of changes in demographic composition of } \\
\text { society. }\end{array}$ \\
\hline 15. Employment in society & Impact on overall employment in society. \\
\hline $\begin{array}{l}\text { 16. Impact on consumption } \\
\text { behaviour }\end{array}$ & Impact on the consumption of the general population. \\
\hline $\begin{array}{l}\text { 17. Impact on gross domestic } \\
\text { product (GDP) }\end{array}$ & Impact on gross domestic product in general. \\
\hline 18. Impact on tax revenue & Impact on tax revenues. \\
\hline
\end{tabular}


The questionnaire consisted of four parts: some background questions, a rating scale exercise (RSE), a best worst scaling exercise (BWS) and an optional question on the relevance and data availability of the identified economic impacts. For each identified economic impact, a description was developed that was pilot tested in step two. The descriptions of all the economic impacts of vaccines were included in the introduction part of the questionnaire. With the RSE the priority of the different identified economic impacts was then established using a 0-10 VAS scales to familiarize respondents with the different economic impacts. A BWS was used to further assess the relative importance of these economic impacts. A BWS simplifies the ranking task for respondents by reducing the number of choices they have to make by asking them to indicate the best and worst option among a list of factors. Advantages of this method are robustness for scale-related biases and effectively discrimination between ratings of different factors involved in complex decisions [19]. Therefore, we chose to present only the outcomes of the BWS in the result section.

Respondents were asked to answer 15 choice sets, each composed of a set of 4 factors from the master list of 18 individual items (see table 1 ). In each choice set, respondents were asked to identify the most important and the least important economic impact (an example of a BWS task is given in table 2). We used Sawtooth Software's SSI Web platform (version 8.3) to design the BWS questions. In order to create an efficient design, the following measures were taken. First, each item in the total six versions of the questionnaire was shown 20 times, displayed 4 to 6 times in every position and paired 3 to 4 times with every other item on the master list. No sets were shown twice and questions were divided in 6 different versions of the questionnaire to reduce context bias [20]. The six versions of the questionnaire were randomly assigned to the respondents via online questionnaire software [21].

Table 2. Example of a best-worst scaling question.

\begin{tabular}{ccc}
\hline Most important & Least important \\
\hline & Equity considerations & $\mathrm{X}$ \\
\hline Economic information & \\
\hline $\mathrm{X}$ & Effectiveness vaccines \\
\hline
\end{tabular}

This expert indicated that in this scenario "mortality rates" are the most important impact and "equity considerations" the least important impact in their decision-making process.

Only respondents who filled out the BWS questions were included in the analysis. Descriptive analysis was performed on the background questions regarding work experience, type of stakeholder and self-reported knowledge on economic evaluations, policy decisions and vaccines. A Hierarchical Bayes (HB) analyses was performed to analyze the BWS questions using Sawtooth Software. This software uses HB modelling [22] to calculate raw scores and relative importance score (RIS) of each item on the 
master list. All 26 respondents were included in the calculations as all scored above the 0.282 fit statistic [23]. In this research only the RIS scores are used. These scores indicate the likelihood of one item being selected and sums up to $100 \%$ [23].

Subgroups analyses were conducted for stakeholders working in LMIC and HIC and between stakeholders with a research background and other stakeholders. One-way ANOVA tests were conducted to assess statistical differences between groups [24]. If normality assumption was not met, Mann-Whitney non-parametric tests were executed [24].

\section{Results}

\section{Identification}

In total, 23 economic impacts of vaccines were identified after the expert consultation round (steps 1-3). With the input of the consultations with the experts, a final list of 18 items to be included in the survey was made during the consensus meeting (see table 1). The 18 items can be subdivided into four different domains [15]. The first domain $A$ ( 3 items), "health-related benefits to vaccinated individuals" consists of health gains and health care cost-savings. The second domain B ( 3 items) includes "short-term and long-term productivity gains". These gains refer to the individual (long-term) productivity due to better physical and mental health. The third domain C (6 items) consists of "community or health systems externalities", which are related to the decline of prevalence and incidence of vaccine-related diseases and different types of equity considerations. Finally, the fourth domain D (6 items) includes "broader economic indicators", such as the impact of vaccine immunization programmes on GDP and tax revenues.

\section{Prioritization}

In total, 35 respondents started the questionnaire, of which 26 respondents were included in the analysis. As the last part of the questionnaire was optional, nineteen respondents answered the questions on the relevance and data availability of the identified economic impacts. The average working experience was thirteen years and most respondents $(61.5 \%)$ had a research background. Furthermore, two health advocates, five health policy makers and three providers of immunization services filled out the questionnaire. Fifteen respondents worked in LMIC and ten in HIC. The selfreported knowledge of the respondents was 6.2 (1.4) on economic evaluations, 3.4 (2.0) on decision making and 5.9 (1.3) on vaccines measured on a 7-point Likert-scale (strongly disagree - strongly agree). The general ranking of the domains was consistent for both RSE and BWS. Also, the ranking of the individual items was quite similar to the 
ranking of the domains. Results of the RSE, which are available upon request from the first author, were similar to results from the BWS.

\section{Best-Worst Scaling}

The BWS was rated $6.2(S D=2.4$ ) on a scale of 10 (extremely easy - extremely difficult). Information on the domain A "health-related benefits to vaccinated individuals" was ranked first, domain B "short-term and long-term productivity-related gains" ranked second, domain C "community or health system externalities" third and domain D "broader economic indicators" ranked fourth (see table 3). Looking at individual items, mortality, healthcare expenditure and morbidity are statistically the three most important economic impacts since their confidence intervals are not overlapping with other impacts. Almost all the items of domain D "broader economic indicators" scored the lowest except for behavior-related productivity, which is ranked fourth. Risk reduction and outbreak prevention costs are seen as more important than the other items of domain C "community or health system externalities". While school absenteeism is seen as not as important when compared with domain B "outcomerelated productivity" and "care-related productivity".

Table 3. Overview Ranking BWS, relevance and data availability.

\begin{tabular}{llll}
\hline Economic impact (domain) & RIS (95\% CI) & $\begin{array}{l}\text { Relevance (\%) } \\
\mathrm{n}=26\end{array}$ & $\begin{array}{l}\text { Data avail- } \\
\text { ability (\%) } \\
\mathrm{n}=19\end{array}$ \\
\hline 1. Mortality (A) & $13.96(12.88-15.04)$ & $17(89.5 \%)$ & $13(68.4 \%)$ \\
\hline 3. Healthcare expenditure (A) & $12.76(11.43-14.09)$ & $15(78.9 \%)$ & $9(47.4 \%)$ \\
\hline 2. Morbidity (A) & $12.69(11.53-13.85)$ & $19(100 \%)$ & $8(42.1 \%)$ \\
\hline 13. Behavior-related productivity (D) & $8.07(6.73-9.41)$ & $14(73.7 \%)$ & $3(15.8 \%)$ \\
\hline 11. Risk reduction (C) & $6.62(4.64-8.59)$ & $13(68.4 \%)$ & $2(10.5 \%)$ \\
\hline 9. Outbreak prevention costs (C) & $6.52(4.46-8.59)$ & $16(84.2 \%)$ & $8(42.1 \%)$ \\
\hline 6. Outcome-related productivity (B) & $6.35(4.60-8.10)$ & $16(84.2 \%)$ & $4(21.1 \%)$ \\
\hline 5. Care-related productivity (B) & $6.05(4.51-7.59)$ & $17(89.5 \%)$ & $6(31.6 \%)$ \\
\hline 12. Economies of scale (C) & $5.59(3.57-7.60)$ & $15(78.9 \%)$ & $5(26.3 \%)$ \\
\hline 8. Community health externalities (C) & $4.15(2.93-5.37)$ & $17(89.5 \%)$ & $4(21.1 \%)$ \\
\hline 7. Impact on other diseases (C) & $4.07(2.54-5.61)$ & $14(73.7 \%)$ & $2(10.5 \%)$ \\
\hline 10. Equity (C) & $3.69(1.93-5.45)$ & $11(57.9 \%)$ & $3(15.8 \%)$ \\
\hline 4. School absenteeism (B) & $3.04(2.25-3.83)$ & $17(89.5 \%)$ & $3(15.8 \%)$ \\
\hline 17. Impact on GDP (D) & $2.44(1.13-3.74)$ & $8(42.1 \%)$ & $2(10.5 \%)$ \\
\hline 15. Employment in society (D) & $1.72(0.73-2.70)$ & $8(42.1 \%)$ & $1(5.2 \%)$ \\
\hline 16. Impact on consumption behavior (D) & $0.85(0.00-3.75)$ & $7(36.8 \%)$ & $0(0.0 \%)$ \\
\hline 14. Demographic dividend (D) & $0.82(0.34-1.31)$ & $8(41.2 \%)$ & $3(17.6 \%)$ \\
\hline 18. Impact on tax revenues (D) & $0.60(0.13-1.07)$ & $7(35.3 \%)$ & $1(5.9 \%)$ \\
\hline
\end{tabular}




\section{Relevance and data availability}

Most respondents found the included individual items relevant and applicable in their countries except for domain D "broader economic indicators" (table 3). However, table 3 also shows data on domain A "health-related benefits to vaccinated individuals" is available in some countries. This is not the case for data on domain B "short-term and long-term productivity-related gains", domain C "community or health system externalities" and domain D "broader economic indicators" where data on these individual items are often unavailable or not used. In figure 2, a scatterplot of the percentage of respondents that have data available in their country for every economic impact is plotted against the outcomes of the RIS. You can see that known data availability in the country of work of the respondent is positively related to the scores on the BWS ratio.

Figure 2. Scatterplot impact of data availability on outcome BWS ratio.

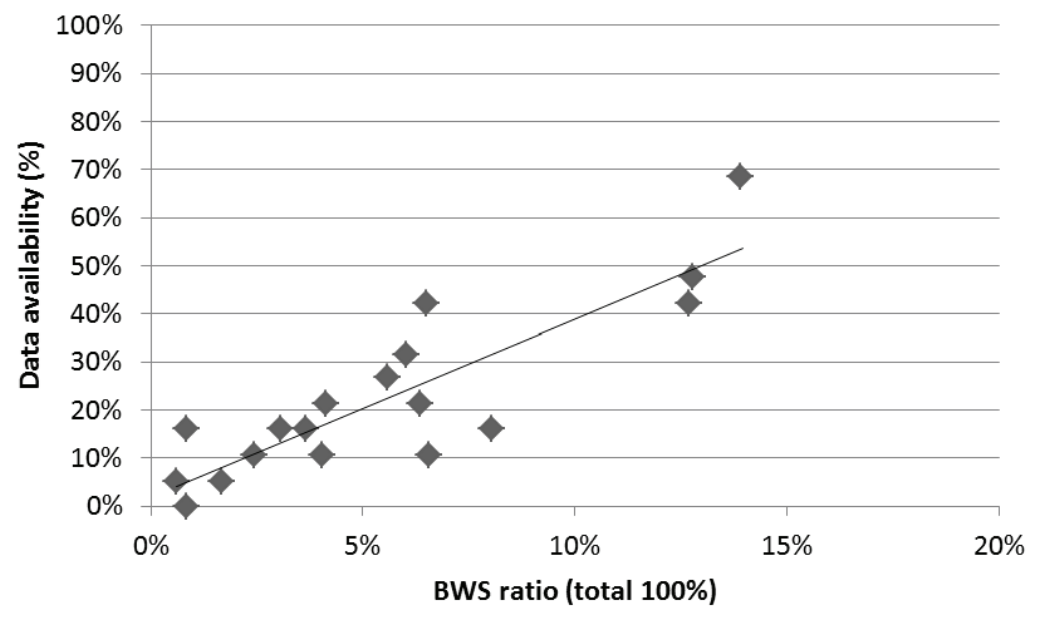

\section{Subgroups analyses}

For some of the individual items, researchers $(n=16)$ have a different viewpoint than policy makers, providers of immunization services and health advocates $(n=10)$. Impact on GDP, care-related productivity, and equity are seen as more valuable by stakeholders of the latter group while researchers value information on morbidity. None of the individual items were significantly different (see figure $3 a$ ).

When looking at the outcomes of respondents working in LMIC ( $n=15)$ and respondents working in HIC $(n=10)$, no significant differences could be established for the individual items either. Although outcome-related productivity were regarded as more important in HIC while economies of scale and outbreak prevention costs are valued more in LMIC (see figure $3 b$ ). 
Figure 3a. Results BWS measured on a sum scale of $100 \%$ researchers vs other stakeholders.

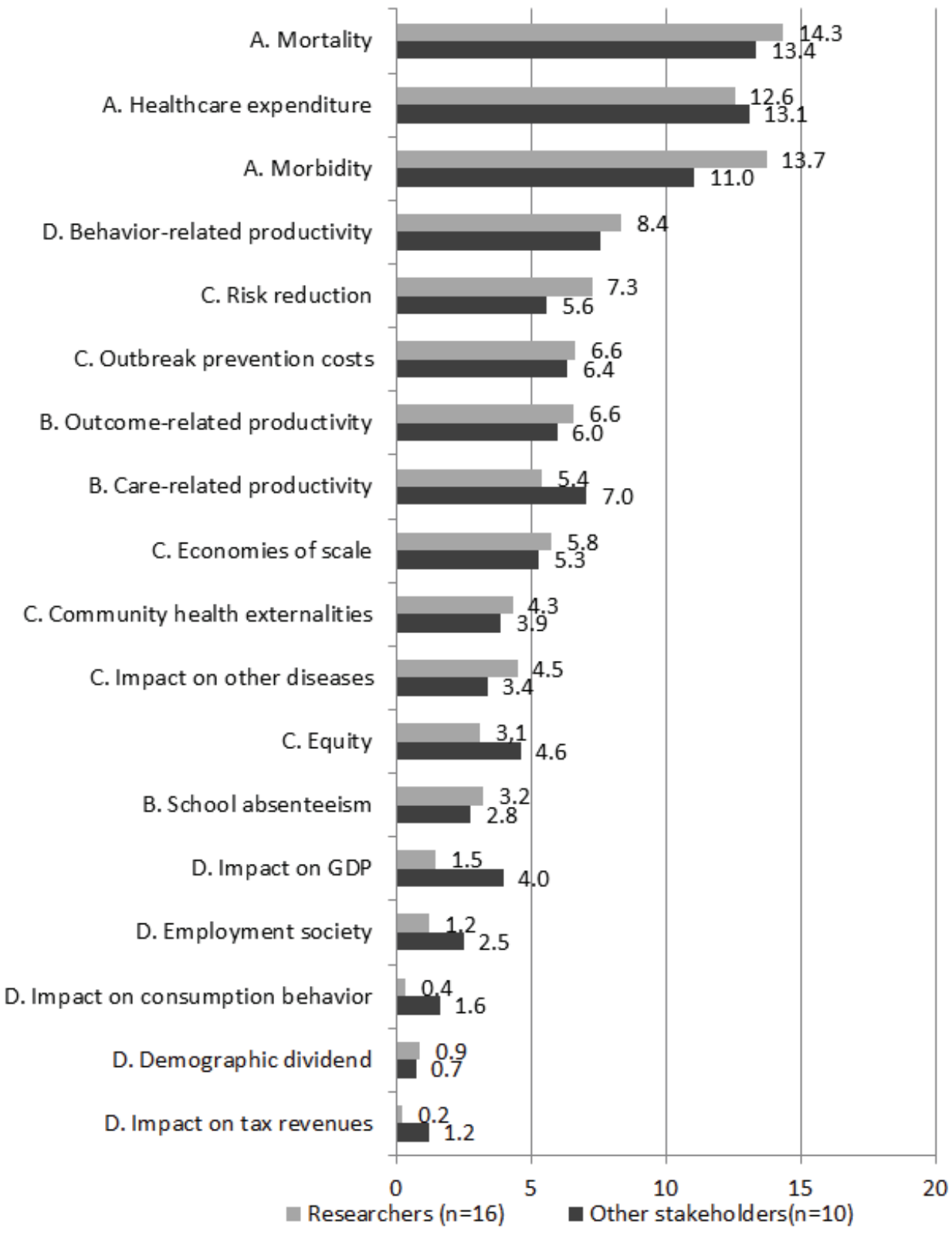


Figure $3 b$. Results BWS measured on a sum scale of $100 \%$ LMIC vs HIC.

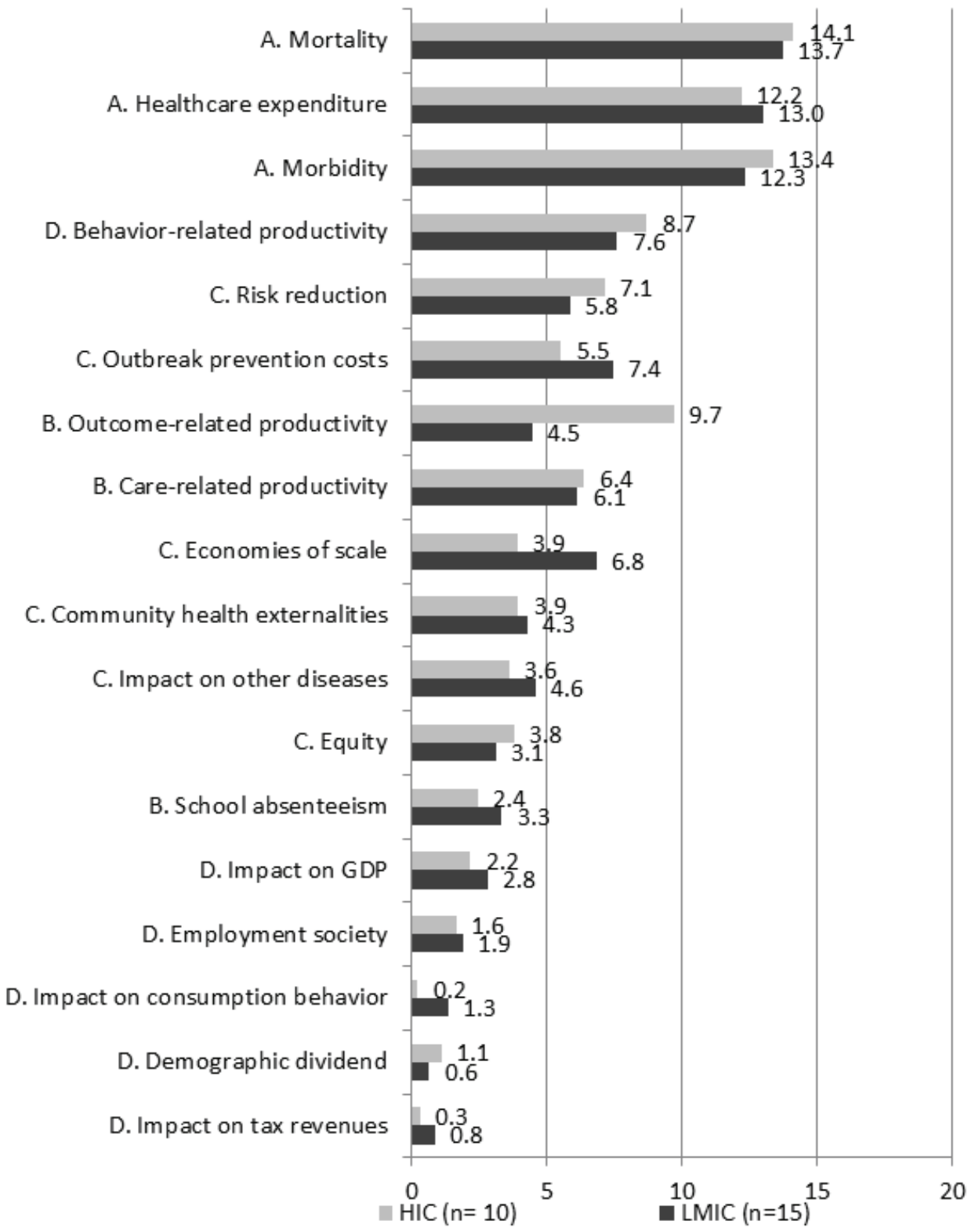




\section{Discussion}

The aim of this study was to find out which of the broader economic impacts of vaccines could be included in economic evaluations to better meet the needs of the previously identified stakeholders, because developing new outcomes for economic evaluations could help stimulate evidence-informed decision making in LMIC and HIC.

This study identified 23 economic impacts that could be relevant for vaccine introduction. The BWS suggested that domain A "health-related benefits to vaccinated individuals" are valued as more important than the other domains. Most individual items were seen as relevant, except of several items of domain D "broader economic indicators". The outcomes of the analysis of the data availability in specific countries suggest a positive relationship with the RIS score. Furthermore, group comparison of the BWS outcomes for different stakeholder groups showed no significant differences.

Many steps were taken to identify the economic impact of vaccines and to develop the questionnaire used. Each step added rigorousness to the design of this study. Selected individual items were checked based on face validity by the 8 experts. The general ranking of the domains was consistent for both RSE and BWS, also the ranking of the individual items was quite similar, which suggests that the outcomes are reliable. Although we used numerous strategies to find the right respondents, one main shortcoming of this study in general is the low response rate. More specifically, health decision makers inside and outside the healthcare sector were underrepresented. Therefore, results of the subgroup analysis should be interpreted with caution. Moreover, as you need a reasonable number of respondents for calculating the RIS scores to obtain stable results from the analysis. Samples smaller than twenty are not recommended [22]. The difficulties in the data collections lead to a relatively long data collection period of 1.5 year. The overrepresentation of researchers in the sample also makes it more difficult to generalize about the preferences attributed to other stakeholder groups involved in the decision making around vaccine introduction.

Three main findings of this research should be discussed. First, with some minor difference the framework we propose largely overlaps with alternative frameworks recently published in the literature $[15,18]$. One difference is that Bärnighausen et al. chooses to divide the impacts in narrow and broad categories and we opted to use the domain classification of Jit et al. Another difference is that in the publication of the framework by Bärnighausen et al., health gains were transferred from narrow to broad while we opted to keep mortality and morbidity outcomes in the first domain [18]. Second, the findings of this study are not fully consistent with a study undertaken earlier with a preliminary framework in which we found that the broader economic impacts were as important as the narrow economic impacts [17]. However, this study 
was also undertaken in a small sample $(n=26)$, and the method used in this study (BWS) has several advantages over Likert-scales, as it can be used to better discriminate between the items to be ranked and is less prone to scale-related biases [19]. Third, our study also suggests that information and data on broader impact of vaccines are also less available in countries. This can have several meanings, for example, that information on BEIVs are not available as they are not seen as very helpful for policymaking, or that respondents are not aware of the possibilities of these values and therefore put a lower value on these types of impacts.

On the basis of these results, we recommend looking at broader outcome measures, while retaining the more traditional measures on mortality, morbidity and healthcare expenditure as the focus of economic evaluations. Furthermore, this study could indicate that it is important to better inform decision makers with the broader economic impact of vaccines before making decisions about the usefulness of such economic impacts. Therefore, we recommend developing programmes to educate stakeholders on the possibilities of BEIVs and research how to impact the stated preferences of the different groups of stakeholders. To gather these data we would recommend organizing workshops around this subject during trainings and meetings where all stakeholder groups are already represented. This could be in the form of very short questionnaires or data collection in a workshop setting. Although the framework was initially developed for LMIC [13-15,17], parts of the framework are also applicable to HIC, to stimulate the introduction of newly developed vaccines especially in HIC with highly variable incomes. For example introduction decisions on both pandemic and seasonal influenza vaccines and recently registered dengue vaccines may include broader social and economic considerations [25-28].

\section{Conclusion}

This study suggests that the domain A "health-related benefits to vaccinated individuals" which are traditionally used in economic evaluations are valued as most important by both policy makers and researchers, and in both LMIC and HIC. 


\section{References}

1. UNICEF. Commiting to child survival: a promise reviewed. New York: UNICEF, 2013.

2. World Health Organization. Global Health Observatory: Under Five Mortality 2017 [cited 201714 December]. Available from: http://www.who.int/gho/child_health/mortality/mortality_under_ five_text/en/index.html.

3. World Health Organization. Immunization coverage 2015 [cited 201529 June]. Available from: http://www.who.int/mediacentre/factsheets/fs378/en/.

4. WHO, UNICEF, World Bank. State of the world's vaccines and immunization. Geneva: 2009.

5. WHO. Principles and considerations for adding a vaccine to a national immunization programme: from decision to implementation and monitoring. Geneva; Switserland: 2014.

6. Chan M. Investing in health: progress but hard choices remain. The Lancet. 2013;382(9908):e34-e5.

7. Burchett $H$, Mounier-Jack $S$, Griffiths $U$, Biellik R, Ongolo-Zogo $P$, Chavez E, et al. New vaccine adoption: qualitative study of national decision-making processes in seven low-and middle-income countries. Health policy and planning. 2012;27(suppl 2):ii5-ii16.

8. Burchett $\mathrm{H}$, Mounier-Jack S, Griffiths U, Mills A. National decision-making on adopting new vaccines: a systematic review. Health policy and planning. 2012;27(suppl 2):ii62-ii76.

9. Mansoor O, Shin S, Maher C, WPRO tIFo. Assessing new vaccines for national immunization programmes. A framework to assist decision makers. Manila: World Health Organization Regional Office for the Western Pacific Manila, 2000 2012/5/29. Report No.

10. Engström H, Khin PT, Coll-Seck A, Petersen RH, Asamoa-Baah A, Machel G, et al. Reinvesting in health post-2015. The Lancet. 2013;382(9908):1861-4.

11. Jit M, Hutubessy R. Methodological Challenges to Economic Evaluations of Vaccines: Is a Common Approach Still Possible? Applied health economics and health policy. 2016;14(3):245-52.

12. Barnighausen T, Berkley S, Bhutta ZA, Bishai DM, Black MM, Bloom DE, et al. Reassessing the value of vaccines. The Lancet Global health. 2014;2(5):e251-2.

13. Deogaonkar R, Hutubessy R, van der Putten I, Evers S, Jit M. Systematic review of studies evaluating the broader economic impact of vaccination in low and middle income countries. BMC public health. 2012;12(1):878.

14. Ozawa S, Mirelman A, Stack ML, Walker DG, Levine OS. Cost-effectiveness and economic benefits of vaccines in low-and middle-income countries: A systematic review. Vaccine. 2012:96-108.

15. Jit M, Hutubessy R, Ee PM, Sudaram N, Audilam J, Salim S, et al. The broader economic impact of vacination: reviewing and appraising the strength of evidence. BMC Med. 2015(13):209.

16. Schwartz JL, Mahmoud A. When Not All That Counts Can Be Counted: Economic Evaluations And The Value Of Vaccination. Health Affairs. 2016;35(2):208-11.

17. van der Putten IM, Evers SM, Deogaonkar R, Jit M, Hutubessy RC. Stakeholders' perception on including broader economic impact of vaccines in economic evaluations in low and middle income countries: a mixed methods study. BMC Public Health. 2015;15(1):356.

18. Bärnighausen T, Bloom DE, Cafiero-Fonseca ET, O'Brien JC. Valuing vaccination. Proceedings of the National Academy of Sciences. 2014;111(34):12313-9.

19. Mühlbacher AC, Kaczynski A, Zweifel P, Johnson FR. Experimental measurement of preferences in health and healthcare using best-worst scaling: an overview. Health economics review. 2015;6(1):114.

20. Flynn TN, Louviere JJ, Peters TJ, Coast J. Best-worst scaling: What it can do for health care research and how to do it. Journal of Health Economics. 2007;26(1):171-89.

21. Qualtrics LLC. Qualtrics 2016 [cited 201623 May]. Available from: https://www.qualtrics.com/.

22. Johnson R. Understanding HB: an intuitive approach. Sawtooth Software 2000. 2010.

23. Orme; B. SSI Web v8.3: Software for web interviewing and conjoint analysis. Orem, Utah: Sawtooth Software, Inc., 2014.

24. Field A. Discovering statistics using IBM SPSS statistics: Sage; 2013. 
25. Ferguson NM, Rodriguez-Barraquer I, Dorigatti I, Mier YT-RL, Laydon DJ, Cummings DA. Benefits and risks of the Sanofi-Pasteur dengue vaccine: Modeling optimal deployment. Science (New York, NY). 2016;353(6303):1033-6.

26. de Francisco Shapovalova N, Donadel M, Jit M, Hutubessy R. A systematic review of the social and economic burden of influenza in low- and middle-income countries. Vaccine. 2015;33(48):6537-44.

27. Tozan Y. Current issues in the economics of vaccination against dengue. Expert review of vaccines. 2016;15(4):519-28.

28. Flasche S, Jit M, Rodríguez-Barraquer I, Coudeville L, Recker M, Koelle K, et al. Comparative modelling of dengue vaccine public health impact (CMDVI). Geneva: World Health Organization, SAGE; 201617 March 2016. 


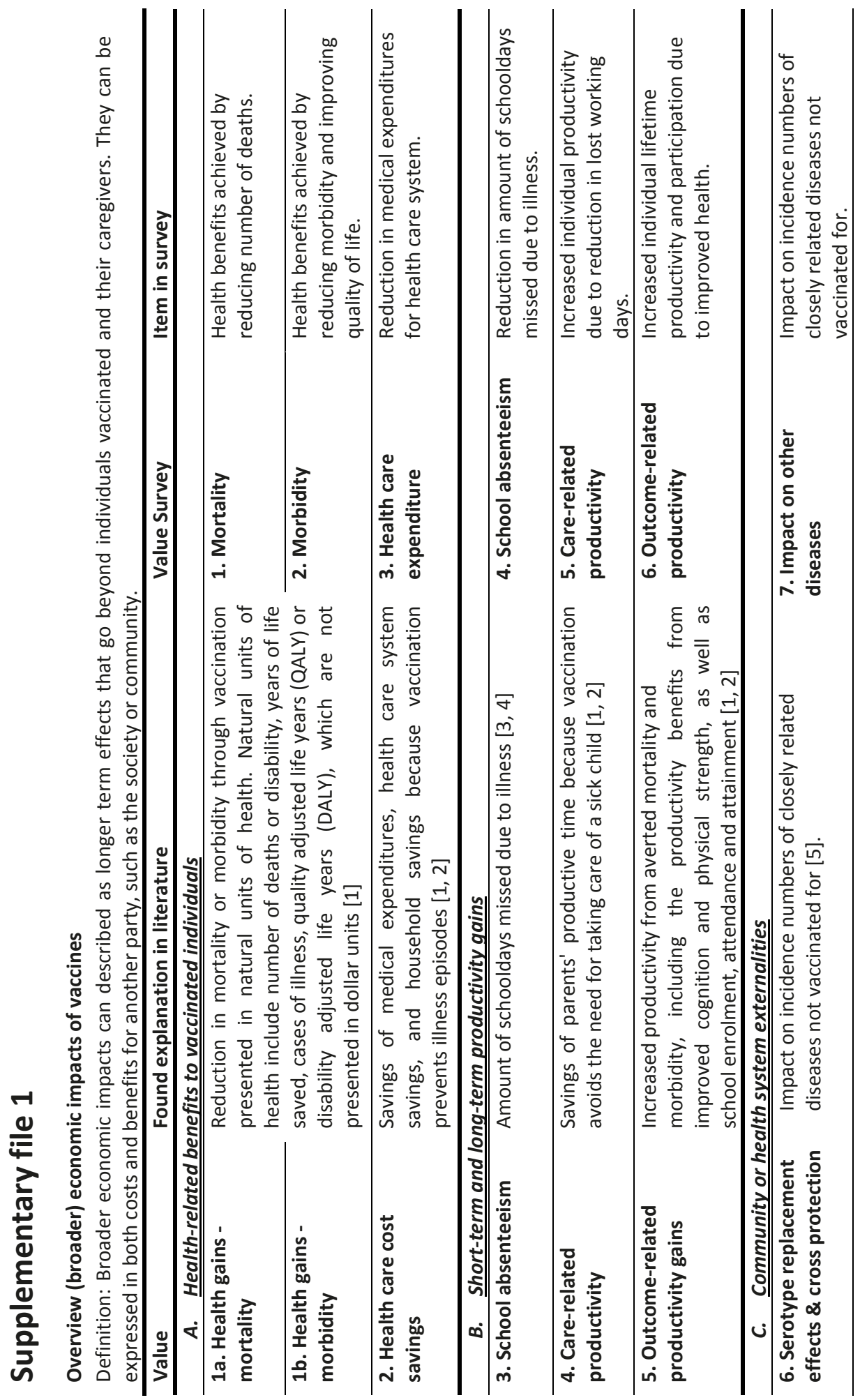




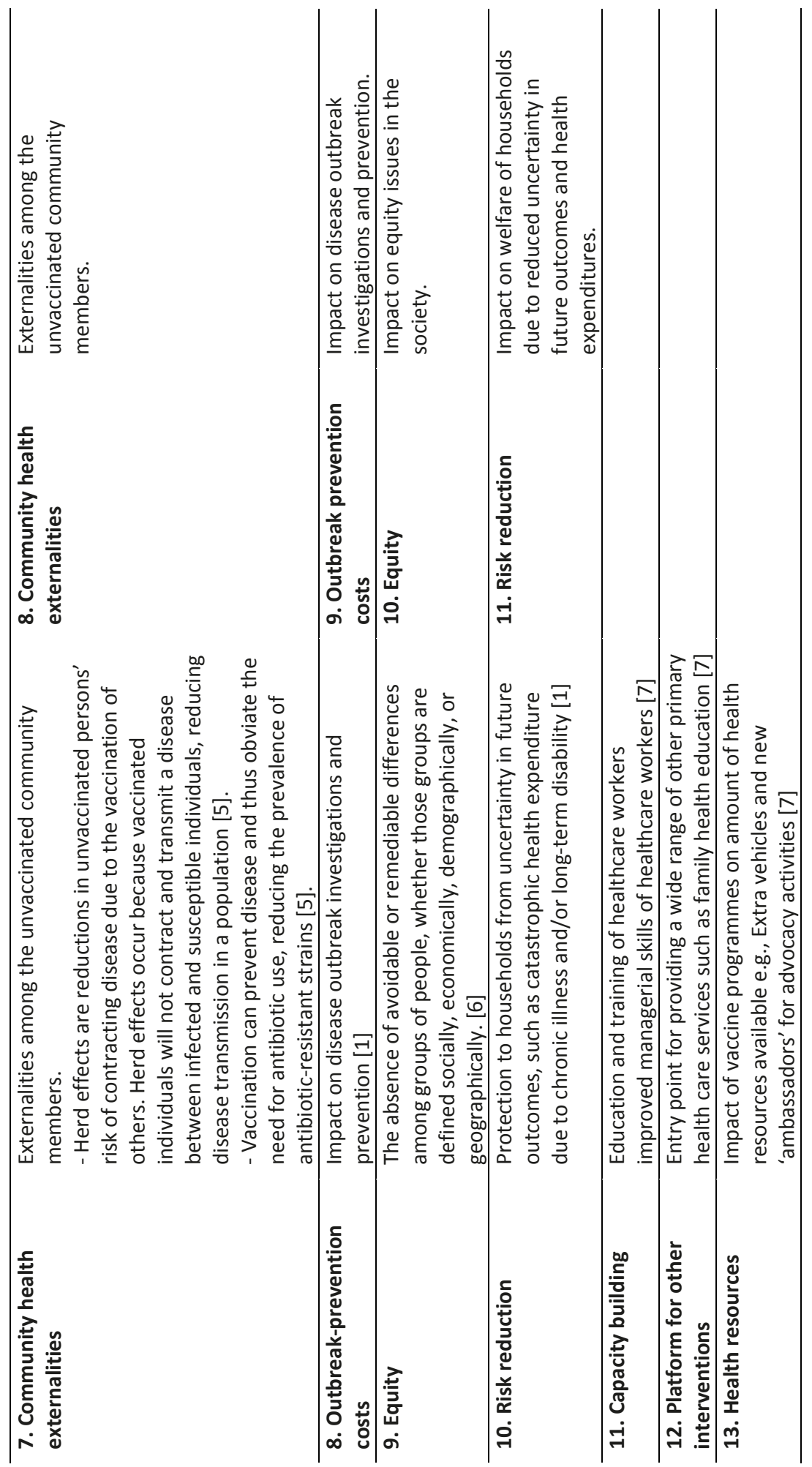


CHAPTER 4

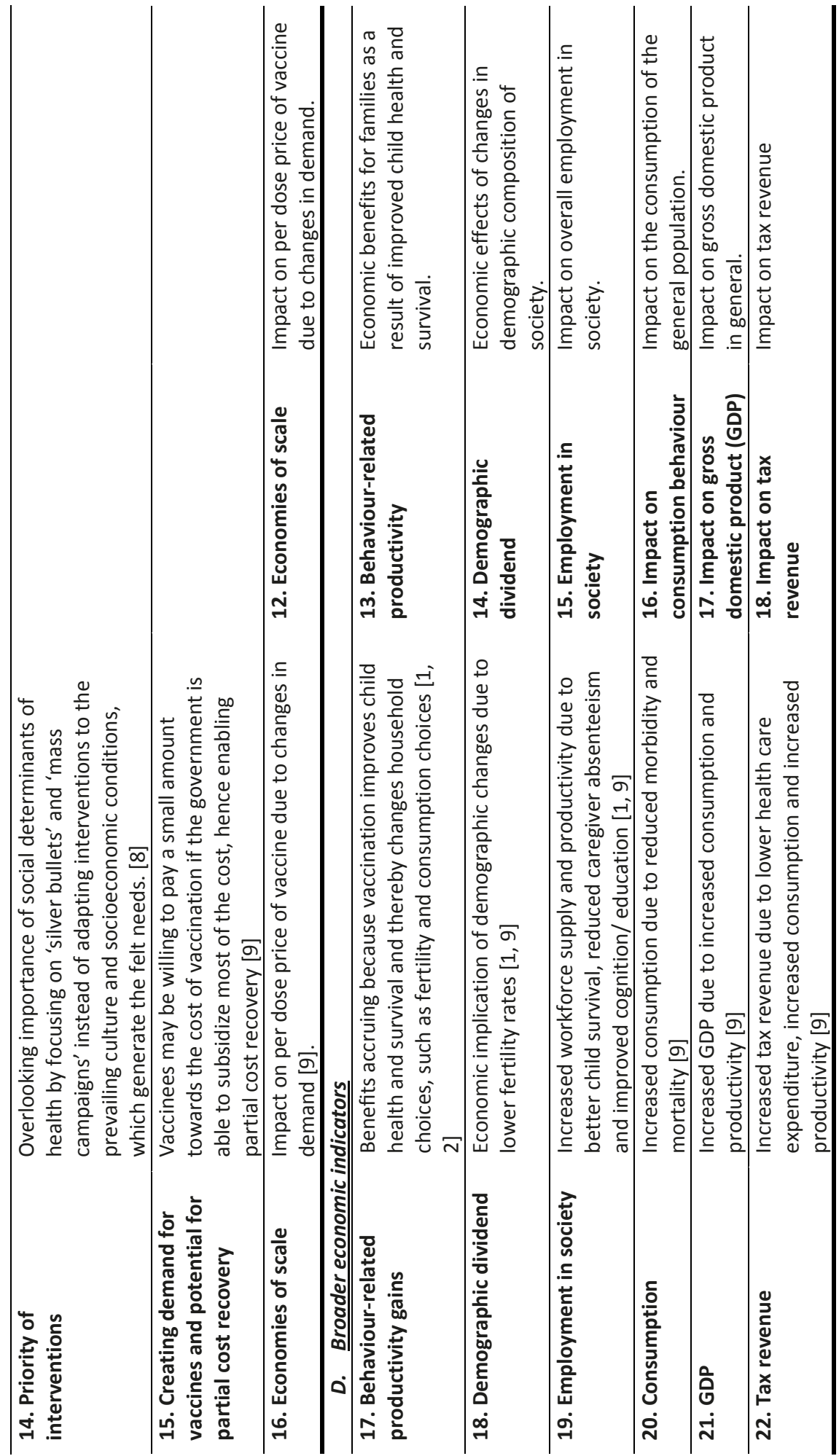




\section{References Supplementary file 1}

1. Ozawa, S., et al., Cost-effectiveness and economic benefits of vaccines in low-and middle-income countries: A systematic review. Vaccine, 2012: p. 96-108.

2. Bärnighausen, T., et al., Accounting for the full benefits of childhood vaccination in South Africa. South African Medical Journal, 2008. 98(11): p. 842-.

3. Dickson, R., et al., Effects of treatment for intestinal helminth infection on growth and cognitive performance in children: systematic review of randomised trials. BMJ, 2000. 320(7251): p. 16971701.

4. Sakti, H., et al., Evidence for an association between hookworm infection and cognitive function in Indonesian school children. Tropical Medicine \& International Health, 1999. 4(5): p. 322-334.

5. Beutels, P., N. Thiry, and P. Van Damme, Convincing or confusing?: Economic evaluations of childhood pneumococcal conjugate vaccination: a review (2002-2006). Vaccine, 2007. 25(8): p. 13551367.

6. World Health Organization. Equity. 2014 [cited 2014 10th January]; Available from: http://www.who.int/healthsystems/topics/equity/en/.

7. Shearley, A.E., The societal value of vaccination in developing countries. Vaccine, 1999. 17: p. S109S112.

8. Banerji, D., Serious crisis in the practice of International health by the World Health Organization: The Commission on Social Determinants of Health. International Journal of Health Services, 2006. 36(4): p. 637-650.

9. Jit, M., et al., The broader economic impact of vacination: reviewing and appraising the strength of evidence. BMC Medicine, 2015(13): p. 209. 


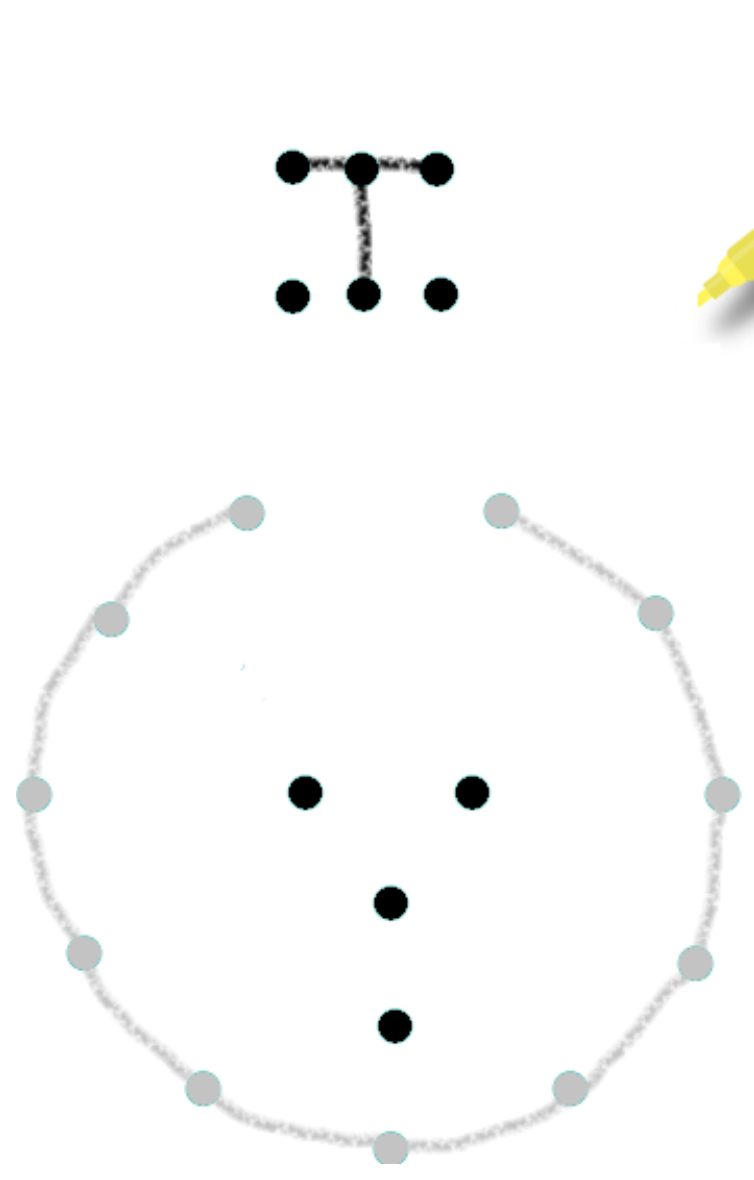


\section{CHAPTER 5}

\section{Evidence-informed vaccine decision making: The introduction of Human Papilloma Virus (HPV) vaccination in the Netherlands}

Submitted as:

Van der Putten IM, Paulus ATG, Hiligsmann, M, Hutubessy RCW, and Evers SMAA. 2018.

Evidence-informed vaccine decision making: The introduction of Human Papilloma Virus (HPV) vaccination in the Netherlands. 


\section{Abstract}

Little is known about the role of (economic) information or evidence in the different stages of the decision-making process on vaccine introduction. By conducting a document analysis on the public decision-making process of introducing HPV vaccine into the national vaccination programme (NVP) in the Netherlands, we aim to gain insight into which information plays a role during the introduction of a vaccination programme.

A document analysis was performed on the public decision-making process regarding the introduction of HPV vaccine into the NVP in the Netherlands. Information used or asked for by various stakeholders during different stages of the policy-making process was identified. In total, 42 documents were found, analyzed and synthesized, for the period between August 2006 and September 2009. Documents were analyzed using directed content analysis based on eight broad categories of criteria used in decisionmaking frameworks for introducing a vaccine.

Our analysis demonstrates that a wide variety of stakeholders is involved in the process. Financial or economic issues were stipulated in $64.3 \%$ of the documents and information on vaccine characteristics were discussed in 59.5\%. Economic information from economic evaluations was discussed most (47.6\%). Based on our analysis, it can be concluded that economic information, in particular information from economic evaluations, played an important role in the decision-making process regarding the introduction of HPV-vaccination. 


\section{Introduction}

Providing vaccination included in the expanded programme of immunization to the general public is one of the cornerstones of public health systems [1]. Vaccination schedules are mostly organized through national vaccination programmes (NVP) [2]. In countries with an NVP, generally the Ministry of Health, together with the parliament, decides which vaccines should be included in the country-specific vaccine schedules based on the evidence provided by National Immunization Technical Advisory groups (NITAGS) (if available), or other groups of experts [3]. Not all countries have included the same vaccines in their national vaccination schedules due to differences in the decision-making process, based on cultural differences, the socio-economic context, the health systems context, epidemiological profiles, and funding mechanisms employed [2]. In addition, due to the rise of expensive vaccines, several initiatives have been initiated to make the process of introducing a vaccine more evidence-informed [4$6]$.

In the literature the use of information or evidence in decision making and/or policymaking is often researched [7-9]. Some authors talk about evidence-based decision making, in which evidence is a product of research and is seen as facts that can be used as a base for decision making $[8,10]$. Others argue that decisions have meaning only if evidence is placed in the political and practical context of policymaking. Therefore they suggest using the term 'evidence-informed policymaking', defined as 'the use of different types of information in a variety of forms and from a variety of sources, reflective of, and responsive to the policy and practice context' [7]. Evidence can be the result of different types of research, and includes knowledge and information such as the results of consultation processes with networks/groups, discussions on internet, published documents/reports, the expressed ideas and interests of individuals, groups and networks, information derived from the political context, economic information such as the implications for financing and resourcing, economic evaluations and opportunity costs [7, 11]. Information is defined as "data that has meaning". During the $65^{\text {th }}$ World Health Assembly in 2012, the importance of evidence-based vaccine decision making was stipulated by endorsing the Global Vaccine Action Plan (GVAP) [12]. This plan [13] states that "National legislation, policies and resource allocation decisions should be informed by credible and current evidence regarding the direct and indirect impact of immunization." The importance of using economic information in decision making was specifically pinpointed during the $67^{\text {th }}$ World Health Assembly in 2017 , by putting it on the agenda of member states.

There is a need for more research exploring when and how often such information is used in the decision-making process and by which stakeholders [14]. Many articles 
discussed the implementation of the HPV vaccination in countries in general $[15,16]$ or barriers to and facilitators for the uptake of the vaccine [17]. To our knowledge only two studies researched the use of evidence-informed decision making on the introduction of vaccines in the Netherlands and France; these were studies on the annual decision-making process regarding vaccination for seasonal influenza. [18, 19]. The findings of the studies suggest that NITAGs played a central role in the decisionmaking process [19] and used clinical/epidemiological studies and, increasingly, economic models as information, although the overall quality of evidence was regarded as poor [20]. However, the decision-making process regarding influenza vaccines is a repeated process for a new version of a vaccine that is provided outside the NVP [19]. In this research we therefore aim to investigate when different types of information was used or asked for by stakeholders to support their decision-making process. By conducting a document analysis on the public decision-making process of HPV vaccine in the NVP in the Netherlands, we aim to gain insight into which information plays a role in the public funding of introducing a vaccine.

The decision-making process around the decision to introduce HPV vaccination was selected for several reasons. First, it is an example of a vaccine that prevents cancer in the long term, making it difficult to evaluate the effectiveness of the vaccine to determine a cause and effect relationship. Most studies available in 2006 to 2009 related the effectiveness of the vaccine to HPV infection and not to overcoming cervical cancer, although the rate of HPV infection is regarded as a good proxy [21, 22]. Second, prior to its introduction, the HPV vaccine was discussed extensively in the public domain and media, in comparison with the discussion around other vaccines when they were being considered, making it an excellent case study for investigating in detail the use of information in the decision-making process. Last, the government is currently planning to assess whether the HPV vaccination programme should be expanded to offer the gender-neutral vaccination. For these reasons, there was a need for rigorous scientific evidence that would support decision-making regarding the introduction of the vaccine [23].

The objective of this research was (1) to map how the decision-making process on the introduction of the HPV vaccine in the Netherlands took place and identify which stakeholders were involved (2) to identify what type of information was used during the decision-making process by the different stakeholders and (3) to identify to what extent economic information did play a role in this decision-making process. 


\section{Methods}

A case study design was used to investigate retrospectively the decision-making process of the introduction of HPV vaccination in the Netherlands [24].

\section{Data selection}

To analyse the case we conducted a document analysis to systematically review publicly available documents from August 2006, when the first questions about HPV vaccination were posted in parliament, until September 2009 , when the vaccine was officially introduced and became available to the general public. Data was collected from the database of official announcements, "Officiele bekendmakingen", of the Dutch government [25], using the key words HPV and vaccination. All documents published by the government, including the parliament records of the House of Representatives and the senate, can be found in this database [25].

A document analysis was performed to investigate the decision-making process surrounding the vaccine that took place in 2006-2009. Documents are the most effective means of gathering data and information as events can no longer be observed and informants are likely to have forgotten details. Parliament records are the main source of our analysis as these are the official minutes (edited verbatim reports), letters and reports of the process itself, and contain the most accurate information on the events that occurred.

In total 70 documents of parliament records were scanned on the basis of title. Documents that did not discuss the decision-making process on HPV vaccination (24) were deleted, as were those which did not provide new information (11). After these deletions, 35 documents remained. In the parliament records references were made to 7 additional documents of the CVZ and National Health Council. As these organizations play a fundamental role in the decision-making process, these documents were added, making a total of 42 documents in our study pool.

\section{Data analysis}

To provide insight into the decision-making process of introducing HPV vaccine in the Netherlands, a timeline from 2006 to 2009 was developed. Events are included in the timeline if a specific event was mentioned in the documents or the document itself represented a specific event. Nvivo 9.2 software [26] was used to indicate per document the date the document was published, the phase in the decision-making process (Prioritization; Development; Implementation), the kind of stakeholder involved (Parliament; Ministry of Health; National Health Council; CVZ), and the position of the document on implementing the HPV vaccine (Positive; neutral; 
negative). Furthermore, the stakeholders mentioned and documents cited in the documents were described per document. Based on these three sources, a table was made which provides for every event the date, a short description of the event, the stakeholders involved and the decision phase (See supplementary file 1). This was translated into a figure providing the most important events in the decision-making process of introducing the HPV vaccine in the Netherlands.

To analyse the information used during the decision-making process of introducing the HPV vaccine in the Netherlands, all selected documents were uploaded to Nvivo 9.2 and analysed by coding the text. Direct content analysis was used for this process; the framework of Burchett was adapted and operationalised per code [27]. This framework gives an overview of information used during the decision-making process regarding the introduction of a vaccine. In total, nine categories are identified in this classification scheme, ranging from financial and economic issues to vaccine characteristics. As the decision-making process itself is one of the categories, this was removed from our analysis, leaving eight categories used.

The role of economic information was researched by including equity and the costs of alternative interventions in the financial and economic issues. The criterion financial and economic issues included economic evaluation, incremental costs, funding sources, the vaccine price and financial sustainability. To make sure no information was missed we included 'other economic issues' as an extra category.

To pilot our framework, five preselected documents (based on dates) were hand coded by two researchers (IvdP \& AP) to see if there were differences in interpretations of the codes. Based on the differences in interpretation, the overall structure of coding did not have to be altered. The other documents were further coded by (IvdP). In case of doubt, classification choices were discussed by the team. Eventually all codes were also checked separately per code to make sure the same themes are covered per code. After that code matrices were made using the explore function of Nvivo categorizing the documents in policy phases and stakeholder categories.

\section{Vaccine decision making in the Netherlands}

Childhood vaccination is traditionally provided at no charge through the National Vaccination Programme (NVP) which is managed by the Dutch National Institute for Public Health and the Environment (RIVM) [16]. The RIVM works together with 51 youth health services (JGZ) and the service for vaccine provision and prevention programmes (DVP) to provide the vaccines to the Dutch population [17]. The total exploitation costs were $€ 83.5$ million in 2016 [17]. The Dutch NVP was established in 1957 and provides vaccines against 12 antigens including Diphtheria, Pertussis, (whooping cough), Tetanus, Polio, Haemophilus influenzae type b, Pneumococcal 
disease, Hepatitis B, Mumps, Measles, Rubella (German measles), Meningococcal disease and HPV [15].

Vaccines can be $100 \%$ reimbursed through the basic national insurance plan, for which the National Healthcare Institute ( $\mathrm{ZiNL}$ ) previously called the Health Care Insurance board (CVZ,) provides advice to the Minister of Health. The decision to include a new vaccine in the NVP is made by the Ministry of Health with input from National Health Council $[16,19]$. Both ZiNL and the National Health Council use specific lists of criteria to evaluate the appropriateness of implementing a new vaccine [20]. Economic information is part of these frameworks, although at ZiNL the pharmaceutical companies are responsible for providing the economic evaluations, while the National Health Council uses independent researchers to provide the necessary economic analysis [20]. Parliament is also informed on the steps taken and provides input and communicates questions.

\section{Results}

\section{Stakeholders involved}

During the decision-making process regarding the introduction of HPV vaccination, different stakeholders were involved, with each playing a different role. In the prioritization phase, the media and members of parliament, and also the RIVM and the National Health Council played important roles in reviewing information on HPV vaccines available on the market and in getting the introduction of the HPV vaccine on the agenda. During the development phase, the different advisory committees, together with the Ministry of Health, played a central role. Furthermore, the members of parliament and pharmaceutical companies were trying to influence the process from the sideline. In the implementation phase, the RIVM and JGZ took over, from the Ministry of Health, the role of implementing the HPV vaccine. During the implementation period the parliament was still discussing the implications of the decisions made and the progress being made by various institutions, such as the appropriate ways to inform girls and their parents and the independence of the National Health Council.

\section{The decision-making process}

In describing the decision-making process in the Netherlands regarding the uptake of new vaccines it is useful to distinguish three important phases: the prioritization phase, i.e. from august 2006 to March 2007; the development phase, i.e. from March 2007 to July 2008, and the implementation phase, i.e from July to 2008 to August 2009. A timeline of the most important events can be found in Figure 1, and a full overview of events can be found in Supplementary file 1. 


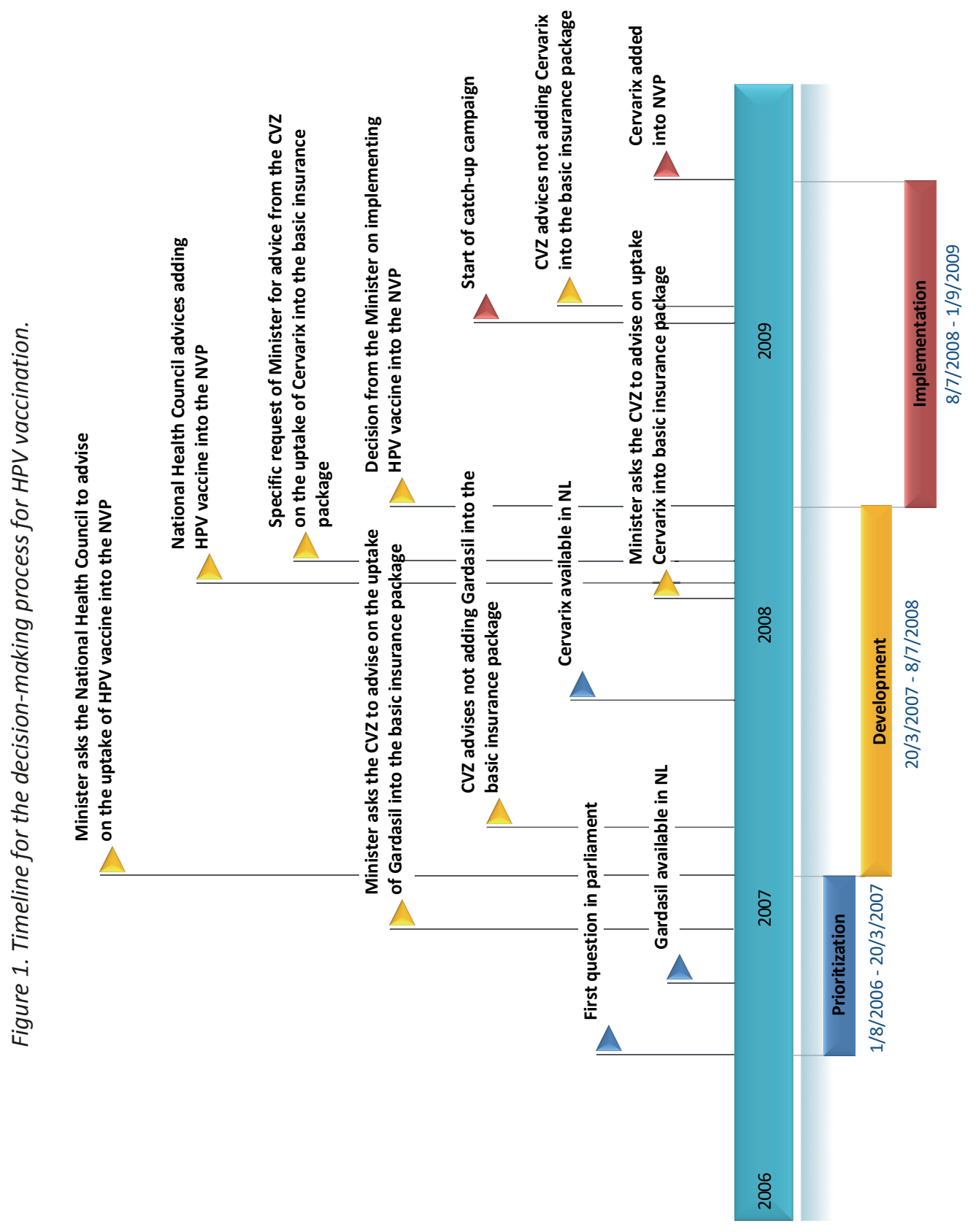


The prioritization phase of the decision-making process for providing HPV vaccination to the Dutch population started when the Labour Party asked questions regarding the usefulness of the vaccine for the Dutch population. These questions were based on a news article that reported the approval of Gardasil (Sanofi Pasteur MSD) for the European Market [28]. The advice was put on the work agenda of the National Health Council for 2007, although an official request for the recommendation was only sent on the $20^{\text {th }}$ of March 2007, after a reminder by the Dutch People's Party for Freedom and Democracy. This delay was due in large part to the fact that the government fell on the $22^{\text {nd }}$ of November and a new government wasn't formed until the $22^{\text {nd }}$ of February, then with a new Minister of Health. Before this the former Minister of Health had sent, on the $10^{\text {th }}$ of January 2007, a request to the CVZ to ask if the uptake of Gardasil in the basic insurance package was advisable. A spurt of new questions regarding the introduction of the HPV vaccination started 8 December 2007 after a second HPV vaccine, Cervarix (from GlaxoSmithKline), was added to the Dutch market, leading to second request from the Minister of Health to the CVZ, for advice on the uptake of Cervarix in the basic insurance package.

The development phase stretches roughly from the moment the official request was given to the National Health Council until the official decision was made to implement the vaccine in the NVP. During this time discussions in parliament were mainly on the possible influence of lobbying by pharmaceutical companies; several attempts were made by the Labour Party to implement the vaccine in the NVP or in the basic insurance package before the official recommendation reports were finished. The official recommendations of the National Health Council were delayed several times. Eventually the advice of the National Health Council was delivered to the parliament on the $31^{\text {st }}$ of March 2008 advising the addition of the HPV vaccine to the schedule for girls of 12 years and doing a of catch up campaign for girls 13-16 years old. The CVZ advised for both vaccines separately that they not be included in the basic insurance package, as they thought the treatment was more eligible for the NVP and questions were asked about the strength of evidence delivered by the pharmaceutical companies.

After the decision on the $8^{\text {th }}$ of July 2008 by the Minister of Health, the implementation phase of the decision-making process for inclusion in NVP started. The planned implementation given in this decision was the first of September 2009, but the actual implementation was delayed by half a year due to the national vaccination campaign for the $\mathrm{N} 1 \mathrm{H} 1$ virus. After the decision was issued by the Ministry of Health, questions were asked regarding the decision as made by the Minister of Health. A parliamentary meeting was held to evaluate the decision-making process as members of parliament raised questions regarding the costs of the HPV vaccine, the marketing strategies of the pharmaceutical companies and the reliability of advice given by the National Health Council. Moreover, the choices made by RIVM and the public health institutes (GGDs) 
during the implementation of the HPV vaccine were questioned. For example, the information included in the information leaflets was considered incomplete and not comprehensive enough and establishing an IPod lottery for girls being vaccinated was considered unethical.

\section{Use of information}

In Table 1 an overview is given, for each phase and for each stakeholder, of how many documents mention certain categories by providing information or asking for information based on the categories provided by Burchett [14]. Overall it can be said that financial or economic issues (64.3\%) are discussed most, closely followed by vaccine characteristics $(59.5 \%)$. The importance of the health problem, vaccine characteristics and acceptability seem to be more important in the prioritization phase than in the other phases. In the prioritization stage the importance of the health problem was stipulated by using information on the burden of disease of cervical cancer in the Netherlands. For example, facts on prevalence or incidence, mortality rates and also the prognosis of the disease were discussed in parliament. The HPV vaccine was perceived to be important by various parties in parliament, with the Labour Party playing a leading role. Politicians asked for information on vaccine characteristics as was provided by both the Ministry of Health and the advisory bodies. The efficacy and effectiveness, followed by vaccine safety, was most discussed. Other characteristics, as for example the opportunities for cross protection against other HPV types, were discussed in the Health Council's report. Financial and economic issues, and consideration of alternative interventions were seen as almost equally important in the prioritization and development phases, although there were some differences in the details. In the prioritization phase, economic information was asked for and named as a prerequisite for implementing the HPV vaccine, and in the development phase the outcomes of economic evaluations studies were discussed. When looking at the differences in information used by the different stakeholders it can be seen that the documents of the National Health Council did not take into consideration any programmatic considerations, while CVZ did not take acceptability into account. All categories are discussed in parliamentary and ministerial documents, although some categories are mentioned in only one document from the ministry. The documents also reveal that the quality of evidence was a concern in the reports, although this was related more to the absence of data on the long-term consequences of HPV vaccinations and not to the studies in general. 


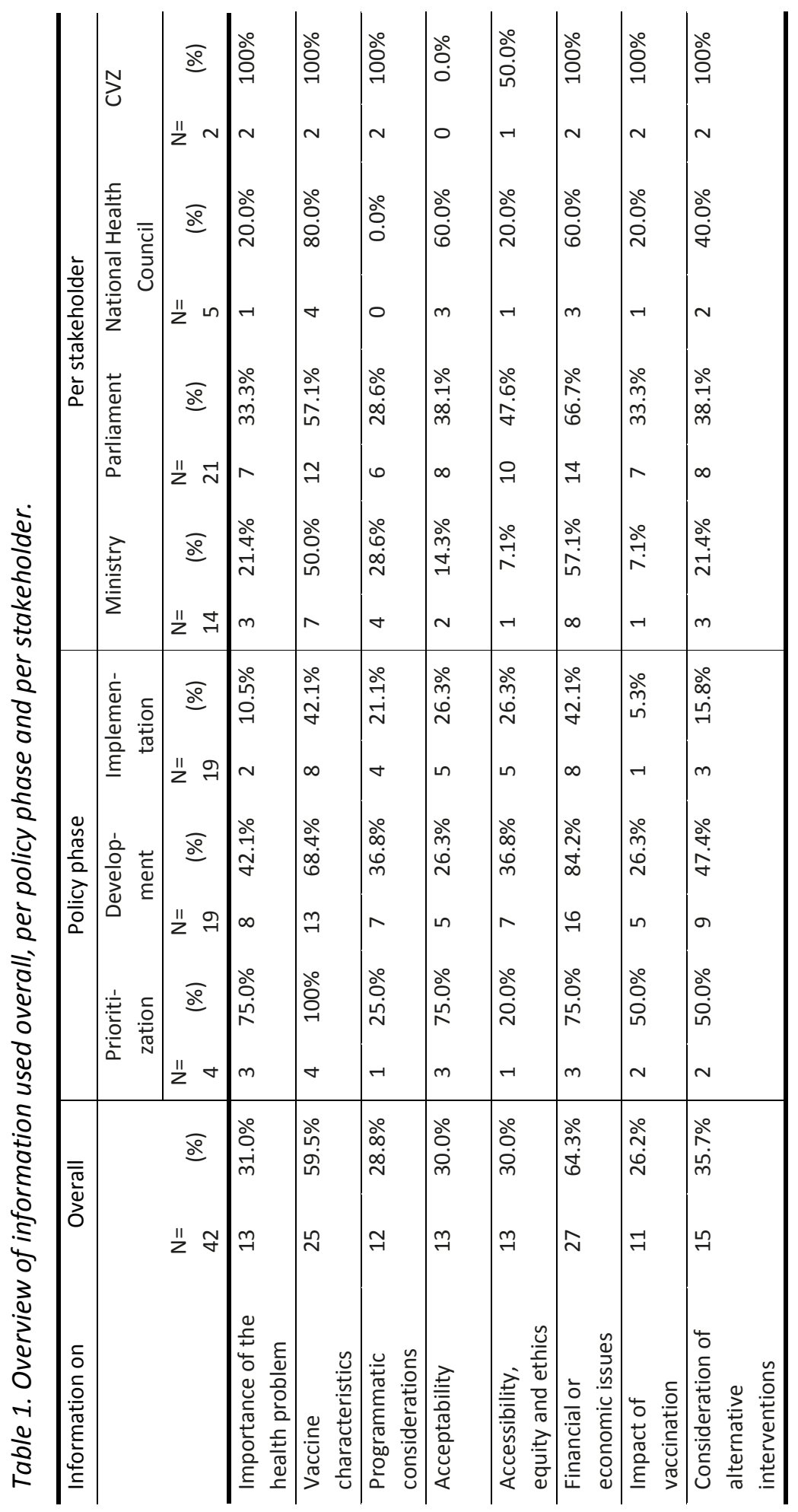




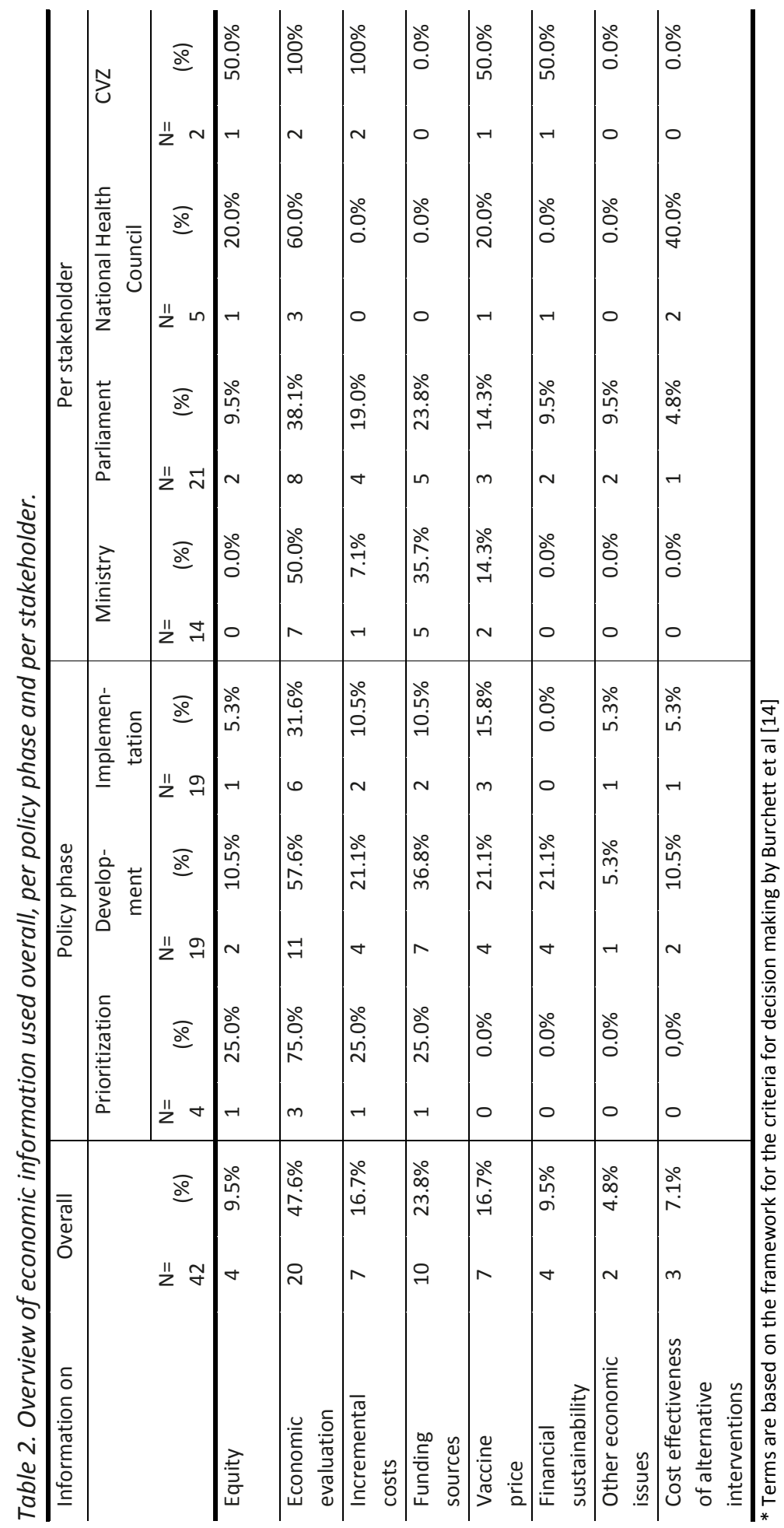




\section{Role of economic information}

In Table 2 an overview of the economic information (adjusted from Burchett et al. [14]) mentioned in different documents can be found. When looking at economic information, economic evaluations (47.6\%) are most referred to in the analysed documents, followed by funding sources $(23.8 \%)$ and the vaccine price and incremental costs (16.7\%). In total four economic modelling studies were performed, of which two were prepared by the pharmaceutical industry for the CVZ and 2 were prepared by independent research institutes for the National Health Council. Economic modelling studies of other countries were also taken into account by the National Health Council. The assumptions used in the different studies differed, leading to different conclusions. This resulted in questions in parliament regarding the interpretation of the results provided in the reports of the CVZ and the National Health Council. In the documents that cover funding sources, the amount of funding needed and the amount of funding to be covered by the Ministry of Health are discussed. The vaccine price was considered to be very expensive and a reason to not implement the vaccine. Almost no other economic issues were named in the documents. In one parliamentary document a policymaker asked why the Dutch are the first to not fund the HPV vaccine in the basic insurance package in Europe. The other parliamentary document raised awareness on the ethical problems of pharmaceutical companies sponsoring educational and promotional activities.

In the prioritization phase, the importance of economic outcomes was stipulated in almost all documents, naming the cost effectiveness of the HPV vaccine as a prerequisite for implementation. During the development phase, in addition to economic evaluations, attention was also given to funding sources, mostly in regard to organizing the funding needed for implementation of the vaccine. In general, not much attention was given to economic information in the implementation phase, although the positive results of the cost effectiveness studies if the vaccination price was not too high were used as an argument in defence of introducing the HPV vaccine.

Half of the documents provided by the Ministry of Health discussed economic evaluations. Equity, financial sustainability, other economic issues and the cost effectiveness of alternative interventions were not mentioned in these documents. The parliamentary documents covered each criterion at least one time. It is clear that not all categories were taken into account in the advice given by the National Health Council and the CVZ. 


\section{Discussion}

The objective of this research was (1) to map how the decision-making process on the introduction of the HPV vaccine in the Netherlands took place and identify which stakeholders were involved, (2) to identify what type of information was used during the decision-making process by the different stakeholders, and (3) to identify to what extent economic information played a role in this decision-making process. Looking back at the process, it can be said that the process of decision-making around introducing HPV vaccine in the Netherlands was complex. Many stakeholders were involved, with central roles for the Ministry of Health and parliament, with the National Health Council and the Health Insurance Board (CVZ) as advisory bodies. The media played a more indirect role by initiating many of the questions asked in parliament, through reporting on developments in Dutch society. Financial and economic issues (64.3\%), especially economic evaluations (47.6\%), played an important role, particularly in the prioritization (75.0\%) and development (57.9\%) phases of the policymaking process. Accordingly, it can be concluded that economic information, in particular the information resulting from economic evaluations, played an important role during the decision-making process for the introduction of HPV-vaccination.

Due to the difference in focus, the findings of this study are different from the findings of the qualitative study with the same framework conducted by Burchett et al. in 7 low and middle income countries [29]. In contradiction to their results, we found that economic evaluations play an important role in the decision-making process. Moreover, typically for low and middle income countries, the decision-making process is heavily influenced by overseas donor agencies such as the GAVI Alliance and the Bill and Melinda Gates Foundation. An analysis of the annual decision-making process for seasonal influenza vaccination in the Netherlands and France found that the evidence used was considered to be of low quality [18]. We also found that the quality of evidence was a concern in the reports, although it was related more to the absence of data on the long-term consequences of HPV vaccinations and not to the studies in general. In addition, Silva et al. found that the advisory process of the National Health Council could be more transparent; this was also debated in parliament regarding the report by the National Health Council on HPV vaccination [19].

This study adds to the body of literature [14-16] on the decision-making process of vaccine introduction by focusing on parliamentary documents, and performs a detailed analysis of the actual use of information and evidence in decision making. It gives insight into the information used in the different stages of the policymaking process by the different stakeholder groups. Furthermore, this study shows that the framework of Burchett can also be applied to high income countries. 
This study has four major limitations that should be discussed. First, we used only written documents for our analysis. Other data, such as interviews or observations, were not possible, making triangulation impossible [24]. As the decision-making process evolved from 2006 to 2009, recall bias would have made interviews an unreliable source; accordingly, documented information is the most reliable source for our analysis. Furthermore, it is important to stress that such documents should not be seen as containing all the information on the decision-making process, but as depicting a part of the events that have occurred. Second, the analysis of the documents was mostly done by one researcher. Although extra checks were performed to improve the analysis and all results were discussed by the research team, some bias may have resulted. Third, search engines covering media and published articles were not incorporated in this analysis. Media articles were used only indirectly in this study, as many of the sources mentioned in the parliamentary records are no longer available. However, articles that impacted the policymaking process were mentioned in the parliamentary records. Research articles were not included as they are already indirectly cited in the reports written by the National Health Council and the CVZ. Fourth, we interpreted 'evidence' in a broad sense, whereby the asking for information or mentioning one of the categories, or the citation of findings mentioned in media, reports or publications by politicians were also seen as evidence. We did this as these are all examples of the practical use of evidence in compliance with the broader definition of evidence-informed decision making. If we had used a stricter definition of evidence, the number of documents discussing evidence would have been lower.

Regarding the different needs per policy phase we recommend remembering the importance of acceptability in the decision-making process and add it as a criterion for the assessment performed by ZiNL. Furthermore, the different outcomes from the National Health Council and CVZ (now ZiNL) were confusing for the policymakers. Therefore it was wise that the National Health Council and ZIN started with revaluating nine vaccines together to explore eligibility for the NPV, the basic insurance package, or whether some vaccines should be made available in the private market in 2015 [21]. Currently advice has been published on three of the vaccines, for Pertussis, shingles, and Rota. Advice on vaccine for pneumococcal disease for the elderly and on HPV vaccine for both girls and boys is expected in 2017, while vaccines for Meningococcal disease, influenza (pregnant ladies) and Varicella still have to be discussed [21]. However, the establishment of one commission working for both organizations will be beneficial for the decision-making process. With regards to research, we would recommend using the Burchett framework as a basis for analysing the decision-making process on vaccine introduction in high income countries as well as in low and middle income countries. Moreover, we would recommend using media search tools such as Coosto and Lexis Nexis to search media, in addition to searching parliamentary records with the database of official announcements as we have done. 


\section{References}

1. PATH. The cornerstone of public health. Washington: PATH; 2015.

2. Arias D, O'Connell M, Cashin C, Bloom D, Saxenian H, Wilson P. Immunization Financing: A Resource Guide for Advocates, Policymakers, and Program Managers. Wachington D.C.: Results for Development, 2017.

3. Blau J, Sadr-Azodi N, Clementz M, Abeysinghe N, Cakmak N, Duclos P, et al. Indicators to assess National Immunization Technical Advisory Groups (NITAGs). Vaccine. 2013;31(23):2653-7.

4. Janusz $C B$, Jauregui $B$, Sinha $A$, Clark $A D$, Bolaños $B M$, Resch $S$, et al. Performing country-led economic evaluations to inform immunization policy: ProVac experiences in Latin America and the Caribbean. Value in Health Regional Issues. 2012;1(2):248-53.

5. Jauregui B, Sinha A, Clark AD, Bolanos BM, Resch S, Toscano CM, et al. Strengthening the technical capacity at country-level to make informed policy decisions on new vaccine introduction: Lessons learned by PAHO's ProVac Initiative. Vaccine. 2011;29(5):1099-106.

6. Senouci K, Blau J, Nyambat B, Faye PC, Gautier L, Da Silva A, et al. The Supporting Independent Immunization and Vaccine Advisory Committees (SIVAC) initiative: a country-driven, multi-partner program to support evidence-based decision making. Vaccine. 2010;28:A26-A30.

7. Bowen S, Zwi AB. Pathways to "evidence-informed" policy and practice: a framework for action. PLoS Med. 2005;2(7):e166.

8. Hanney SR, Gonzalez-Block MA. Evidence-informed health policy: are we beginning to get there at last? Health Res Policy Syst. 2009;7:30.

9. Lavis JN, Ross SE, Hurley JE, Hohenadel JM, Stoddart GL, Woodward CA, et al. Examining the role of health services research in public policymaking. The Milbank quarterly. 2002;80(1):125-54.

10. Hanney SR, Gonzalez-Block MA, Buxton MJ, Kogan M. The utilisation of health research in policymaking: concepts, examples and methods of assessment. Health Res Policy Syst. 2003;1(1):2.

11. Office; TC. Professional policy-making for the 21st century London. In: Office TC, editor. London1999.

12. Jauregui B, Janusz C, Felix G. 4.7 Evidence-based policy-making for national immunization programs. In: Family Gender and Life Course, editor. Washington D.C.: Pan American Health Organization; 2013.

13. Organization WH. Global Vaccine Action Plan 2011-2020. Global Vaccine Action Plan 2011-2020. 2013.

14. Burchett $\mathrm{H}$, Mounier-Jack S, Griffiths U, Mills A. National decision-making on adopting new vaccines: a systematic review. Health policy and planning. 2012;27(suppl 2):ii62-ii76.

15. Haas M, Ashton T, Blum K, Christiansen T, Conis E, Crivelli L, et al. Drugs, sex, money and power: an HPV vaccine case study. Health Policy. 2009;92(2-3):288-95. doi: 10.1016/j.healthpol.2009.05.002. Epub Jun 7.

16. Kane MA, Serrano B, de Sanjose S, Wittet S. Implementation of human papillomavirus immunization in the developing world. Vaccine. 2012;30(Suppl 5):F192-200. doi: 10.1016/j.vaccine.2012.06.075.

17. Ferrer HB, Trotter C, Hickman M, Audrey S. Barriers and facilitators to HPV vaccination of young women in high-income countries: a qualitative systematic review and evidence synthesis. BMC Public Health. 2014;14:700.(doi):10.1186/471-2458-14-700.

18. Silva ML, Paget WJ, Mosnier A, Buthion V, Cohen JM, Perrier L, et al. Development of Seasonal Influenza Vaccination Recommendations: Relevance and Influence of the Evidence on the DecisionMaking Process in France and the Netherlands. Value in health : the journal of the International Society for Pharmacoeconomics and Outcomes Research. 2016;19(5):670-9.

19. Silva ML, Perrier L, Paget JW, Mosnier A, Buthion V, Cohen JM, et al. Influenza vaccination policymaking processes in France and The Netherlands: Framework and determinants. Health Policy. 2016;120(3):293-305.

20. Silva ML, Perrier L, Paget J, Mosnier A, Buthion V, Cohen JM, et al. Information Used in the DecisionMaking Process Regarding Influenza Vaccination Policy: Perceptions of Stakeholders in France and the Netherlands. Value in health : the journal of the International Society for Pharmacoeconomics and Outcomes Research. 2014;17(7):A329. 
21. Munoz N, Castellsagué X, de González AB, Gissmann L. HPV in the etiology of human cancer. Vaccine. 2006;24:S1-S10.

22. Schiffman M, Castle PE, Jeronimo J, Rodriguez AC, Wacholder S. Human papillomavirus and cervical cancer. The Lancet. 2007;370(9590):890-907.

23. RIVM. Rijksvaccinatie programma: Geschiedenis. 2015. Available from: http://rijksvaccinatieprogramma.nl/Over_Rijksvaccinatieprogramma/Geschiedenis.

24. Yin RK. Case study research: Design and methods: Sage publications; 2013.

25. Officiele bekendmakingen [Internet]. Overheid.nl. 2016. Available from: https://zoek.officielebekendmakingen.nl/zoeken/parlementaire_documenten.

26. QSR. What is NVivo 2016. Available from: http://www.qsrinternational.com/what-is-nvivo.

27. Hsieh HF, Shannon SE. Three approaches to qualitative content analysis. Qualitative health research. 2005;15(9):1277-88.

28. Steenhorst R. Nog dit jaar vaccin cervixkanker. Telegraaf. 2006 29th of July 2006.

29. Burchett H, Mounier-Jack S, Griffiths U, Biellik R, Ongolo-Zogo P, Chavez E, et al. New vaccine adoption: qualitative study of national decision-making processes in seven low-and middle-income countries. Health policy and planning. 2012;27(suppl 2):ii5-ii16. 


\section{Supplementary file 1}

\begin{tabular}{|c|c|c|c|c|}
\hline$\#$ & Date & Event & Stakeholders involved & Phase \\
\hline \multicolumn{5}{|c|}{2006} \\
\hline 1 & May & $\begin{array}{l}\text { Orientation meeting on } \\
\text { HPV }\end{array}$ & $\begin{array}{l}\text { Minister of Health } \\
\text { National Health Council } \\
\text { RIVM }\end{array}$ & Prioritization \\
\hline 2 & 28 July & $\begin{array}{l}\text { Approval of Gardasil for the } \\
\text { European market }\end{array}$ & EMEA & Prioritization \\
\hline 3 & August & First question in parliament & $\begin{array}{l}\text { Minister of Health } \\
\text { Parliament }\end{array}$ & Prioritization \\
\hline 4 & 19 September & $\begin{array}{l}\text { Added to agenda of the } \\
\text { National Health Council for } \\
2007\end{array}$ & National Health Council & Prioritization \\
\hline 5 & November & $\begin{array}{l}\text { Gardasil available in the } \\
\text { Netherlands }\end{array}$ & CBG & Prioritization \\
\hline \multicolumn{5}{|c|}{2007} \\
\hline 6 & 10 January & $\begin{array}{l}\text { Request for } \\
\text { recommendation regarding } \\
\text { the uptake Gardasil in the } \\
\text { basic insurance package }\end{array}$ & $\begin{array}{l}\text { Minister of Health } \\
\text { CVZ }\end{array}$ & Prioritization \\
\hline 7 & 6 February & $\begin{array}{l}\text { Request for update on HPV } \\
\text { vaccine }\end{array}$ & $\begin{array}{l}\text { Minister of Health } \\
\text { Parliament }\end{array}$ & Prioritization \\
\hline 8 & 20 March & $\begin{array}{l}\text { Official request for } \\
\text { recommendation from the } \\
\text { National Health Council on } \\
\text { HPV vaccine in the national } \\
\text { vaccination programme }\end{array}$ & $\begin{array}{l}\text { Minister of Health } \\
\text { National Health Council }\end{array}$ & Prioritization \\
\hline 9 & 2 April & $\begin{array}{l}\text { NVKP sues Sanofi for } \\
\text { inappropriate promotion of } \\
\text { HPV vaccine }\end{array}$ & $\begin{array}{l}\text { NVKP } \\
\text { Sanofi } \\
\text { Code commission CGR }\end{array}$ & Development \\
\hline 10 & 12 April & $\begin{array}{l}\text { Questions regarding } \\
\text { lobbying by pharmaceutical } \\
\text { companies on HPV vaccine }\end{array}$ & $\begin{array}{l}\text { Parliament } \\
\text { Minister of Health }\end{array}$ & Development \\
\hline 11 & 21 May & $\begin{array}{l}\text { Advise not adding HPV } \\
\text { vaccine to basic insurance } \\
\text { package }\end{array}$ & $\begin{array}{l}\text { CVZ } \\
\text { Ministry of Health }\end{array}$ & Development \\
\hline 12 & 29 June & $\begin{array}{l}\text { Proposal for transitional } \\
\text { arrangements for } \\
\text { implementing HPV vaccine } \\
\text { in basic insurance package } \\
\text { for women between 13-26 } \\
\text { years }\end{array}$ & $\begin{array}{l}\text { Parliament } \\
\text { Minister of Health }\end{array}$ & Development \\
\hline 13 & 2 July & $\begin{array}{l}\text { Minister declines proposal } \\
\text { of June } 29^{\text {th }}\end{array}$ & Minister of Health & Development \\
\hline
\end{tabular}




\begin{tabular}{|c|c|c|c|c|}
\hline 14 & 3 July & $\begin{array}{l}\text { Motion of Labour Party to } \\
\text { start vaccination and } \\
\text { reimbursement and start } \\
\text { taking action before } 1^{\text {st }} \text { of } \\
\text { September }\end{array}$ & $\begin{array}{l}\text { Parliament } \\
\text { Minister of Health }\end{array}$ & Development \\
\hline 15 & 29 July & $\begin{array}{l}\text { Complaint of NVKP on } \\
\text { inappropriate promotion of } \\
\text { HPV vaccine is judged to be } \\
\text { ungrounded }\end{array}$ & $\begin{array}{l}\text { NVKP } \\
\text { Sanofi } \\
\text { Code commission CGR }\end{array}$ & Development \\
\hline 16 & 24 September & $\begin{array}{l}\text { Announcement that } \\
\text { decision regarding } \\
\text { introduction of the HPV } \\
\text { vaccine will be made in } \\
2008 \text {; the report of the } \\
\text { National Health Council is } \\
\text { expected at the end of } \\
2007\end{array}$ & Minister of Health & Development \\
\hline 17 & 30 September & $\begin{array}{l}\text { HPV vaccine not included in } \\
\text { the budget Ministry of } \\
\text { Health } 2008\end{array}$ & Ministry of Health & Development \\
\hline 18 & 31 September & $\begin{array}{l}\text { Amendment to include } \\
\text { expenses for early } \\
\text { introduction of HPV vaccine } \\
\text { in the budget of the } \\
\text { Ministry of Health } 2008\end{array}$ & Parliament & Development \\
\hline 19 & 1 November & $\begin{array}{l}\text { Cervarix available in the } \\
\text { Netherlands }\end{array}$ & CBG & Prioritization \\
\hline 20 & 8 December & $\begin{array}{l}\text { Question addressed to } \\
\text { minister regarding } \\
\text { introduction of HPV vaccine } \\
\text { in the Netherlands }\end{array}$ & $\begin{array}{l}\text { Parliament } \\
\text { Minister of Health }\end{array}$ & Prioritization \\
\hline 21 & $\begin{array}{l}\text { 13-14 } \\
\text { December }\end{array}$ & $\begin{array}{l}\text { Discussion Ministry of } \\
\text { Health budget - no extra } \\
\text { budget for early } \\
\text { implementation of HPV } \\
\text { vaccine }\end{array}$ & $\begin{array}{l}\text { Parliament } \\
\text { Minister of Health } \\
\text { Minister of Finance }\end{array}$ & Development \\
\hline \multicolumn{5}{|c|}{2008} \\
\hline 22 & 11 March & $\begin{array}{l}\text { Request for } \\
\text { recommendation by CVZ on } \\
\text { the uptake Cervarix in basic } \\
\text { insurance package }\end{array}$ & $\begin{array}{l}\text { CVZ } \\
\text { Ministry of Health }\end{array}$ & Development \\
\hline 23 & 31 March & $\begin{array}{l}\text { Advice of National Health } \\
\text { Council on adding HPV } \\
\text { vaccine to NVP }\end{array}$ & National Health Council & Development \\
\hline 24 & 15 April & Meeting of parliamentary & Parliament & Development \\
\hline
\end{tabular}




\begin{tabular}{|c|c|c|c|c|}
\hline & & $\begin{array}{l}\text { committee and minister on } \\
\text { the benefits of introducing } \\
\text { the HPV vaccine }\end{array}$ & Minister of Health & \\
\hline 25 & 28 April & $\begin{array}{l}\text { Request for } \\
\text { recommendation by CVZ on } \\
\text { uptake Cervarix in basic } \\
\text { insurance package for } \\
\text { women from } 17 \text { to } 25 \\
\text { years. }\end{array}$ & $\begin{array}{l}\text { CVZ } \\
\text { Ministry of Health }\end{array}$ & Development \\
\hline 26 & 8 July & $\begin{array}{l}\text { Decision to implement HPV } \\
\text { vaccination in the } \\
\text { Netherlands. Start of catch- } \\
\text { up campaign for girls } 13-16 \\
\text { years in beginning of } 2009 \text {. } \\
\text { Implementation of regular } \\
\text { programme for girls of } 12 \\
\text { years from September } \\
2009 \text {. }\end{array}$ & Minister of Health & Development \\
\hline 27 & 11 July & $\begin{array}{l}\text { Questions to minister } \\
\text { regarding the decision to } \\
\text { implement HPV vaccine in } \\
\text { the Netherlands }\end{array}$ & $\begin{array}{l}\text { Parliament } \\
\text { Minister of Health }\end{array}$ & Implementation \\
\hline 28 & 16 September & $\begin{array}{l}\text { HPV vaccine included in the } \\
\text { national budget }\end{array}$ & Cabinet & Implementation \\
\hline 29 & ND October & $\begin{array}{l}\text { Visits to GSK and Sanofi to } \\
\text { evaluate marketing } \\
\text { strategies for HPV vaccine }\end{array}$ & Health inspectorate & Implementation \\
\hline 30 & 28 October & $\begin{array}{l}\text { Questions based on article } \\
\text { published in NTG about } \\
\text { costs HPV vaccine }\end{array}$ & $\begin{array}{l}\text { Parliament } \\
\text { Ministry of health }\end{array}$ & Implementation \\
\hline 31 & 31 October & $\begin{array}{l}\text { Questions on reliability of } \\
\text { advice given by the } \\
\text { National Health Council }\end{array}$ & $\begin{array}{l}\text { Parliament } \\
\text { Ministry of health }\end{array}$ & Implementation \\
\hline 32 & 17 November & $\begin{array}{l}\text { Sanofi appeals decision for } \\
\text { GSK to supply HPV vaccine, } \\
\text { but appeal is denied }\end{array}$ & $\begin{array}{l}\text { Pharmaceutical } \\
\text { companies } \\
\text { Government } \\
\text { Court }\end{array}$ & Implementation \\
\hline 33 & 26 November & $\begin{array}{l}\text { Contract with GSK to supply } \\
\text { HPV vaccine }\end{array}$ & $\begin{array}{l}\text { Pharmaceutical } \\
\text { companies } \\
\text { Minister of health }\end{array}$ & Implementation \\
\hline 34 & 9 December & $\begin{array}{l}\text { Meeting of parliamentary } \\
\text { committee to evaluate } \\
\text { decision-making process }\end{array}$ & $\begin{array}{l}\text { Parliament } \\
\text { Minister of Health }\end{array}$ & Implementation \\
\hline 35 & 17 December & $\begin{array}{l}\text { Update on marketing } \\
\text { strategies of }\end{array}$ & $\begin{array}{l}\text { Minister of Health } \\
\text { Parliament }\end{array}$ & Implementation \\
\hline
\end{tabular}


CHAPTER 5

\begin{tabular}{|c|c|c|c|c|}
\hline & & $\begin{array}{l}\text { pharmaceutical companies } \\
\text { with regard to HPV vaccine }\end{array}$ & Health inspectorate & \\
\hline 36 & 18 December & $\begin{array}{l}\text { Four motions based on } \\
\text { meeting } 9 \text { December }\end{array}$ & Parliament & Implementation \\
\hline \multicolumn{5}{|c|}{2009} \\
\hline 37 & 19 February & $\begin{array}{l}\text { Questions on the JGZ I-pod } \\
\text { lottery to improve } \\
\text { vaccination coverage in } \\
\text { catch-up campaign }\end{array}$ & $\begin{array}{l}\text { Youth health services } \\
\text { (JGZ) } \\
\text { Minister of Health } \\
\text { Parliament }\end{array}$ & Implementation \\
\hline 38 & 23 February & $\begin{array}{l}\text { More questions on the JGZ } \\
\text { I-pod lottery to improve } \\
\text { coverage in catch-up } \\
\text { campaign }\end{array}$ & $\begin{array}{l}\text { Minister of Health } \\
\text { Parliament }\end{array}$ & Implementation \\
\hline 39 & 11 March & $\begin{array}{l}\text { Questions on the } \\
\text { usefulness of the HPV } \\
\text { vaccine based on } \\
\text { publications by Erasmus MC } \\
\text { and NTG }\end{array}$ & $\begin{array}{l}\text { Minister of Health } \\
\text { Parliament }\end{array}$ & Implementation \\
\hline 40 & 12 March & $\begin{array}{l}\text { Questions choice made by } \\
\text { RIVM in vaccination } \\
\text { campaign }\end{array}$ & $\begin{array}{l}\text { Minister of Health } \\
\text { Parliament }\end{array}$ & Implementation \\
\hline 41 & 23 March & $\begin{array}{l}\text { Advise not adding Cervarix } \\
\text { vaccine to basic insurance } \\
\text { package for women from } \\
17 \text { to } 25 \text { years }\end{array}$ & $\begin{array}{l}\text { CVZ } \\
\text { Ministry of Health }\end{array}$ & Development \\
\hline 42 & 24 March & $\begin{array}{l}\text { Debate on influence of anti- } \\
\text { vaccine lobby on the uptake } \\
\text { of HPV vaccine in the catch- } \\
\text { up campaign }\end{array}$ & $\begin{array}{l}\text { Minister of Health } \\
\text { Parliament }\end{array}$ & Implementation \\
\hline 43 & 20 May & $\begin{array}{l}\text { Annual report of the } \\
\text { Ministry of Health } \\
\text { announcing the legislative } \\
\text { decision to implement the } \\
\text { HPV vaccination }\end{array}$ & Ministry of Health & Implementation \\
\hline 44 & 28 May & $\begin{array}{l}\text { Questions regarding } \\
\text { physicians declining to } \\
\text { vaccinate girls }\end{array}$ & Parliament & Implementation \\
\hline 45 & 29 July & $\begin{array}{l}\text { Implementation of HPV } \\
\text { vaccine for } 12 \text { year old girls } \\
\text { delayed by half a year } \\
\text { because of vaccination for } \\
\text { N1H1 (Mexican flu) }\end{array}$ & RIVM & Implementation \\
\hline
\end{tabular}




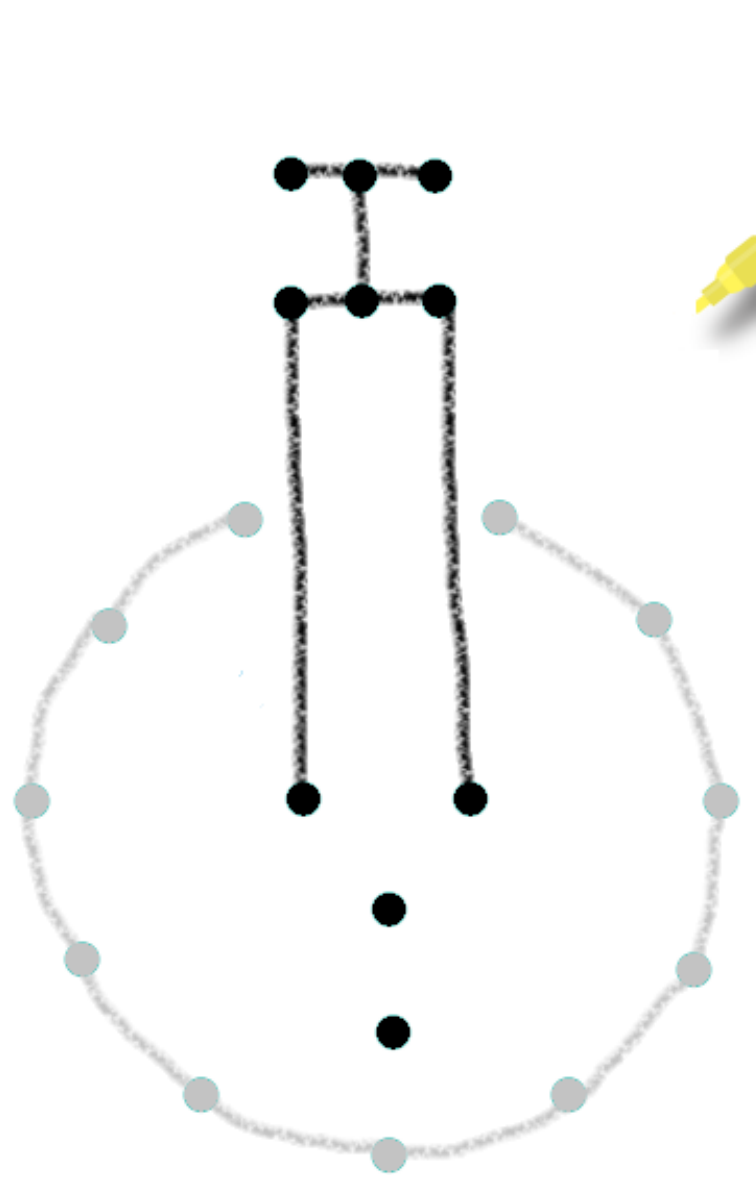


CHAPTER 6

General Discussion 
The need for evidence-informed decision-making in healthcare is becoming increasingly stronger, as seen in the decision-making process on the introduction of vaccines. As advances in technology contribute to the rising costs of healthcare, and new developments in healthcare interventions compete for resources, the role of economic information is gaining importance. With regard to the introduction of vaccines, currently most economic information comes from economic evaluations that focus on the direct impact of immunization programmes within the healthcare sector and not on the programmes' impact on society as a whole (i.e. the societal perspective). Several authors have proposed methodologies to include broader economic impacts into economic evaluations in order to fully capture the costs and benefits of immunization programmes [1-9]. Nevertheless, the usefulness of taking these broader economic impacts into account for decision-making on the introduction of vaccines has received little attention so far.

Therefore, we formulated four objectives that have been addressed in this dissertation: 1) to determine how the broader perspective (i.e. the societal perspective) is applied in economic evaluations in general (Chapter 2), 2) to identify which economic impacts seem relevant towards aiding decision making for vaccine introduction (Chapters $\mathbf{3}$ and $4), 3$ ) based on stakeholders' perceptions, to determine the relative importance of the identified economic impacts (Chapters 3 and 4) and 4) to retrospectively analyze the role of information in vaccine decision making in a real life case (Chapter $\mathbf{5}$ ). This final chapter summarizes the main findings of this dissertation, discusses its strengths and weaknesses and presents implications for policymakers and researchers.

\section{Summary of main findings}

The first objective of this dissertation was to determine how the broader perspective (i.e. the societal perspective) is applied in economic evaluations in general. We conducted a literature review (Chapter 2 ) and concluded that there is a great variety in the way the societal perspective is conceptualized and addressed within economic evaluations. Often, authors assumed that a societal perspective was considered when productivity costs were included with healthcare costs in economic evaluations. Patient and family costs and costs in other sectors were reported in only a few studies. In total, ten articles on infectious diseases were identified; all of these included intervention and healthcare costs; six of them also included patient and family cost and/or productivity costs. Only two studies included costs in other sectors; both of these studies included household and informal care costs and one study included educational costs. Therefore, it can be argued that taking the broader perspective into account is still not common in economic evaluations. 
To meet the second objective (i.e. to identify which narrow and broader economic impacts are relevant in aiding decision-making on the introduction of a vaccine), a theoretical and comprehensive framework of relevant narrow and broader economic impacts of vaccines was developed. Two studies were completed, of which Chapter 3 can be seen as a preliminary study to the study described in Chapter 4. In Chapter 3, sixteen economic impacts divided over five different domains, that could be relevant for vaccine introduction, were identified and discussed with different stakeholders. Based on these findings, new published research $[2,3,9]$ and seven interviews with experts, 23 economic impacts were identified (Chapter 4). These were divided in four domains. The first domain consisted of three impacts that can be seen as 'healthrelated benefits to vaccinated individuals'. In the second domain three 'short-term and long-term productivity gains' were found. For the third domain eleven 'community or health systems externalities' were identified and for the last domain six 'broader economic indicators' (See Chapter 4 Supplementary file 1 for full overview).

The third objective was to determine, based on stakeholders' perceptions, the relative importance of the identified (broader) economic impacts. In Chapter 3, preliminary research showed that the broader economic impact of vaccines was regarded as being equally important as narrow economic impacts. However, in Chapter 4, stakeholders considered health-related benefits, which can be seen as narrow, to be most important and broader economic indicators were seen as less important, with the exception of behavior-related productivity. Furthermore, we found a positive relationship between the data availability in countries and the relative importance score of the economic impacts. This suggests that data on the broader economic impact of vaccines is currently lacking and is also seen as not as important, while information on narrow economic impacts is more common and is also regarded as important. This can have several meanings. On the one hand, it could mean that, as information on the broader economic impact of vaccines is not available, it is not seen as very helpful for policymaking. On the other hand, respondents may not be aware of the possibilities of these impacts and, therefore, they put less value on these types of economic impacts.

The last objective of this dissertation was to retrospectively analyze the role of information in vaccine decision-making by conducting a real-life case study on the introduction of HPV vaccination into the Dutch national vaccination programme. Based on our findings in Chapter $\mathbf{5}$, we can conclude that economic information plays an important role in the decision-making process. However, decisions are mostly based on information that can be seen as narrow. Outcomes related to the broader economic impact of vaccines are hardly discussed, although equity is discussed, to some degree.

Overall it can be concluded that there is a discrepancy between the theoretical arguments to include the broader economic impact of vaccines in decision making and 
research, and the preferences and actual use of these impacts. In our research we found 23 possible economic impacts in four domains. Of these economic impacts, stakeholders preferred the health-related benefits to vaccinated individuals' over the broader economic impacts, with the exception of behaviour-related productivity gains. Our case study further suggests that, with the exception of equity, outcomes related to the broader economic impact of vaccines were hardly discussed during the decisionmaking process on introducing HPV vaccination in the national vaccination programme in the Netherlands.

\section{Strengths and limitations of this dissertation}

In this dissertation, we used different types of methods to find answers to our research objectives in a relatively new field of science. All of the studies we used in our research were explorative and/or descriptive. Chapter 3 included a mixed method approach, consisting of interviews and a survey. The combination of both helped us to get a better overview of the preferences of the different stakeholder groups active in making decisions on the use of vaccines. Complementing the findings of the survey with the results of the interviews gave us valuable new perspectives for the further development of this dissertation. In Chapter 4, seven experts were interviewed to develop a final overview of the different narrow and broader economic impacts. This added rigor to the theoretical framework, which we used as a basis for the rating scale and for the best/worst scaling survey that 26 respondents filled out as a follow-up to the study presented in Chapter 3. Although small, the sample size of the best-worst scaling survey was not less than twenty, which is sufficient for obtaining stable results for the relative importance scores presented in Chapter 4 [10]. Moreover, both the rating scale and the best/worst scaling gave similar results, which validates both methods. In Chapter 5, we conducted a single case study. This allowed us to obtain detailed insights into the types of information used in different phases of the decision-making process. As this was one of the first studies which conducted such a detailed analysis, further case studies are necessary, so that our outcomes can be compared with those of other countries.

Different methods have been used to study the preferences of stakeholder groups in this dissertation. In general, two types of preferences can be distinguished: stated preferences and revealed preferences $[11,12]$. With stated preferences, respondents fill out what they would do in a hypothetical situation; revealed preferences measure actual choices by looking back at records of decisions made [11, 12]. The strength of this dissertation is that we looked at both types of preferences. First, stated preferences were researched quantitatively and qualitatively by conducting two surveys, including interviews (Chapter $\mathbf{3}$ ), rating scales (Chapters 3 and 4 ) and best/worst scaling exercises (Chapter 4). Both methods (rating scales and best/worst 
scaling exercises) are shown to be retrieving similar results in Chapter 4, although the results found in Chapter 3 differ from Chapter 4. This can be explained by the different group of stakeholders questioned and the different time period. In Chapter $\mathbf{5}$ we looked at the revealed preferences of different stakeholder groups, although a different framework [13] was used than the one developed in Chapters 3 and 4.

Research on the broader economic impact of vaccines is still in development. The conceptual consideration of the broader economic impact of vaccination in addition of indirect population effects of vaccination has been advocated by Bloom et al since 2004 [8]. Based on this publication multiple studies have been done to develop this notion further $[1,4-6,14]$. The first meetings to discuss the studies and develop an overall framework with different stakeholder groups were initiated by the World Health Organization. Meetings were held in Canada (2011) and Switzerland (2012), followed by meetings in France, Australia (in 2014), Thailand (2014) and the United States (2016), during which the framework was discussed and developed to capture the full range of vaccine effects [7]. Although the framework has been developed to a large extent, some parts of the causal relationship between different broader economic impacts described in the framework are based on evidence of low quality, such as modelling studies [3]. This is especially the case for the broader macroeconomic impacts. Moreover, methods for measuring broader economic impacts are still in development and data that can be used to calculate the broader economic impact of vaccines are not yet available $[3,4,7]$. Currently, initiatives for developing additional frameworks that include a broader perspective and/or decision-making criteria are underway [15-17].

Because the field is still in development, frameworks on the broader economic impact of vaccines have been under constant revision. Accordingly, in this dissertation, frameworks have been changing, adapting to the new developments in the field. This can be seen as both a strength and weakness. On the one hand, this allowed us to use the most up-to-date knowledge on the broader economic impact of vaccines. Moreover, research done by our team before and during this dissertation has played a role in the development of the frameworks, as we presented preliminary results and participated in five of the seven meetings mentioned above. On the other hand, it also made comparison of the results presented in Chapters 3 and 4 complex. Due to the changing developments described, it is hard to estimate how interested decision makers would be if this kind of data were available. This is confirmed by the finding of Chapter 4, where we found a relation between the availability of data and the importance given to it. 


\section{Implications for policy makers}

Based on our findings, we can conclude that the interpretation of the societal perspective currently used by researchers is quite narrow, as it includes only productivity costs in addition to healthcare costs. Policymakers need to be aware that other relevant costs might exist. Inclusion or exclusion of information on such costs could lead to different decisions, in particular for decisions that transcend the healthcare sector [18]. In these cases, looking only at the narrow economic impact of vaccines will be insufficient [7]. This is especially important in many low and middle income countries, where publicly funded mandatory immunization programmes are lacking, resulting in out-of-pocket payments by households and/or budget deficiencies $[16,19,20]$. Moreover, many of the low income countries first eligible for funding from overseas development aid and/or international donors are now graduating from the support as a result of economic prosperity, and need to secure domestic resources [21]. In these situations, including the broader economic impact of vaccines could be useful in convincing Ministries of Finance and/or national treasuries to invest more in health care in general [18].

\section{Implications for Research}

First, following from the results of Chapter 2, we would recommend that researchers provide a clear explanation of their interpretation of the societal perspective as used in their study. Moreover, explaining how the perspective relates to the policy question and indicating why certain costs were in- or excluded is also recommended.

Second, as the framework for the broader economic impact of vaccines is still in development, further research on how the different broader economic impacts of vaccines can be included is necessary. It is also recommended to specify the amount of extra work needed to use more complicated models and methods to perform the economic evaluations [22] and to extend the framework to other public health interventions. The expected value of this information can support choices for certain designs and prioritize research [23].

Third, and comparable with other findings [24], our research in Chapters 3 and 4 shows that data collection via online questionnaires is difficult, resulting in relatively small sample sizes. It is therefore necessary to use other data collection methods to reach stakeholders effectively. Examples include arranging stakeholder meetings and using interactive tools to measure preferences. 
Finally, our results show that a case study approach and the combined use of stated and revealed preferences provided in-depth insights into the role of economic information in decision making on the introduction of vaccines. Additional case studies, for other countries and vaccines, are recommended to further investigate this role. 


\section{References}

1. Barnighausen T, Berkley S, Bhutta ZA, Bishai DM, Black MM, Bloom DE, et al. Reassessing the value of vaccines. The Lancet Global health. 2014;2(5):e251-2.

2. Deogaonkar R, Hutubessy R, van der Putten I, Evers S, Jit M. Systematic review of studies evaluating the broader economic impact of vaccination in low and middle income countries. BMC public health. 2012;12(1):878.

3. Jit M, Hutubessy R, Ee PM, Sudaram N, Audilam J, Salim S, et al. The broader economic impact of vacination: reviewing and appraising the strength of evidence. BMC Med. 2015(13):209.

4. Bärnighausen T, Bloom DE, Cafiero-Fonseca ET, O'Brien JC. Valuing vaccination. Proceedings of the National Academy of Sciences. 2014;111(34):12313-9.

5. Bärnighausen T, Bloom DE, Canning D, Friedman A, Levine OS, O'Brien J, et al. Rethinking the benefits and costs of childhood vaccination: The example of the Haemophilus influenzae type $b$ vaccine. Vaccine. 2011;29(13):2371-80.

6. Bärnighausen T, Bloom DE, Canning D, O'Brien J. Accounting for the full benefits of childhood vaccination in South Africa. South African Medical Journal. 2008;98(11):842-.

7. Bloom DE, Brenzel L, Cadarette D, Sullivan J. Moving beyond traditional valuation of vaccination: Needs and opportunities. Vaccine. 2017;35 Suppl 1:A29-a35.

8. Bloom DE, Canning D, Weston M. The value of vaccination. World Economics. 2005;6(3):15-.

9. Ozawa S, Mirelman A, Stack ML, Walker DG, Levine OS. Cost-effectiveness and economic benefits of vaccines in low-and middle-income countries: A systematic review. Vaccine. 2012:96-108.

10. Johnson R. Understanding HB: an intuitive approach. Sawtooth Software 2000. 2010.

11. Bridges JF, Hauber AB, Marshall D, Lloyd A, Prosser LA, Regier DA, et al. Conjoint analysis applications in health-a checklist: a report of the ISPOR Good Research Practices for Conjoint Analysis Task Force. Value in Health. 2011;14(4):403-13.

12. CONNECTIONS W. Patient Preference Methods-A Patient Centered Evaluation Paradigm.

13. Burchett $\mathrm{H}$, Mounier-Jack S, Griffiths U, Mills A. National decision-making on adopting new vaccines: a systematic review. Health policy and planning. 2012;27(suppl 2):ii62-ii76.

14. Bloom DE, Canning D, Shenoy ES. The effect of vaccination on children's physical and cognitive development in the Philippines. Applied Economics. 2012;44(21):2777-83.

15. Baltussen R, Jansen MPM, Bijlmakers L, Grutters J, Kluytmans A, Reuzel RP, et al. Value Assessment Frameworks for HTA Agencies: The Organization of Evidence-Informed Deliberative Processes. Value in Health. 2017;20(2):256-60.

16. van Mastrigt GA, Paulus AT, Aarts M-J, Evers SM, Alayli-Goebbels AF. A qualitative study on the views of experts regarding the incorporation of non-health outcomes into the economic evaluations of public health interventions. BMC Public Health. 2015;15(1):954.

17. Drost RMWA. Intersectoral costs and benefits of health interventions: A change of perspective in economic evaluation: Maastricht University; 2016.

18. Jit M, Hutubessy R. Methodological Challenges to Economic Evaluations of Vaccines: Is a Common Approach Still Possible? Applied health economics and health policy. 2016;14(3):245-52.

19. Loganathan $\mathrm{T}$, Lee $\mathrm{W}-\mathrm{S}$, Lee $\mathrm{K}-\mathrm{F}$, Jit M, Ng C-W. Household catastrophic healthcare expenditure and impoverishment due to rotavirus gastroenteritis requiring hospitalization in Malaysia. PLoS One. 2015;10(5):e0125878.

20. Verguet $S$, Jamison DT. Benefits Beyond Health: Evaluating financial risk protection and equity through extended cost-effectiveness analysis. In: Glassman A, editor. What's In, What's Out: Designing Benefits for Universal Health Coverage. Washington DC: Center for global development; 2017.

21. Kallenberg J, Mok W, Newman R, Nguyen A, Ryckman T, Saxenian H, et al. Gavi's Transition policy: moving from development assistance to domestic financing of immunization Programs. Health Affairs. 2016;35(2):250-8.

22. Claxton KP, Sculpher MJ. Using value of information analysis to prioritise health research. Pharmacoeconomics. 2006;24(11):1055-68.

23. Claxton K, Sculpher M, Drummond M. A rational framework for decision making by the National Institute For Clinical Excellence (NICE). The Lancet.360(9334):711-5.

24. Fan W, Yan Z. Factors affecting response rates of the web survey: A systematic review. Computers in Human Behavior. 2010;26(2):132-9. 



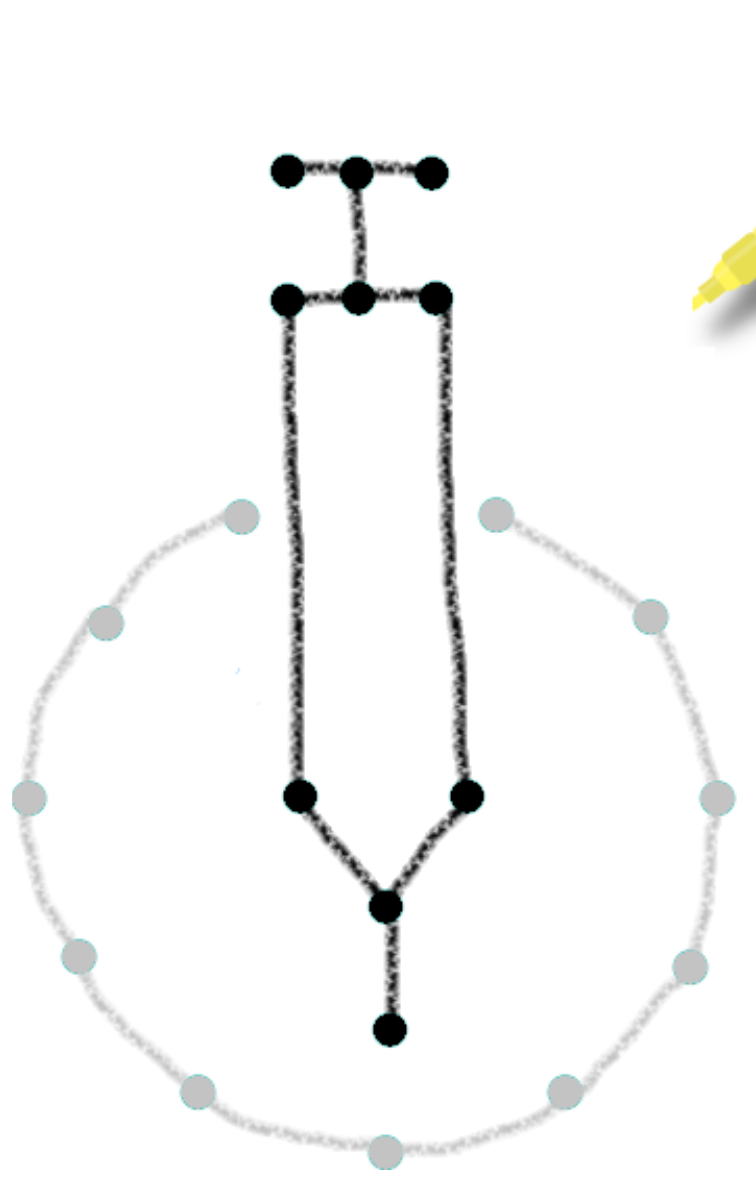


Addenda

Summary

Samenvatting

Valorisation

Dankwoord

List of publications \& Awards

About the author 

Summary 


\section{Chapter 1}

The need for evidence-informed decision making is rapidly increasing, also with regard to decisions on the introduction of new vaccines. The role of economic information in particular is gaining importance due to the rising costs of health care and the need to set priorities in this sphere. Currently most economic information is derived from economic evaluations that focus on immunization programmes' direct impact within the healthcare sector. The (economic) impact of these programmes for society as whole (i.e. the societal perspective), however, is often neglected. Several authors have proposed ways to include these broader economic impacts into economic evaluations in order to fully capture the cost and benefits of immunization programmes. Nevertheless, the usefulness of taking information on these broader economic impacts into account for decision making on the introduction of vaccines has received little attention so far.

We therefore formulated four objectives that have been addressed in this dissertation: 1) to determine how the broader perspective (i.e. the societal perspective) is applied in economic evaluations in general, 2) to identify which economic impacts seem relevant towards aiding decision making for vaccine introduction, 3) based on stakeholders' perceptions, to determine the relative importance of the identified economic impacts and 4) to retrospectively analyze the role of information in vaccine decision-making in a real life case.

\section{Chapter 2}

The aim of Chapter 2 was to investigate how the societal perspective is actually conceptualized in economic evaluations and to assess how intersectoral costs and benefits (ICBs), that is the costs and benefits pertaining to sectors outside the healthcare sector, impact the results of economic evaluations.

Based on a search up to July 2015 using PubMed, Embase, CINAHL and PsychINFO, a systematic literature review was performed to identify economic evaluations using a societal perspective. Conceptualizations of the societal perspective were assessed in NVivo version 11, using conventional and directed content analysis.

A total of 107 studies were assessed, of which 74 (69.1\%) provided conceptualizations of the societal perspective. These varied in the types of costs included and in the descriptions of cost bearers. Labour productivity costs were included in 72 studies (67.3\%), while only 38 studies (35.5\%) included other ICBs, most of which entailed the costs of informal care and/or social care. In total, ten articles on infectious diseases 
were identified. All studies on infectious diseases included intervention and healthcare costs; six studies also included patient and family costs and/or productivity costs. Only two studies included costs in other sectors; both of these studies included household and informal care costs and one study included educational costs. ICBs within the educational and criminal justice sectors were each included five times. Most of the trial-based evaluations (75\%) analysed reported productivity costs. In nine studies, these comprised more than $50 \%$ of total costs. Criminal justice and informal care costs were also important in several studies. We concluded that there is a great variety in the way the societal perspective is conceptualized and used within economic evaluations. The term 'societal perspective' is often related to including merely productivity costs, while other ICBs could be relevant as well.

\section{Chapter 3}

Current economic evaluation guidelines concentrate mainly on immediate health gains and cost savings for the individuals involved in the intervention. However, it has been argued that these guidelines are too narrow to capture the full impact of vaccination and immunization programmes, especially in low and middle income countries. Including the broader economic impact of vaccines (BEIVs) has therefore been proposed. Examples of BEIVs include productivity-related gains, macro-economic impact, and various externalities. Despite their potency, the extent to which these BEIVs can and should be incorporated into economic evaluations of vaccination is still unclear.

A mixed methods study was conducted to assess the relevance of BEIVs to different stakeholders involved in decision making on the introduction of vaccines. An internetbased survey was sent to attendees of the New and Underutilized Vaccines Initiative meeting in Montreux, Switzerland in 2011. In addition, semi-structured interviews were conducted during the meeting. Study participants included decision makers, experts and funders of vaccines and immunization programmes in low and middle income countries. A descriptive analysis of the survey, along with identification of common themes and factors extracted from the interviews and open survey questions, was undertaken.

We found that evidence on the macro-economic impact, burden of disease and ecological effects were perceived as being most valuable towards aiding decision making on the introduction of vaccines by the 26 survey respondents. The 14 interviewees highlighted the importance of the burden of disease and of different types of indirect effects. Furthermore, some new interpretations of BEIVs were discussed, such as the potential negative impact of waste during immunization programmes and 
the idea of using vaccines as a platform for delivering other types of health interventions. Interviewees also highlighted the importance of using a broader perspective in connection with measuring economic impacts, particularly when attempting to derive the value of newer, more expensive vaccines. According to participants, BEIVs were seen as being equally important to traditional outcome measures used in cost-effectiveness analyses. Such insights can be used to shape research agendas within the field and to eventually create broader, more inclusive practical guidelines for the economic evaluations of vaccines.

\section{Chapter 4}

Understanding the most important economic impacts of vaccines can provide relevant information to stakeholders when they are selecting vaccine immunization strategies. This study was therefore designed first to identify the economic impacts for vaccinated individuals, and second, to assess the relative importance of these economic impacts. A four-step approach was used, including a review of the literature, a pilot study and an expert consultation. As a fourth step, a survey utilizing a best/worst scaling was conducted among 26 different stakeholders to assess the relative importance of the identified economic impacts. In each of the 15 choice tasks, participants were asked to choose the most important and the least important economic impact from a set of four from the master list. We identified 23 economic impacts relevant for vaccine introduction in four domains: health-related benefits for vaccinated individuals, shortand long-term productivity gains, community or health systems externalities and broader economic indicators. Our study suggests that the first domain "health-related benefits for vaccinated individuals" is valued as more important than the other domains, with mortality, healthcare expenditure, and morbidity ranking in the top three overall.

\section{Chapter 5}

As little is known about the role of (economic) evidence in the different stages of the decision-making process on the introduction of vaccines in a real life case, the study in Chapter 5 aimed (1) to map how the decision-making process on the introduction of the HPV vaccine in the Netherlands took place, and which stakeholders were involved; (2) to identify what type of information was used during the decision-making process by the different stakeholders and (3) to identify to what extent economic information played a role in this decision-making process. 
A document analysis was performed to identify the information or evidence used or requested by various stakeholders in the different stages of the policy process (prioritization, development and implementation). In total, 42 documents were found, analysed and synthesized, for the period between August 2006 (when the Dutch parliament first raised a question on the possibility of introducing HPV vaccination) and September 2009 (when HPV vaccination was planned to be introduced into the national vaccination programme). Documents were analysed using directed content analysis based on eight broad categories of criteria used in decision-making frameworks for the introduction of vaccines.

Our analysis demonstrates that a wide variety of stakeholders is involved in the decision-making process of new vaccines, with a key role for the Minister of Health, parliament and the National Health Council. Financial or economic issues were stipulated in $64.3 \%$ of the documents, and in $59.5 \%$ evidence on vaccine characteristics was discussed. Economic information from economic evaluations was most discussed (47.6\%), followed by evidence on funding sources for HPV vaccination (23.8\%) and on incremental costs related to the implementation of the vaccination in the Netherlands and the price of the vaccine $(16.7 \%)$. Based on this study, it can be concluded that economic information, in particular the evidence resulting from economic evaluations, played an important role during the decision-making process on the introduction of HPV-vaccination in the Netherlands. Outcomes related to the broader economic impact of vaccines, however, were scarcely discussed during the decision-making process on the introduction of HPV vaccination in the Netherlands, although equity was discussed to some degree.

\section{Chapter 6}

Overall it can be concluded that there is a discrepancy between the theoretical arguments for including the broader economic impact of vaccines in decision making and research, and the preferences and actual use of evidence on these impacts. In our research we found 23 possible economic impacts in four domains. Of these economic impacts, stakeholders preferred the 'health-related benefits to vaccinated individuals' over the broader economic impacts, with the exception of 'behaviour-related productivity gains'. Our case study further suggests that, with the exception of equity, outcomes related to the broader economic impact of vaccines were scarcely discussed during the decision-making process on the introduction of HPV vaccination in the national vaccination programme in the Netherlands.

The field of research in this dissertation is relatively new. This leads to certain limitations. Because the field is still in development, frameworks on the BEIVs are 
changing. All studies included were of an explorative and/or descriptive nature, while the studies in Chapters 3 and 4 also had relatively small sample sizes. To be able to explore this relatively new field of research, a combination of methods had to be used, including both quantitative and qualitative methods. This combination of methods, together with an in-depth case study and the use of revealed as well as stated preferences of stakeholders and decision-makers, can be considered as the strengths of this dissertation.

Given the relatively new field of research, further research is recommended. In addition to developing a theory on BEIVs in relation to the societal perspective, and assessing further the usefulness of evidence-informed decision making on the introduction of vaccines, it is recommended to develop and employ additional and combined datacollection methods to effectively reach more stakeholders and decision-makers. Performing more case-studies in different countries and with different vaccines is also recommended. From a policy point of view, our studies show that decision-makers should be aware that vaccination can have broad economic impacts. Basing decisions on information from economic evaluations that use a narrow perspective may neglect this broader impact and lead to less than optimal decisions. In particular, this may be the case for decision making on the introduction of vaccines in low- and middle income countries and for decisions on interventions whose impact transcends the healthcare sector. 


Samenvatting 


\section{Hoofdstuk 1}

De behoefte aan geïnformeerd beleid neemt snel toe, ook met betrekking tot besluitvorming rondom de introductie van nieuwe vaccins. Door de stijgende zorgkosten wordt de noodzaak om prioriteiten te stellen groter, waarmee ook de vraag naar economische informatie groeit. Op dit moment wordt voornamelijk informatie gebruikt uit economische evaluaties die zich richten op de directe impact van immunisatieprogramma's binnen de gezondheidszorg. De (economische) impact van deze programma's op de gehele samenleving (het maatschappelijke perspectief) wordt minder vaak meegenomen. Verschillende auteurs hebben, om dit op te lossen, voorstellen gedaan om de bredere economische impact van vaccinatie mee te nemen in economische evaluaties om alle relevante kosten en baten in kaart te brengen. Dit is vooral gebleven bij theorieën. De meerwaarde om deze informatie te verzamelen is tot nu onderbelicht gebleven.

Om meer inzicht te krijgen in het nut van deze informatie hebben we vier doelstellingen geformuleerd die in dit proefschrift worden behandeld: 1) het bepalen van hoe het bredere perspectief (maatschappelijke perspectief) momenteel wordt toegepast in economische evaluaties, 2) het bepalen van welke economische impacts relevant zijn ter ondersteuning van de besluitvorming rondom de introductie van vaccinaties, 3) op basis van de percepties van betrokken stakeholders, te bepalen welke gevonden economische impacts het meest van belang zijn tijdens het besluitvormingsproces en 4) het uitvoeren van een retrospectieve case studie, om de rol van informatie tijdens het besluitvormingsproces rondom de introductie van vaccinaties te testen.

\section{Hoofdstuk 2}

Het doel van hoofdstuk 2 was om inzicht te krijgen hoe het maatschappelijke perspectief gebruikt wordt in economische evaluaties en om te bekijken wat voor invloed het meenemen van dit perspectief kan hebben op de gevonden resultaten.

Op basis van een zoekopdracht in verschillende wetenschappelijke databases werden alle relevante economische evaluaties die gebruik maakten van het maatschappelijke perspectief tot juli 2015 geselecteerd. Door gebruik te maken van kwalitatieve onderzoeksmethodes werden algemene en specifieke definities in kaart gebracht.

In totaal zijn 107 studies beoordeeld, waarvan er $74(69,1 \%)$ inzicht gaven in de interpretatie van het maatschappelijke perspectief. Onderzoekers hadden verschillende interpretaties van dit perspectief, tot uitdrukking komend in verschillende kostensoorten of kostendragers die werden aangewezen. De meeste studies noemden arbeidsproductiviteit als een relevante kostenpost (72 studies, 67.3\%), maar in 
sommige studies (36 studies, 35,5\%) werden de kosten voor andere sectoren, zoals mantelzorg en sociale zorg genoemd. Kosten in de sectoren 'onderwijs' en 'justitieel systeem' werden elk in vijf studies benoemd. In de analyse waren ook 10 studies over infectiezieken opgenomen. In al deze studies werden interventiekosten en zorgkosten meegenomen. Daarnaast namen zes studies ook kosten voor de patiënt en familie en/of productiviteitskosten mee. In slechts twee studies werden de kosten voor andere sectoren meegenomen, waaronder kosten voor huishoudelijke en informele zorg; één studie rapporteerde kosten met betrekking tot het onderwijs. In de onderzochte economische evaluaties gebaseerd op resultaten van experimenten werd in $75 \%$ van de gevallen productiviteitskosten meegenomen. In negen studies waren deze meer dan $50 \%$ van de totale kosten. In sommige studies zagen we dat de kosten het 'justitieel systeem' en 'informele kosten' een belangrijke rol spelen.

Op basis van onze gevonden resultaten kunnen we concluderen dat de interpretatie en toepassing van het maatschappelijke perspectief verschilt in economische evaluaties. Vaak wordt het meenemen van productiviteitskosten gezien als voldoende basis voor het classificeren van een economische evaluatie vanuit maatschappelijk perspectief, echter het meenemen van kosten in andere sectoren kan ook relevant zijn.

\section{Hoofdstuk 3}

Zoals aangegeven in de conclusie van hoofdstuk 2 is de huidige interpretatie van het maatschappelijke perspectief beperkt in economische evaluaties. Auteurs geven aan dat hierdoor de impact van vaccinatie- en immunisatie-programma's, in laag- en midden-inkomenslanden, op de maatschappij onderschat wordt. Om dit te voorkomen stellen ze voor om de bredere economische impact van vaccinaties (BEIV's) mee te nemen in economische evaluaties. Voorbeelden van dit soort impacts zijn: diverse soorten arbeidsproductiviteit, macro-economische impacts en externaliteiten (gemaakte kosten of geleden schade door andere als gevolg van economische activiteiten). Ondanks de mogelijke potentie van deze BEIV's is de mate waarin ze kunnen en moeten worden meegenomen in economische evaluaties onduidelijk.

Om dit uit te zoeken is een gecombineerde studie uitgevoerd, met zowel kwalitatieve als kwantitatieve onderzoeksmethodes, om de relevantie van de BEIV's voor de verschillende stakeholders die betrokken zijn bij de besluitvorming over de introductie van vaccinaties te onderzoeken. Voorbeelden van stakeholders zijn beleidsmakers, deskundigen en geldschieters van vaccinatie en immunisatie programma's van laag- en midden-inkomenslanden. Een online vragenlijst werd verstuurd naar de deelnemers van een meeting ter bevordering van nieuwe en onderbenutte vaccinaties in Montreux, Zwitserland in 2011. Daarnaast werden tijdens deze meeting semigestructureerde 
interviews uitgevoerd. Op basis van de verzamelde data zijn beschrijvende analyses en thematische kwalitatieve analysis gedaan.

Op basis van de gevonden resultaten, gebaseerd op 26 respondenten, zagen we dat stakeholders de macro-economische impact, de ziektelast en de ecologische effecten als meest waardevol zien voor het besluitvormingsproces. Daarnaast gaven veertien geïnterviewden ook aan dat de ziektelast en indirecte effecten van belang zijn om mee te nemen in economische evaluaties. Ook wezen ze op een aantal nieuwe BEIV's, zoals de mogelijke negatieve impact van verspilling tijdens de uitvoer van immunisatie programma's en het idee om immunisatie programma's te gebruiken als een platform voor het implementeren van andere gezondheidsinterventies. Het belang van het gebruik van het bredere perspectief in economische evaluaties werd vooral gezien voor nieuwe relatief dure vaccinaties die nog niet lang op de markt zijn. Op basis van de gevonden resultaten kunnen we concluderen dat de stakeholders BEIV's als even belangrijk beschouwden als meer traditionele uitkomstmaten zoals ziektelast (bijv. mortaliteit) of productiviteitswinsten.

\section{Hoofdstuk 4}

Aangezien het belang van BEIV's werd onderschreven door de stakeholders, ondervraagd in hoofdstuk 3 , hebben we op basis van de uitkomsten van deze studie, literatuur reviews en raadpleging van deskundigen, een overzicht gemaakt van de verschillende mogelijke impacts. Daarnaast hebben we gekeken hoe belangrijk deze impacts waren voor verschillende stakeholders, die betrokken zijn bij de besluitvorming over de introductie van vaccinaties. We hebben ze telkens gevraagd te kiezen tussen de belangrijkste en minst belangrijkste uit een selectie van vier opties. Elk van de 26 respondenten kreeg vijftien van deze opties uit een selectie van achttien van de 23 gevonden impacts.

De 23 gevonden economische impacts van vaccinaties kunnen verdeeld worden in vier domeinen: directe gezondheidswinst voor gevaccineerde personen, productiviteitswinst op korte en lange termijn, externaliteiten in de maatschappij of het gezondheidssysteem en bredere economische indicatoren. Uit de keuzes van de verschillende stakeholders bleek dat in contrast met onze eerder gevonden resultaten de directe gezondheidswinst voor gevaccineerde personen als belangrijkst werd gewaardeerd, met uitkomsten van mortaliteit, uitgaven voor de gezondheidszorg en morbiditeit in de top drie. 


\section{Hoofdstuk 5}

In de laatste studie hebben we gekeken hoe (economische) informatie wordt gebruikt in de verschillende stadia van het besluitvormingsproces bij de introductie van HPVvaccinatie (vaccinatie tegen baarmoederhalskanker) in Nederland. Dit is gedaan door eerst in kaart te brengen hoe het besluitvormingsproces in Nederland heeft plaatsgevonden en welke stakeholders hierbij betrokken waren. Daarna hebben we geprobeerd om vast te stellen welke type informatie tijdens het besluitvormingsproces door verschillende stakeholder groepen is gebruikt en in hoeverre economische informatie hier dan weer een rol bij speelde.

Dit is gedaan door middel van een document analyse op basis van acht categorieën van informatie. In het totaal werden 42 documenten gevonden in relatie tot het besluitvormingsproces rondom HPV-vaccinatie tussen augustus 2006 (eerste vraag van tweede kamer over de invoering van HPV-vaccinatie in rijksvaccinatieprogramma) en september 2009 (officiële planning om HPV-vaccinatie op grote schaal in te voeren).

Onze analyse toont aan dat een breed scala van stakeholders betrokken is bij het besluitvormingsproces, met een sleutelrol voor de minister van Volksgezondheid, het Parlement en de Gezondheidsraad. Financiële en economische kwesties werden genoemd in $64,3 \%$ van de documenten, en in 59,5\% werd over de kenmerken van het HPV-vaccin zelf gesproken. Specifiek kijkend naar economische informatie werden economische evaluaties (47,6\%) gevolgd door financieringsbronnen voor HPVvaccinatie $(23,8 \%)$ en incrementele kosten voor het invoeren van het vaccin in Nederland en de prijs van het vaccin (beide $16,7 \%$ ) genoemd.

Op basis van de resultaten uit dit onderzoek kan geconcludeerd worden dat economische informatie en meer specifiek de informatie die voortvloeit uit economische evaluaties zeker een rol speelden in het besluitvormingsproces over de introductie van HPV-vaccinatie in Nederland. Informatie rondom de BEIV's werd nauwelijks besproken tijdens het besluitvormingsproces, met uitzondering van equity. Deze werd wel in zekere mate besproken.

\section{Hoofdstuk 6}

Al met al kan worden geconcludeerd dat er een discrepantie bestaat tussen de theoretische argumenten voor het opnemen van de BEIV's bij besluitvorming en onderzoek, en de voorkeuren en het feitelijke gebruik van informatie over deze impacts. In ons onderzoek vonden we 23 mogelijke economische impacts in vier domeinen. Van deze economische impacts gaven stakeholders de voorkeur aan de 
directe gezondheidswinst voor gevaccineerde personen boven de bredere economische indicatoren, met uitzondering van '(gedragsgerelateerde) productiviteitswinsten'. Onze case studie suggereert verder dat, met uitzondering van equity, de uitkomsten met betrekking tot de BEIV's nauwelijks werden besproken tijdens het besluitvormingsproces over de introductie van HPV-vaccinatie in het rijksvaccinatieprogramma.

Het onderzoeksgebied dat centraal staat in dit proefschrift is relatief nieuw. Dit brengt bepaalde beperkingen met zich mee. Ten eerste omdat het veld nog in ontwikkeling is, zijn de theorieën over de BEIV's ook nog steeds in ontwikkeling. Ten tweede zijn alle onderzoeken opgenomen in dit proefschrift exploratief en beschrijvend met kleine steekproefgroottes. Om hiermee om te gaan zijn zowel kwalitatieve als kwantitatieve methodes gebruikt om de gestelde doelstellingen van dit proefschrift te beantwoorden. Daarnaast is ook niet alleen gekeken naar theoretische voorkeuren ('stated preferences') van de stakeholders, maar ook de gemanifesteerde voorkeuren ('revealed preferences') (zie case studie hoofdstuk 5). Samen zijn dit de sterke punten van dit proefschrift.

Gezien het relatief nieuwe onderzoeksveld, is verder onderzoek zeker aanbevolen. Naast het stroomlijnen van de verschillende theorieën over BEIV's in relatie tot het maatschappelijke perspectief, en het verder beoordelen van de meerwaarde van het gebruik van economische informatie in besluitvorming over de introductie van vaccins, wordt aanbevolen om aanvullende en gecombineerde methoden voor gegevensverzameling te ontwikkelen en te gebruiken voor het ondervragen van stakeholders. Het uitvoeren van meer case studies in andere landen en voor verschillende vaccins kan ook worden aanbevolen.

Vanuit beleidsoogpunt tonen onze studies aan dat beleidsmakers zich bewust moeten zijn van het feit dat de impact van vaccinaties op de maatschappij mogelijk breder is dan tot nu toe wordt aangenomen. Het verwaarlozen van een dergelijke brede impact binnen economische evaluaties kan in sommige gevallen (waaronder bij besluitvorming over interventies die ook buiten de gezondheidszorg een grote impact hebben of besluitvorming over de introductie van vaccinaties in laag- en midden-inkomenslanden) tot suboptimale keuzes leiden. 


Valorisation 
In this chapter we discuss the valorization of this dissertation, i.e. "the process of value creation from knowledge, by making it applicable and available for economic or societal utilization" [1].The goal of the chapter is to provide insight into what this dissertation adds to society. To provide a good overview of what can be done with the results of this dissertation, we discuss for each stakeholder group, what the added value of this dissertation could be, together with the efforts already undertaken to disseminate the knowledge and the additional actions that will be taken. Two groups of stakeholders were identified: 1) the scientific community and 2) policymakers and advisory bodies in high, middle and low income countries.

\section{The scientific community}

This dissertation has added value for the scientific community. This group includes researchers in the field of health economics, decision- and policy making, and those researching (the economic impact of) vaccination.

\section{What this dissertation adds}

The outcomes of our research add several new insights which can be important for the scientific community.

First, our research has shown that taking the broader perspective (i.e. the societal perspective) into account is still not common in economic evaluations. Comparing the outcomes of studies that include a broader perspective with those that exclude it could provide a further understanding of the impact of using a broader perspective. It could also further enhance the optimization of economic evaluation research in general and the optimization of cost-effectiveness research on immunization specifically. Moreover, extending such research to areas outside immunization could offer the possibility of developing a tailor-made and standardized framework for including the broader perspective in different areas and for different interventions.

Second, we saw that if researchers choose to use the societal perspective, there is a need to clearly explain the interpretation of this perspective as it is applied in any particular study. Moreover, explaining how the perspective relates to the specific policy question and indicating the rationale of why certain costs were included or excluded would add validity to future economic studies.

Third, our research shows that the methodology used in this field of research needs further attention, especially the use of mixed methods approach to reach stakeholders effectively. Moreover, our results show that a case study approach and the combined use of stated and revealed preferences can provide in-depth insights into the role of 
economic information in decision making on vaccines. The methods and frameworks used in our studies can form the basis for additional case studies on other types of vaccines and/or vaccines in other countries. Furthermore, the methods and frameworks can be adapted for analyzing decision making in other areas, particularly now that more focus is being directed towards the concept of health in all policies [2, 3].

\section{Efforts made to disseminate this knowledge}

Several efforts have been undertaken to disseminate these new insights. As can be seen in the publication list, we presented the results of our studies at several international and national conferences and meetings. For example, the preliminary results of Chapter 5 (a case study on the introduction of HPV vaccination in the Netherlands) were presented at the symposium of the Dutch Association of Health Technology Assessment (NVTAG). We were also invited to present our work at several expert meetings (including World Health Organization (WHO)-supported meetings in Toronto, Geneva, Bangkok and Boston between 2012-2017) on the broader economic impact of vaccines, where, as part of an international team, we shared our results, discussed possible future research and wrote new research proposals. We have, for instance, contributed to the proposal on the "The use of economic information in the decision-making process of NITAGs in Asia" proposing social network analysis for analyzing the networks of national immunization technical advisory groups, in collaboration with the Center for Disease Control and Prevention (CDC), the WHO and the International Vaccine Institute (IVI).

In addition, we published most of our papers in peer-reviewed open access journals to make our results easily available to the research community. We also used our results in educational activities at Maastricht University in the Netherlands.

\section{Additional actions to be taken}

However, some actions can still be undertaken to further inform the scientific community. First, we are still in the process of getting Chapter 5 published in a peerreviewed journal. Second, we plan to make this dissertation publicly available online to the scientific community. Third, we are planning to publish summaries of this dissertation in the Immunization Economics Newsletter and the newsletters of professional bodies in the Netherlands (such as the NVTAG, Health Economic Study Group (VGE)) and internationally, for example, in the newsletter of the International Society for Pharmacoeconomics and Outcomes Research (ISPOR). 


\section{Policy makers and advisory bodies}

The findings of this dissertation can also be of major interest for policy makers and advisory bodies. These include national immunization technical advisory groups (NITAGs), reimbursement institutes (such as ZiNL in the Netherlands), policy makers and employees of the ministries of health and ministries of finance in low, middle and high income countries. Furthermore, our results can be of particular interest to international agencies, donors and advisory bodies for low and middle income countries; these bodies include the World Health Organization (WHO), the Bill and Melinda Gates Foundation, United Nations International Children's Emergency Fund (UNICEF) and Médicins Sans Frontières (MSF).

\section{What this dissertation adds}

Several results found in this dissertation can be of interest for the policy makers and advisory bodies identified above.

First, we found twenty-three possible economic impacts among four domains that can be relevant for decision making on the introduction of a vaccine. Decision makers can use these as a checklist to see if the information provided (e.g. the results of economic evaluations on the impact of vaccines) for supporting decision making is complete.

Second, this dissertation creates awareness that there may be other relevant costs besides healthcare costs. The inclusion or exclusion of information on such costs could lead to different decisions, in particular for decisions that transcend the healthcare sector [4]. In these cases, looking only at the narrow economic impacts of vaccines will be insufficient [5]. As explained in Chapter 6, the current state (looking only at the economic impact of a particular vaccine) is insufficient for two reasons. First, mandatory vaccination programmes sometimes lack public funding, resulting in out-ofpocket payments by households and/or budget deficiencies in both high income and low and middle income countries [6-8]. Second, many of the low income countries which were at first eligible for funding from overseas development aid and/or international donors are now graduating from that support as a result of economic prosperity, and need to secure domestic resources [9]. In these situations, including the broader economic impacts of vaccines could be useful in convincing ministries of finance and/or national treasuries to invest more in health care in general [4].

\section{Efforts made to disseminate this knowledge}

Several efforts have already been undertaken to disseminate the issues presented above to policy makers and advisory bodies. First of all, we purposefully choose to publish most results in open access journals as policy makers and advisory bodies, especially in low- and middle income countries, do not always have access to paid 
journals. Second, in the expert meetings in which we presented our results policy makers from different countries, including low and middle income countries, were present. The preliminary findings in Chapter 2, for instance, were presented at the first expert meeting, held in Canada, on the broader economic impact of vaccination. One of the foundations for the development of a new framework with regard to vaccination was laid during this meeting. We also interviewed and held a survey among the participants (including policy makers and advisory bodies) of the new and underutilized vaccine initiative (NUVI) meeting. We also shared our results with specific institutions, such as the Dutch National Institute for Public Health and the Environment (RIVM) and Supporting Independent Immunization and Vaccine Advisory Committees (SIVAC). Third, the collaboration with the WHO and indirectly with other international stakeholders such as the Global Alliance for Vaccine Introduction (Gavi Alliance), and UNICEF, among others, provided us with an important link with policy makers from low and middle income countries and provided insights into their needs and enabled us to share our results via their networks.

\section{Additional actions to be taken}

We intend to send copies of this dissertation to the stakeholders identified earlier, to make them aware of our findings. The list of stakeholders includes both individual persons and organizations, such as the RIVM, National Healthcare Institute (ZiNL), the health council for the Netherlands, as well as the WHO, the Bill and Melinda Gates Foundation, UNICEF, SIVAC, HITAP, CDC, IVI, and other organizations. We also intend to send a summary of the dissertation to Vaccines and Global Health: The Week in Review, which is sent each week to professionals from "public health, clinical practice, government, NGOs and other international institutions, academia and research organizations, and industry" to update them on "news, events, announcements, articles and research in vaccine and global health ethics and policy space [10]." 


\section{References}

1. Board of Deans Maastricht University: Regulation governing the attainment of doctoral degrees, decreed by resolution of the board of deans. In. Edited by University M. Maastricht: Maastricht University; 2013: 52.

2. Kemm J: Health impact assessment and health in all policies. Health in all policies: prospects and potentials Helsinki: Ministry of Social Affairs and Health 2006:189-208.

3. Pepin D, Winig BD, Carr D, Jacobson PD: Collaborating for health: health in all policies and the law. The Journal of Law, Medicine \& Ethics 2017, 45(1_suppl):60-64.

4. Jit M, Hutubessy R: Methodological Challenges to Economic Evaluations of Vaccines: Is a Common Approach Still Possible? Applied health economics and health policy 2016, 14(3):245-252.

5. Bloom DE, Brenzel L, Cadarette D, Sullivan J: Moving beyond traditional valuation of vaccination: Needs and opportunities. Vaccine 2017, 35 Suppl 1:A29-a35.

6. Loganathan T, Lee W-S, Lee K-F, Jit M, Ng C-W: Household catastrophic healthcare expenditure and impoverishment due to rotavirus gastroenteritis requiring hospitalization in Malaysia. PLoS One 2015, 10(5):e0125878.

7. Verguet S, Jamison DT: Benefits Beyond Health: Evaluating financial risk protection and equity through extended cost-effectiveness analysis. In: What's In, What's Out: Designing Benefits for Universal Health Coverage. edn. Edited by Glassman A. Washington DC: Center for global development; 2017.

8. van Mastrigt GA, Paulus AT, Aarts M-J, Evers SM, Alayli-Goebbels AF: A qualitative study on the views of experts regarding the incorporation of non-health outcomes into the economic evaluations of public health interventions. BMC Public Health 2015, 15(1):954.

9. Kallenberg J, Mok W, Newman R, Nguyen A, Ryckman T, Saxenian H, Wilson P: Gavi's Transition policy: moving from development assistance to domestic financing of immunization Programs. Health Affairs 2016, 35(2):250-258.

10. Vaccines and Global Health: The Week in Review [https://centerforvaccineethicsandpolicy.net/weekin-review/] 


Dankwoord 
$\mathrm{Na}$ 4,5 jaar is het moment dan eindelijk aangebroken. De laatste regels van de Nederlandse samenvatting zijn getypt en dan is er nog een hoofdstuk te schrijven. Het is spannend om aan dit hoofdstuk te beginnen aangezien ik dit boekwerk nooit af had kunnen maken zonder de steun, geloof en hulp van vele mensen om mijn heen. Niet alleen hebben jullie me geïnspireerd met jullie verhalen, inzichten en kennis, maar veel van jullie hebben ook daadwerkelijk meegeschreven aan en meegedacht met stukken van dit boekwerk. Ik denk dan ook dat ik om iedereen te kunnen bedanken, nog zo'n 20 pagina's meer nodig heb dan ik van plan ben om nu te schrijven. Daarom bij deze alvast dank aan alle mensen die ik op de een of andere manier ben vergeten hier te vernoemen!

Als eerste wil ik alle experts, stakeholders en respondenten bedanken voor de interviews en het invullen van de lange vragenlijsten, waarmee jullie de basis vormen van dit proefschrift.

Gedurende mijn PhD heb ik een team gehad van een promotor en drie co-promotores, die me tijdens dit traject hebben begeleid en gesteund, ieder op hun eigen unieke wijze. Silvia, Raymond en jij hebben me een geweldige kans gegeven om dit onderzoek op te starten tijdens mijn masters en ook om stage te lopen bij de WHO. Na mijn master heb je me, na meerdere meetings, ervan weten te overtuigen om een Kootstra aanvraag te schrijven om verder te gaan met dit onderzoek, ondanks dat ik zelf nog niet zo overtuigd was van mijn talenten als onderzoeker. Jouw praktische manier van aanpakken, mogelijkheden te blijven zien in onmogelijke situaties en onvoorwaardelijke steun hebben ervoor gezorgd dat hier toch uiteindelijk een boekje ligt. Dank dat je me altijd de ruimte hebt gegeven om me te ontwikkelen en mijn eigen weg te zoeken. Raymond, jij bent een van de meest inspirerende personen die ik tijdens mijn werk ontmoet heb. Je hebt me ontzettend veel geleerd over het economische belang van vaccinaties en het reilen en zeilen van de WHO. Daarnaast heb je me voorgesteld aan mensen die me verder op weg konden helpen in mijn onderzoek en was je altijd bereikbaar wanneer ik jouw expertise nodig had, dank daarvoor. Aggie, jouw ondersteuning is moeilijk in woorden te beschrijven. Ik denk dat dit ook te lezen is in alle superlatieven die andere PhD's gebruiken om je te bedanken. Ik kan aan hun mooie woorden eigenlijk alleen nog toevoegen dat ik ontzettend genoten heb van onze samenwerking en hoop dat ik nog lang mag leren van jouw kennis en kunde in onderzoek en onderwijs. Dank dat je me onder je vleugels hebt meegenomen naar dit punt. Mickael, jij bent iets later in het traject ingestapt om te helpen in de nieuwe wereld van DCE, BWS en andere onderzoeksvormen waar ik nog nooit van gehoord had. Bedankt voor je hulp bij de ingewikkelde analyses en je geduld bij het uitleggen hiervan. Je precieze en gerichte commentaar waren vaak verhelderend tijdens besprekingen en een verademing om te lezen. 
Daarnaast wil ik de beoordelingscommissie bestaande uit, Anja Krumeich, Philippe Beutels, Christian Hoebe, Hans Maarse en Maarten Postma bedanken voor het doorlezen van de vele pagina's en hun goedkeuring voor dit proefschrift.

Tijdens mijn PhD heb ik het geluk gehad om met veel mensen te mogen samenwerken aan verschillende projecten in zowel binnen- als buitenland. Ten eerste wil ik mijn coauteurs, Rohan Deogaonkar, Mark Jit, Ruben Drost en Dirk Ruwaard, danken voor hun bijdragen aan artikelen die in dit boekwerk zijn opgenomen. Ruben, jij hebt me 2 jaar geleden benaderd om samen een literatuurreview over het maatschappelijke perspectief te schrijven. Je gestroomlijnde, procesmatige benadering en oog voor detail hebben er voor gezorgd dat we in een relatief snelle tijd alles op papier hadden staan.

Olivia although you are not officially on the author list, I want to thank you for your help with sending out the survey to the experts. I very much enjoyed your company at the expert meeting in Bangkok and the conference in Milano. I also want to thank Professor Dr. Tony Nelson for his invitation, his academic guidance and the warm welcome he gave me when I visited Hong Kong.

Helaas zijn niet alle projecten waarbij ik betrokken was in dit boekje terecht gekomen door tijdsdruk, gebrek aan financiering en door verandering van plannen. Toch wil ik ook Ghislaine, Kei Long, Maria Paula, Tony, Simone, Lisa, Nina, Daan, Federica, Alex, Vittal, Kathy, Taiwo en Rana, bedanken voor de tijd en de energie die jullie in deze projecten gestoken hebben. Helaas zijn ze (nog) niet geheel van de grond gekomen, maar een project is pas dood als niemand het meer aandacht geeft. Dus wordt vervolgd!

Since my topic has an international character, I had the opportunity to travel to several exciting places which made the journey so much more than an academic endeavor. I met new (and old) friends, who warmly welcomed me into their lives and helped me along the way. We talked a lot about cultural differences, tasted new types of foods and tried new things that I would never imagine me doing. Thanks for your friendship and I hope to stay in touch with you guys.

Dear Yankho and Citarra I am so happy that you both chose to do your Master programmes in the Netherlands. Although you guys are not close by anymore we still find time to update each other via WhatsApp or see each other by travelling to India, Malawi and city tripping in Europe by train. I hope to hear many more stories on your adventures with the 'belhamels' and Dario in the coming years.

Then, of course, the Hong Kong gang, Alice, Malini, Ming, Shradda and Sheileen. You guys made my three months in Hong Kong go by so fast! I loved our lunch trips, office 
humour, meditation, dance training and the Hong Kong highlights we experienced together. We truly made memories for life and I am humbled that I could share it together with you. Alice, although the book of geniuses is still work in process, I believe that we will get there someday!

Tja, kamergenootjes op je werk kun je niet kiezen. Maar toch heb ik elke keer weer geluk met de mensen met wie ik 40 uur per week optrek. Vier jaar samen met mij doorbrengen op $12 \mathrm{~m}^{2}$ is best een prestatie. Dus Martine, bij deze ook voor jou een volle alinea in mijn dankwoord $(-)$. Om als TUer in Maastricht te komen werken is best een stap, zeker met ons rare onderwijssysteem. Omdat we zo verschillend zijn, heb ik ontzettend veel van je geleerd! Het is echt super om te zien hoe jij je als onderzoeker in projecten vastbijt en ondanks alle tegenslagen toch dingen voor elkaar krijgt. Jij vervloekt soms je vasthoudendheid, maar ik denk dat het je juist zo bijzonder maakt. Bedankt voor alle vertrouwen, lol, dagelijkse updates en kameruitstapjes. HSR is een stuk saaier met jou niet in de buurt. Ik vond het dan ook super leuk dat jij me bent komen opzoeken in Hong Kong, waarmee we de kamertuitstapjes wel echt tot een nieuwe hoogte gebracht hebben. Gelukkig heb je me beloofd dat je voor een dagje terugkomt om tijdens mijn promotie achter me te staan als paranimf.

Met anderen heb ik iets minder uren doorgebracht aangezien ze af en toe invlogen vanuit het AZM, Wit-Gele kruis en Zuyd. Ron bedankt voor je heerlijk absurde verhalen over consultaties in het Midden-Oosten, de geheugenpoli en de nieuwe hond. Vincent jij werkt ontzettend gedegen en met een kritische blik aan je proefschrift naast je drukke baan en weet ook nog tijd te vinden om kilometers te rennen en leuke dingen te doen met je kinderen. Ongelofelijk hoe je dit alles combineert. Ruth we hebben maar kort samen een kamer gedeeld maar je passie voor de zorg en positieve instelling zijn bewonderingswaardig. Wat fijn dat je binnenkort ook echt met je PhD kan beginnen, ik weet zeker dat je hier een groot succes van gaat maken!

Sinds september ben ik verhuisd naar een volgende kamer waar ik (+ bureau, planten, schilderijen, kaarten en een hoop andere rommel) liefdevol werd opgevangen door Ingrid, Sofie en Linda. Het is fijn om weer nieuwe maatjes te hebben voor de dagelijkse kameruitjes naar de thee en koffie in een heus blokje om. Ingrid het voelt super vertrouwd om samen een kamer te delen. Je staat altijd klaar om anderen te helpen of het nu is met je enorme kennis over onderzoek of toch nog even een foto te maken voor dit proefschrift. Ik ga je zeker in september missen als je richting Canada gaat voor je onderzoek. Sofie we hebben maar een paar weken samen een kamer gedeeld, aangezien je een nieuw avontuur aanging in Brabant. Toch heb ik er van genoten om je te leren kennen! Linda, jij komt ons $1 x$ per week vergezellen. Wat vaak zorgt voor een hoop gezelligheid en levendige discussies over de dagelijkse werkelijkheid. Ik hoop dat we je nog lang mogen hosten $(\dot{)}$. Sinds begin dit jaar zijn we weer op volle sterkte, 
aangezien we er weer een kamergenootje bij hebben gekregen. Viviënne het is leuk om te zien hoe je al in het begin van je project zoveel voor elkaar kunt krijgen. Je enthousiasme en vrolijkheid zijn een aanwinst voor onze kamer. Super dat je je van de halve marathon verlaagt tot de $10 \mathrm{~km}$ om samen met mij en Ingrid over de finishlijn van de Kika Rotterdamloop te gaan. Ik kijk er nu al naar uit!

Maartje officieel zijn we nooit kamergenoten geweest al voelt het wel zo! Ik heb ontzettend veel gehad aan onze koffiemomentjes en je gezelligheid. Aangezien zowel jij als Martine nieuwe uitdagingen buiten de vakgroep gevonden hebben, zullen we onze koffie en borrel momenten maar gaan verplaatsen naar elders in het land. Ook wil ik je nogmaals bedanken voor al je hulp bij de opmaak van dit proefschrift, dit had ik nooit zelf zo mooi voor elkaar gekregen! Het dinertje gaan we binnenkort inplannen $(-)$.

HSR collega's, ondanks dat DUB 30 een donker gebouw aan de buitenkant lijkt, zijn de mensen die er werken dit zeker niet. Wat heb ik toch geluk dat we samen met elkaar voor deze vakgroep werken. Zonder jullie was het werk een stuk eenzamer. Ook was het een stuk lastiger geweest om deze PhD tot een succesvol einde te brengen, aangezien er altijd iemand is waar je binnen kunt lopen met je vragen of voor een praatje. De dagelijkse lunches achter bij de koffiecorner, tripjes naar de Lidl en de wandelgroep waarbij je kunt aansluiten zijn een verademing. Het echte hart van onze afdeling is toch het team van secretaresses en ondersteunend personeel die me menig keer uit de brand geholpen hebben. Bedankt, Janet, Brigitte, Suus, Ine en Willy-Anne voor de keren dat jullie te hulp schoten en jullie gezelligheid. Ook wil ik de leden van het bestuur van de ISPOR student chapter, Ben, Reina, Xavier, Ingrid, Adrienne, Sandra, Kei Long, Marije, Stella, Hoi Yau en Luca bedanken voor de leuke workshops die we samen hebben mogen organiseren. Als laatste wil ik toch Cindy en Tanja bedanken, dat ze me een kans hebben gegeven om mee te werken aan hun PhD projecten en me zo voor te bereiden op mijn eigen onderzoek.

Tijdens het begin van mijn PhD heb ik nog 1,5 jaar bij V\&VN mogen werken op het project Excellente Zorg. Wat heb ik veel over het belang van verpleegkundigen in de gezondheidszorg geleerd. De passie die alle medewerkers hebben voor het vakgebied is me nog steeds bijgebleven. Speciaal wil ik Renate bedanken voor de ontzettende leerzame en leuke samenwerking. Je had altijd een luisterend oor en hebt me ongelooflijk veel over onderzoek doen in de gezondheidszorg bijgebracht. Ook ons gezamenlijke schrijfweekend zal me altijd bijblijven. Angela, je was samen met mij begonnen bij V\&VN en we hebben ook samen ons afscheid gevierd. Ontzettend jammer dat we geen collega's konden blijven. Gelukkig heb je helemaal je plekje gevonden bij het OLVG. 
Ik heb niet alleen op het werk ondersteuning gehad met het afmaken van mijn PhD, ook in de weekenden en avonden hebben verschillende personen geholpen door juist niet naar de voortgang te vragen en soms gevraagd en ongevraagd advies te geven. Chantal, Kirsten, Marjolein, Jasmijn, Emielieke, Els, Samira, Jorine, Bregje en Martine bedankt voor jullie vriendschap!

Tal, we zijn al sinds de middelbare school bevriend en hoewel we elkaar tegenwoordig minder spreken, is onze vriendschap nog steeds hecht. Alle dagen en uren die we samen hebben doorgebracht neemt niemand meer van ons af. Dank dat ik altijd bij je aan kan kloppen als ik hulp nodig heb. Ik vind het geweldig om te zien hoe je het moederschap combineert met je passies en je werk. Gelukkig ben ik nu weer wat dichterbij gaan wonen zodat ik wat vaker bij jou, Luuk en Isa op bezoek kan gaan.

Joor, wat ben ik blij dat je samen met mij in Maastricht bent blijven hangen na onze Global Health master. Onze therapeutische shopsessies, gezellige avonden met heerlijk eten, spelletjes en goochelshows waren een perfecte afleiding van mijn PhD taken. Ik ben zo trots op alle dingen die je de afgelopen tijd voor elkaar hebt gekregen. Het is jammer dat ik sinds ik verhuisd ben niet meer spontaan bij je binnen kan wippen, al is het fijn om te zien hoe je met Ernst je eigen stekje hebt gecreëerd. Ik vind het super dat je beloofd hebt mijn paranimf te zijn op de grote dag en ik kijk nu al uit naar onze shopsessie voor de ultieme jurk.

Lou ik weet nooit helemaal precies waar je uithangt of wat je volgende stappen zullen zijn, toch neem je iedereen in je creatieve wervelstorm mee. Het is inspirerend om te zien hoe je je dromen achterna gaat en ik bekijk met verbazing wat je allemaal voor elkaar weet te krijgen. Bedankt voor spontane en doldwaze acties, wat hebben we toch veel lol samen.

Eem sinds dat ik je heb leren kennen in het $2^{\mathrm{e}}$ jaar van de bachelor heb ik naar je opgekeken. Je enorme creativiteit en je eigenzinnigheid hebben er voor gezorgd dat je niet samen met me bent gaan studeren, maar dat je je eigen weg gekozen hebt. Ik heb hier ontzettend veel bewondering voor. Ik blijf het heerlijk vinden om samen met je te discussiëren over Chinese geneeskunst, acupunctuur en oude wijsheden.

Ook mijn beide families met ooms en tantes, neven en nichten, neefjes en nichtjes wil ik bedanken voor hun vragen tijdens de familiedagen en hun pogingen om te begrijpen waar ik nou precies mee bezig ben. Gelukkig kan ik nog een laatste poging wagen tijdens mijn verdediging. Hopelijk gaat het lukken $\odot$.

Lieve Oma, wat ben ik blij dat u mijn promotie mee kunt maken! Bij elk probleem waar iemand mee komt, biedt $u$ een luisterend oor en biedt u gevraagd advies aan. Hier heb 
ik meer dan eens gebruik van mogen maken, bedankt voor uw warmte en liefde. U zult altijd een groot voorbeeld voor me blijven.

Tante Josée en noonk Ton wat heb ik toch geluk gehad om jullie te krijgen toegewezen als mijn peettante en peetoom. Sinds dat ik verhuisd ben naar Maastricht, om hier te komen studeren, hebben jullie me een tweede huis geboden en stonden jullie altijd voor me klaar. Bedankt dat ik altijd bij jullie terecht kan voor gezelligheid, maar ook als ik mezelf weer eens klem gezet heb op de een of andere manier. Tante Josée, zelfs het nakijken van zowel de Nederlandse samenvatting als het dankwoord waren een 'kleine moeite'. Toch wil ik je ontzettend bedanken, dat je alles zo minutieus nagevlooid hebt op mijn spellingsfouten.

Stache, helaas ben je er 2 juli niet meer bij. Wat had ik deze gebeurtenis toch graag met je willen delen. In ons laatste telefoon gesprek gaf je aan dat ik vooral vol moest houden, dat het me echt wel ging lukken en dat je nu al trots was. Bedankt voor je geloof en voor alle dingen die je samen met tante Yvonne voor ons gezin gedaan hebt.

lets meer dan een jaar geleden heb ik een extra gezin cadeau gekregen. Marianne en Bert, Karla en Pieter-Jan bedankt voor al jullie steun het laatste jaar en het warme welkom in (Neder)Weert. Hopelijk komen er nog vele etentjes, weekendjes weg en fietstochtjes.

Bas, van kleins af aan ben jij altijd mijn grote broer geweest, waar ik naar opkeek en die ik volgde. Ik heb getennist, bij Schola Cantorum gezongen, gevolleybald en ben bij de harmonie gegaan (niet alles met evenveel succes). Ik heb ook nog zelfs even getwijfeld om ook bouwkunde te gaan doen. Uiteindelijk heb ik toch een andere studie gekozen en ben ik nu hier aanbeland. Jij bent inmiddels constructeur en bent super gelukkig met Karla. Ondanks dat onze levens anders zijn gelopen en we elkaar niet vaak zien, vind ik het fijn om te weten dat het gewoon goed tussen ons is. Ik wens jou en Karla dan ook een geweldige bruiloft toe op 20 juli en een gelukkig leven samen met Puck.

Lieve Mam, ik heb eigenlijk nog veel meer ruimte nodig om je te bedanken voor alle steun en liefde van de afgelopen jaren. Bedankt, dat je mij en Bas, samen met papa zo'n liefdevol thuis hebt gegeven om in op te groeien. Jullie hebben ons altijd aangespoord om onze eigen weg te gaan en in onszelf te geloven. Ook nadat we papa zijn kwijtgeraakt, heb je alles op alles gezet om ons leven zo normaal mogelijk door te laten lopen. De afgelopen jaren zijn we ontzettend hecht gebleven, we bellen soms wel meerdere keren per dag voor een kleine update en als ik het even niet meer zie zitten, ben je de eerste die door mijn hoofd schiet. Ik heb heel wat keren voor een deadline gestrest opgebeld en plannen voorgelegd. Niet dat je altijd mijn woordenstroom begreep, maar je wist wel mijn gedachten te stroomlijnen, zodat ik weer verder kon. 
Hoewel je sinds je pensionering een nog drukker schema hebt gekregen, weten we altijd een plekje te vinden om bij te kletsen of elkaar te zien. Ik vind het ontzettend fijn om te zien hoe gelukkig je samen met Nico bent.

Lieve Kris, samen met jou in Weert wonen is zoveel leuker en fijner dan dat ik ooit had gedacht. Het afgelopen jaar heb je me door diepe dalen gesleept en weet ik dat ik blindelings op je kan vertrouwen. Bedankt voor al het geduld en de vele keren dat je dingen van me overgenomen hebt, omdat ik nog dingen moest afmaken. Nu dit grote project is afgerond kijk ik ernaar uit om samen nieuwe projecten te gaan ondernemen. Geweldig om dit samen te kunnen vieren op 2 juli. Ik hou van je lief! 


List of publications \& awards 


\section{Scientific articles in international journals}

Drost M.W.A., van der Putten I.M., Ruwaard D, Evers S.M.A.A., and Paulus A.T.G.. Conceptualizations of the societal perspective within economic evaluations: a systematic review. International Journal of Technology Assessment in Health Care, 2017; 33(2): 1-10.

Van der Putten, I.M., Paulus, A.T.G., Evers, S.M.A.A. and Hutubessy, R. Hiligsmann, M, Identification and prioritization of broader economic impact of vaccines, Biomed Research International, 2016; 8

Van der Putten, I.M., Evers, S.M.A.A., Deogaonkar, R., Jit, M. and Hutubessy, R.C.W. Stakeholders' perception on including broader economic impact of vaccines in economic evaluations in low and middle income countries: a mixed methods study. BMC Public Health, 2015; 15:356.

Wijnen, B.F.M., van der Putten, I.M., Groothuis, S., de Kinderen, R.J.A., Noben, C.Y., Paulus, A.T.G., Ramaekers, B.L.T., Vogeland, G.C.W.M. and Hiligsmann, M. Discretechoice experiments versus rating scale exercises to evaluate the importance of attributes. Expert Review of Pharmacoeconomics \& Outcomes Research, 2015; 15(4): 721-8

Deogaonkar, R., Hutubessy, R., van der Putten, I., Evers, S. and Jit, M. Systematic review of studies evaluating the broader economic impact of vaccination in low and middle income countries. BMC Public Health, 2012; 12: 878.

\section{Submitted articles}

Van der Putten IM, Paulus ATG, Hiligsmann, M, Hutubessy RCW, and Evers SMAA. 2018.Evidence-informed vaccine decision making: The introduction of Human Papilloma Virus (HPV) vaccination in the Netherlands. Under Review

\section{Reports}

Evers, S., van Mastrigt, G., van der Putten, I., Pavlova, M., Hiligsmann M., and Paulus, A. Survey to investigate the current thinking on Inactivated Poliovirus Vaccines (IPV) among financial decision makers in countries that are not GAVI eligible. Confidential report for the Department Immunization, Vaccines and Biologicals of the World Health Organization, July 2014. 


\section{Conference Proceedings - oral presentations}

Van der Putten, I.M., A.T.G. Paulus, M. Hiligsmann R.C.W. Hutubessy and S.M.A.A. Evers, The introduction of HPV vaccination in the Netherlands: the role of (economic) information. abstract symposium NVTAG, 15 February 2017, Utrecht, The Netherlands

Drost, R.M.W.A., I.M. van der Putten, D. Ruwaard, S.M.A.A. Evers and A.T.G Paulus. Conceptualizations of the societal perspective within economic evaluations: systematic review. $8^{\text {th }}$ LolaHeSG conference, 26-27 May 2016, Ghent, Belgium.

Van der Putten, I., S.M.A.A. Evers, A.T.G Paulus, M. Hiligsmann and R. Hutubessy. Identification and prioritization of the broader economic impact of vaccines. 11th World congress 'De Gustibus Disputandum Non Est! Health Economics and Nutrition' of the International Health Economics Association, 12-15 July 2015, Milan, Italy.

Van der Putten, I., M. Hiligsmann, A.T.G Paulus, S.M.A.A. Evers, and R. Hutubessy. Identification and prioritization of broader economic impact of vaccines in economic evaluations in low- middle-income countries. $7^{\text {th }}$ LoLaHeSG conference, 28-29 May 2015, Maastricht, the Netherlands

Van der Putten, I.M., S.M.A.A. Evers, M. Jit, R. Deogaonkar and R.C.W. Hutubessy. The relevance of including broader economic effects in economic evaluations of vaccines in low and middle income countries. 10th World Congress of the International Health Economics Association (IHEA), 13-16 July 2014, Dublin, Ireland.

Van der Putten, I.M, S.M.A.A. Evers, M. Jit, R. Deogaonkar and R.C.W. Hutubessy. A survey among decision makers in low and middle income countries responsible on the broader economic impact of vaccination. European Conference of Health Economics, 18-21 July 2012 Zurich, Switzerland.

\section{Conference Proceedings - poster presentations}

Van der Putten, I.M., M. Hiligsmann, A.T.G Paulus, R.C.W. Hutubessy and S.M.A.A. Evers. A retrospective analysis of the role of (economic) evidence in decision making: the introduction of HPV vaccination in the Netherlands. ISPOR $20^{\text {th }}$ Annual Eruopean congress, 4-8 November 2017, Glasgow, United Kingdom.

Van der Putten, I.M., M. Hiligsmann, A.T.G Paulus, R.C.W. Hutubessy and S.M.A.A. Evers. Identifying the broader value of vaccines in low and middle income countries. ISPOR $17^{\text {th }}$ Annual European congress, 8-12 November 2014, Amsterdam, the Netherlands.

Wijnen, B.F.M., I.M. van der Putten, S. Groothuis, R.J.A. de Kinderen, C.Y. Noben, A.T.G. Paulus, B.L.T. Ramaekers, G.C.W.M. Vogeland, and M. Hiligsmann, Discrete choice 
experiment verse rating scale exercises to evaluate the importance of attributes: a study of the Maastricht ISPOR student chapter. ISPOR $17^{\text {th }}$ Annual European congress, 8-12 November 2014, Amsterdam, the Netherlands.

Deogaonkar, R., R. Hutubessy, I. van der Putten, S. Evers, and M. Jit, Systematic review of studies evaluating the broader economic impact of vaccination in low and middle income countries. European Conference of Health Economics, 18-21 July 2012 Zurich, Switzerland.

\section{Contributions to expert meetings}

Invited chair breakout session at expert meeting Advancing the Value of Vaccines Research Agenda, 26-27 April 2016, Harvard University \& Bill \& Melinda Gate Foundation, Boston, US.

Van der Putten, I.M., S.M.A.A. Evers, A.T.G Paulus, M Hiligsmann and R.C.W. Hutubessy. Including broader economic impact of vaccines in economic evaluations in low and middle income countries. WHO Consultation on the Broader Economic Impact on Vaccines and Immunization, 24-25 November 2014, Bangkok, Thailand.

Van der Putten, I.M., S.M.A.A. Evers, M. Jit, R. Deogaonkar and R.C.W. Hutubessy. A survey among decision makers in low and middle income countries responsible on the broader economic impact of vaccination. WHO consultation on the broader economic impact on vaccines and immunization programmes (BEIVIP). 28-29 June 2012, Geneva, Switzerland

S.M.A.A. Evers, van der Putten, I.M., M. Jit, R. Deogaonkar and R.C.W. Hutubessy. Broader economic impact of immunization programs: Survey \& interviews among decision makers responsible for vaccine introduction. WHO consultation on the broader economy impact of vaccination, 13-14 July 2011, Toronto, Canada

\section{Academic rewards}

Recipient of the ISPOR student travel grant 20th Annual European Congress 2017

Recipient of the Global Scholarship Programme for Research Excellence for 2016-2017 from the Chinese University of Hong Kong

Recipient of the Kootstra Talent Fellowship 2013 from Care and Public Health Research Institute Maastricht University 


About the author

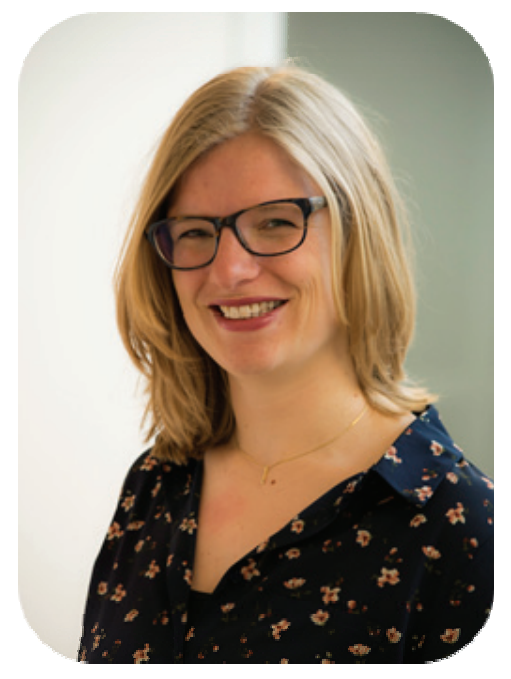


Inge(borg Maria) van der Putten was born on May 31, 1989 in Den Dungen, the Netherlands. After completing the Atheneum at the Sint-JansLyceum in 's-Hertogenbosch, she started her study in Health Sciences in 2007 at Maastricht University, the Netherlands. During her bachelor's programme she studied the specializations Policy and Management, Health Education and Promotion and Health Law. In the second year of her bachelor's programme, she was accepted into the 'International Health' honours programme. She obtained two master's degrees, in Healthcare Policy, Innovation and Management (2012) and in Global Health (2012), respectively. During her master's programme, she followed courses at McMaster University (Canada), conducted fieldwork in India and completed an internship at the World Health Organization (in Geneva, Switzerland), looking at the broader economic impact of vaccines.

After obtaining a Kootstra Fellowship grant in 2013, she started her PhD on a part-time basis at the Department of Health Services Research at Maastricht University. This department is part of the Care and Public Health Research Institute (CAPHRI) of Maastricht University. During her PhD, she continued her work on the broader economic impact of vaccines in collaboration with the World Health Organization. She combined her PhD with a job as a Project Employee in 'Excellente Zorg' (Excellent Care) at the Dutch Nurses Association and, at a later stage, as a teacher at the Department of Health Services Research. She was involved as a tutor, trainer, lecturer, thesis supervisor, planning group member and course coordinator in various bachelor and master's programmes. These included the master's programme on Healthcare Policy, Innovation and Management, the master's programme Global Health, the bachelor's programme in Health Sciences, the bachelor's programme in European Public Health and the bachelor's programme at University College Maastricht. In 2016, she also obtained her basic teaching qualification at Maastricht University.

Inge has participated in and presented her research at several national and international seminars, expert meetings and conferences. She is member of the International Health Economics Association (IHEA) and the professional Society for Health Economics and Outcomes Research (ISPOR) and was involved as a board member and chair for the ISPOR Student Chapter. She also obtained a scholarship from the global scholarship programme for research excellence from the Chinese University of Hong Kong in 2016, which provided the opportunity for her to work for 3 months in the Pediatric Department of the Prince of Wales Hospital in Hong Kong.

She is currently working as a lecturer and researcher at the Department of Health Services Research. She continues to work on her research projects and fulfills various teaching roles, including the coordination of the course Global Health Management as part of the track Global Health Leadership and Organisation, included in the master's programme Global Health. 